
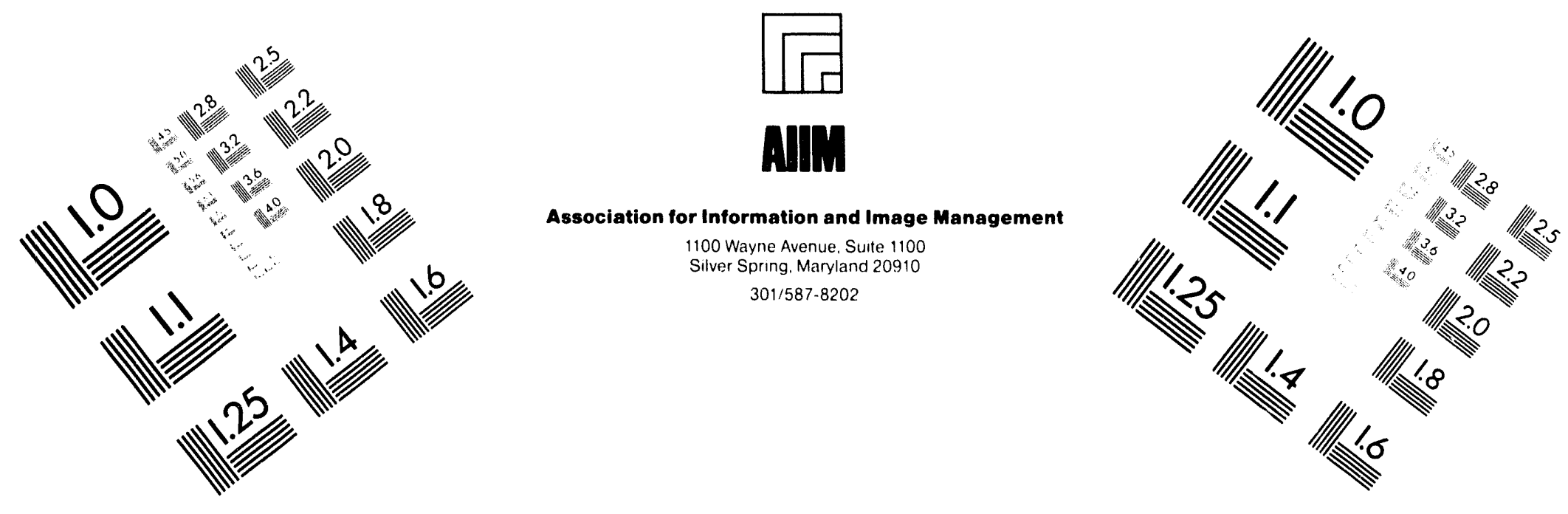

\title{
Centimeter
}

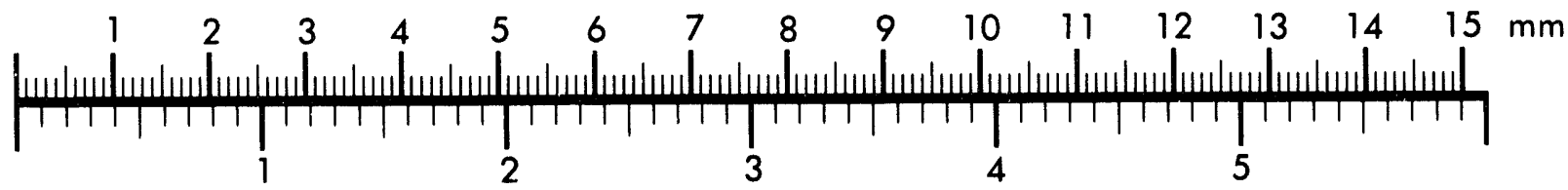

Inches
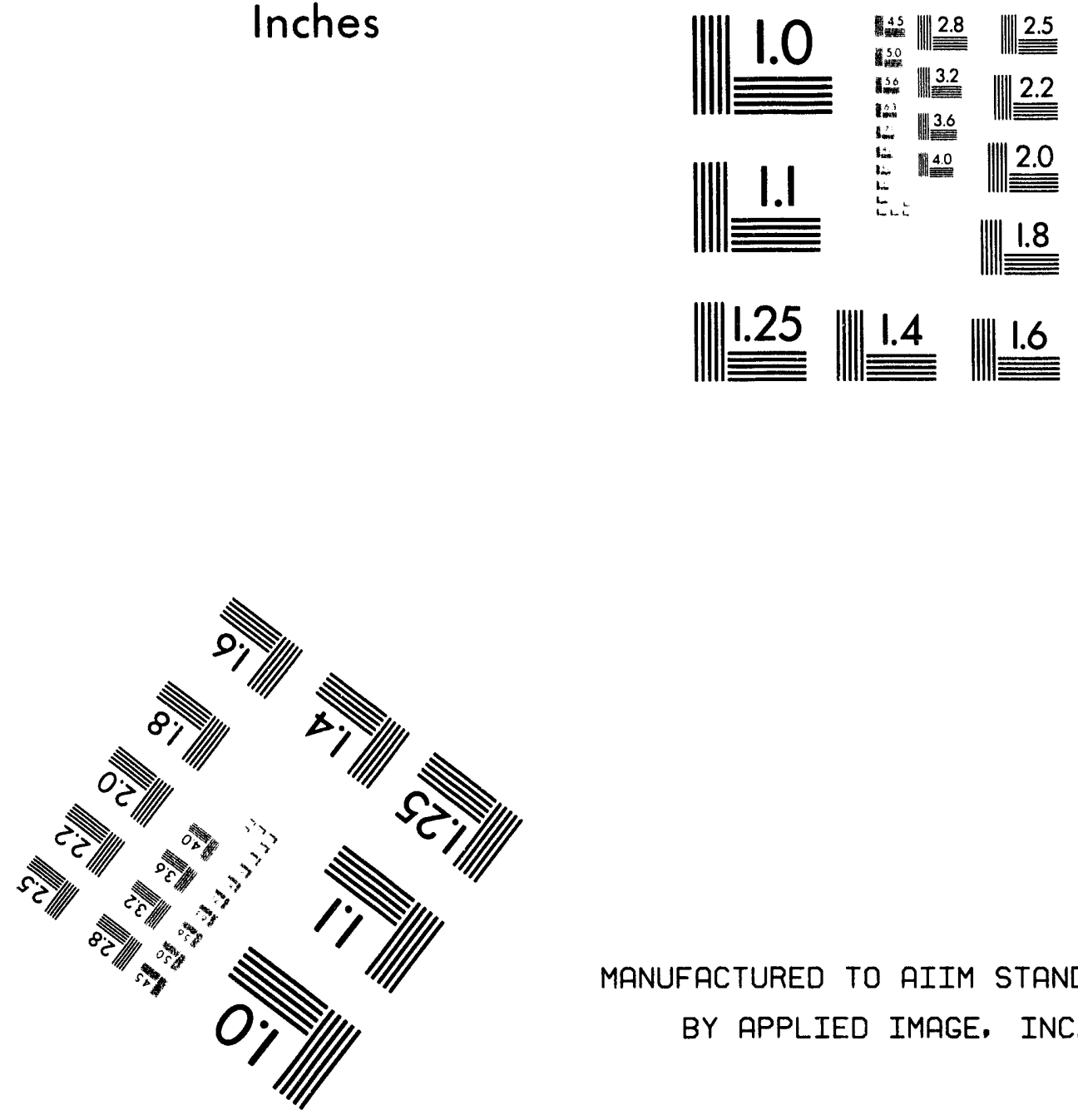

MANUFACTURED TO AIIM STANDARDS

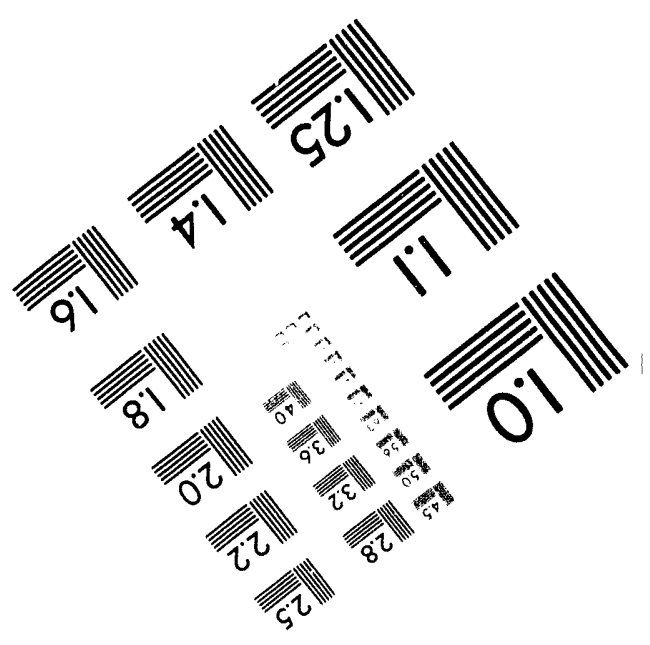



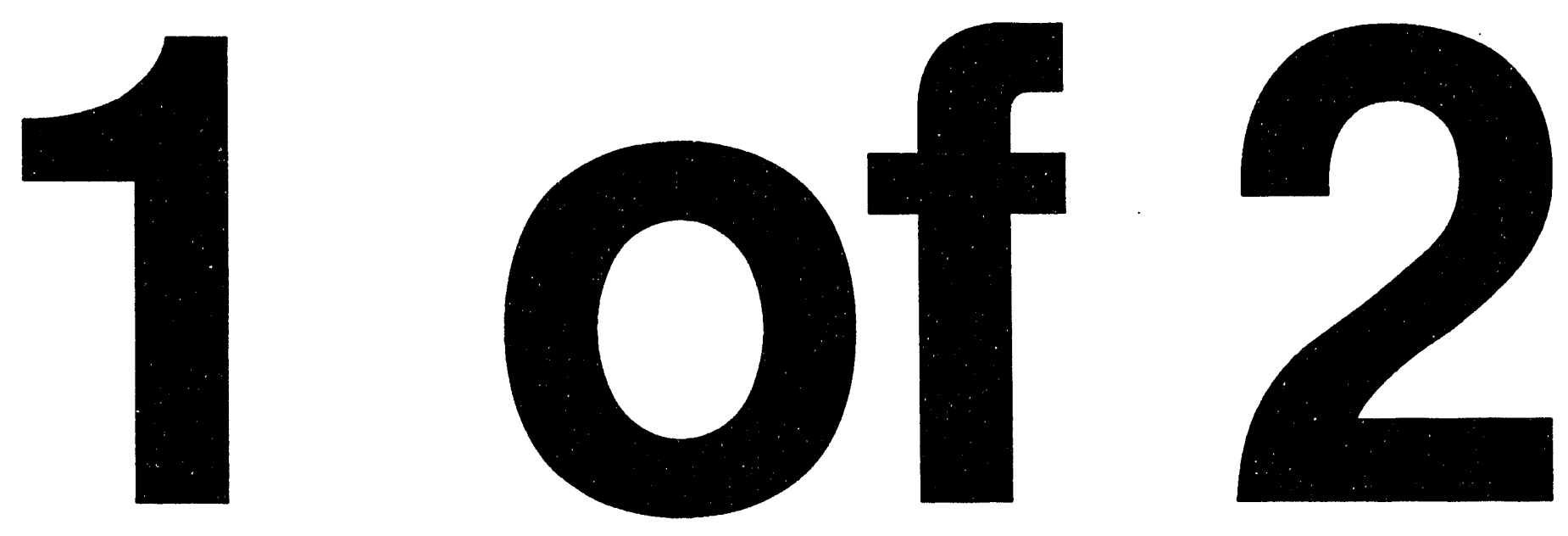


\title{
Weapons-Grade Plutonium Dispositioning Volume 3
}

\section{A New Reactor Concept Without Uranium or Thorium for Burning Weapons-Grade Plutonium}
J. M. Ryskamp
M. J. Gaeta
B. G. Schnitzler
L. B. Lundberg
C. D. Fletcher
S. N. Jahshan
R. L. Moore
G. S. Chang

Contributing Authors
A. M. Ougouag
D. W. Akers
J. W. Sterbentz
J. P. Sekot
C. A. Wemple
D. A. Brownson
V. F. Dean

June 1993

\author{
Prepared for the \\ National Academy of Sciences \\ and for the \\ U.S. Department af Energy \\ Under DOE Idaho Operations Office \\ Contract DE-AC07-76ID01570
}




\begin{abstract}
The National Academy of Sciences (NAS) requested that the Idaho National Engineering Laboratory (INEL) examine concepts that focus only on the destruction of $50,000 \mathrm{~kg}$ of weapons-grade plutonium. A concept has been developed by the INEL for a low-temperature, low-pressure, low-power density, low-coolantflow-rate light water reactor that destroys plutonium quickly without using uranium or thorium. This concept is very safe and could be designed, constructed, and operated in a reasonable time frame. This concept does not produce electricity. Not considering other missions frees the design from the paradigms and constraints used by proponents of other dispositioning concepts. The plutonium destruction design goal is most easily achievable with a large, moderate power reactor that operates at a significantly lower thermal power density than is appropriate for reactors with multiple design goals. This volume presents the assumptions and requirements, a reactor concept overview, and a list of recommendations. The appendices contain detailed discussions on plutonium dispositioning, self-protection, fuel types, neutronics, thermal hydraulics, off-site radiation releases, and economics.
\end{abstract}

\title{
DISCLAIMER
}

This report was prepared as an account of work sponsored by an agency of the United States Government. Neither the United States Government nor any agency thereof, nor any of their employees, makes any warranty, express or implied, or assumes any legal liability or responsibility for the accuracy, completeness, or usefulness of any information, apparatus, product, or process disclosed, or represents that its use would not infringe privately owned rights. Reference herein to any specific commercial product, process, or service by trade name, trademark, manufacturer, or otherwise does not necessarily constitute or imply its endorsement, recommendation, or favoring by the United States Government or any agency thereof. The views and opinions of authors expressed herein do not necessarily state or reflect those of the United States Government or any agency thereof. 


\section{SUMMARY}

A concept has been developed for a low-temperature, low-pressure, low-power-density, low-coolant-flow-rate light water reactor (LWR) that destroys plutonium quickly without using uranium or thorium. This concept is very safe and could be designed, constructed, and operated in a reasonable time frame.

The National Academy of Sciences (NAS) requested that the Idaho National Engineering Laboratory (INEL) examine concepts that focus only on the main goal: destruction of $50,000 \mathrm{~kg}$ plutonium as rapidly as possible. The INEL concept does not produce electricity. Not considering other missions frees the design from the paradigms and constraints used by proponents of other dispositioning concepts. Because of the unique design goal, reactor designers have unusual flexibility in specifying reactor geometry and materials. In particular, the plutonium destruction design goal appears to be more easily achievable with a reactor that operates at a significantly lower thermal power density than is appropriate for reactors with multiple design goals.

High reactor coolant temperatures are required to produce electricity efficiently. Removing this constraint allows the development of very safe concepts. Although revenue from the sale of electricity is lost, capital costs are reduced by eliminating turbines, generators, some support facilities, some backup safety systems, and a thick-walled pressure vessel. Reactor containment costs are reduced. Reactor design becomes simpler and more flexible, which also reduces costs. The mission of destroying plutonium is not impeded by electricity load demand concerns and delays caused by maintenance of electrical systems.

Light water technology was adopted to minimize technology development risk, ensure the greatest chance of success, and reduce costs. Low power densities, temperatures, pressures, and coolant flow velocities were selected to enhance reactor safety. A few (three to six) reactors of this type [each rated at $1,000 \mathrm{MW}(\mathrm{t})$ ] would be able to burn a large fraction (60-80\%) of the weapons-grade plutonium in 30 to 40 years.

\section{Assumptions and Requirements}

The INEL staff developed the following assumptions and requirements following discussions with the NAS:

- Do not use uranium or thorium in this reactor in order to preclude the production of additional weapons material and to reduce the plutonium stockpile as rapidly as possible.

- Focus on the primary goal of plutonium destruction. No attempt will be made to produce electricity, district heating, or beneficial isotopes. However, the design may be able to satisfy some of these missions.

- Destroy the plutonium or produce self-protecting fuel as rapidly as possible.

- Minimize development risk in order to achieve objectives as rapidly as possible.

- Design a reactor as safe as current uraniumfueled advanced reactor designs.

- Design a reactor as environmentally sound as current advanced reactor designs.

Although the INEL has strived to achieve these requirements, the general consensus among the report authors is that plutonium is a valuable resource for electricity generation. Furthermore, it is hoped that this plutonium is used in existing commercial reactors to benefit society. Fuel reprocessing and breeder reactors should be used to extend the benefit of this resource. High priority should be given to examine ways to prevent proliferation without wasting this resource. The INEL concept meets the NAS requirements, but does not fulfill all hopes.

\section{Plutonium Dispositioning}

All reactors without fertile materials (uranium or thorium) at the same power level and capacity fac- 
tor destroy plutonium at the same rate. In addition, this rate is faster than the rate of any reactor containing fertile materials, because fertile materials produce more weapons materials.

The total heat energy available from the fission of $50 \mathrm{MT}$ of ${ }^{239} \mathrm{Pu}$ is approximately $4.2 \times 10^{18}$ joules or 48,600,000 megawatt-days. Burnup times are inversely proportional to power rating, number of reactors, and capacity factor, and are directly proportional to the percent ${ }^{239} \mathrm{Pu}$ burnup. For example, four reactors operating at $1,000 \mathrm{MW}(\mathrm{t})$ each and having a capacity factor of 0.75 would burn up 33.8 MT of plutonium (67.6\% of the total inventory or all of the inventory with $67.6 \%$ burnup) in 30 years. The full $50 \mathrm{MT}$ of plutonium would be burned in 44.4 years.

Irradiated materials can be potent sources of gamma radiation, which reduces the likelihood of material diversion by terrorists. The intense gamma environment can provide a certain degree of self-protection in the form of high biological dose rate levels. Fission products in spent fuel provide a high amount of gamma radiation. Photon source strengths could be increased further by seeding the plutonium. Seeding is the addition of materials that will produce photon-emitting nuclides following irradiation and decay. Seeding offers the potential of enhancing the photon emission of the plutonium following irradiation.

The most attractive self-protection seed candidates are europium and cobalt. Cobalt could be incorporated into the plutonium fuel proper or employed by using a cladding material with high cobalt content. Europium is especially attractive because it may also be required for reactor control purposes. The degree to which any seed material can enhance fuel self-protection will depend primarily on the specific power level of the plutonium burner reactor. The most significant self-protection enhancements will occur for low plutonium exposures accumulated at high power density. For the proposed low-power density concept, generation of fission products provides the best option for self-protection, and seeding is not needed.

\section{Fuel Types}

The plutonium-based fuel form to be used in plutonium-burning reactors is closely coupled to a particular reactor design. However, several general criteria apply to all circumstances. Fuel forms chosen for use in any type of plutonium-burner should (a) possess high burnup capability, (b) provide a high degree of operational safety, (c) offer the cheapest and easiest fabrication methods with minimum hazardous waste generation, and (d) offer the cheapest and easiest end-of-life disposal option.

Only two plutonium-only fuel forms have been tested for any length of time in a nuclear reactor: (1) $\mathrm{PuAl}_{4}$ dispersed in aluminum and (2) $\mathrm{PuO}_{2}$ embedded in carbon and sealed in a silicon carbide shell (TRISO-coated $\mathrm{PuO}_{2}$ ). The INEL has examined these and a few advanced solid fuels that have not been tested. The current fuel choice is the $\mathrm{Pu}-\mathrm{Al}$ composite.

The traditional fabrication methods for the aluminide fuels are fairly simple. The fuel fabrication waste volumes can be minimized. Several variations of the fabrication method of the aluminide fuel form have been successfully applied to produce $\mathrm{Pu}-\mathrm{Al}$ composite fuel elements. Plutonium fabrication facilities currently exist at the Los Alamos National Laboratory and the Savannah River Site. These facilities could be used to produce $\mathrm{Pu}$-Al composite fuel elements in sufficient quantities to verify fuel designs and prove the fuel performance. The Advanced Test Reactor at the INEL could be used to test these fuels.

\section{Neutronics}

Eliminating ${ }^{238} \mathrm{U}$ from the reactor prevents the production of more ${ }^{239} \mathrm{Pu}$ and accelerates plutonium destruction. A major disadvantage of removing ${ }^{238} \mathrm{U}$ is the reduction or elimination of a prompt negative Doppler reactivity coefficient and a negative moderator temperature coefficient. A pure plutonium fuel type is not desirable in LWRs because of the low mass loading per fuel rod (yielding short fuel cycles) and strong positive temperature coefficients. Any workable fuel composition must have a negative prompt temperature coefficient (i.e., reac- 
tor power decreases as temperature increases) for safety and control purposes. Plutonium cores in LWRs can have negative isothermal temperature coefficients if enough erbium or other poisons are added. The addition of burnable poison is also needed to hold down the core reactivity.

\section{Thermal Hydraulics}

A low-power-density, plutonium-burning reactor that is cooled with low-temperature, low-pressure light water flowing at low velocity is recommended. Primary coolant system flow is provided by pumps, but even greater safety advantages would be attained if a natural circulation cooling system could be employed. Preliminary analysis indicates that such a system is feasible, but further study is needed.

This reactor concept has multiple thermal-hydraulic and safety advantages over most existing test and commercial reactor designs: (a) the margin to critical heat flux is very large, (b) the times required to raise fuel temperatures to damage and melting points are long, (c) coolant flowing vertically upward in the core ensures initiation and continuance of natural circulation core cooling should the primary coolant pumps fail, (d) the open, nonchannelized, core flow arrangement avoids safety issues associated with flow instability in parallel channels, (e) the low energy stored in the coolant and structure minimizes the requirements placed on the containment, and ( $f$ ) the low-pressure coolant system significantly reduces the safety risk due to loss-of-coolant accidents and is compatible with passive safety injection systems.

\section{Source Term Evaluation}

Potential offsite doses from hypothetical releases are of concern for any plutonium-based reactor facility. Offsite dose consequences may result from release of both fission products and heavy metals, especially uranium and plutonium. To compare differences in offsite dose impacts of ${ }^{235} \mathrm{U}$ and ${ }^{239} \mathrm{Pu}$ fueled reactors without developing specific reactor accident scenarios, simple aerosol releases were assumed. Equivalent quantities of ${ }^{235} \mathrm{U}$ and ${ }^{239} \mathrm{Pu}$ were assumed to be released along with the fission products associated with those heavy metals. In both cases the calculated dose impact from all pathways is dominated by the fission products. The total dose consequence from ${ }^{239} \mathrm{Pu}$ release is less than $1 \%$ of the fission product dose.

\section{Economics}

Costs associated with construction, operation, decontamination and decommission, and waste processing and disposal must be considered for all facilities. These nuclear facility costs demand that methods, processes, and requirements be critically reviewed and improved if these facilities are to be affordable in the future. Cost-reduction ideas for these concepts have been developed. When several of the cost-reduction ideas that are identified are implemented, the overall cost of designing, constructing, and operating a reactor can be reduced significantly. 


\section{CONTENTS}

ABSTRACT $\ldots \ldots \ldots \ldots \ldots \ldots \ldots \ldots \ldots \ldots \ldots \ldots \ldots \ldots \ldots \ldots \ldots \ldots \ldots \ldots \ldots$

SUMMARY $\ldots \ldots \ldots \ldots \ldots \ldots \ldots \ldots \ldots \ldots \ldots \ldots \ldots \ldots \ldots \ldots \ldots \ldots \ldots \ldots \ldots$

ACRONYMS $\ldots \ldots \ldots \ldots \ldots \ldots \ldots \ldots \ldots \ldots \ldots \ldots \ldots \ldots \ldots \ldots \ldots \ldots \ldots \ldots \ldots \ldots \ldots \ldots$

1. INTRODUCTION $\ldots \ldots \ldots \ldots \ldots \ldots \ldots \ldots \ldots \ldots \ldots \ldots \ldots \ldots \ldots \ldots \ldots \ldots$

2. ASSLIMPTIONS AND REQUIREMENTS $\ldots \ldots \ldots \ldots \ldots \ldots \ldots \ldots \ldots \ldots \ldots$

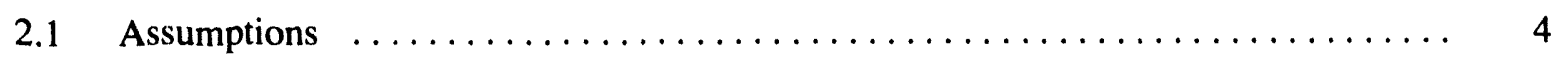

2.2 Requirements $\ldots \ldots \ldots \ldots \ldots \ldots \ldots \ldots \ldots \ldots \ldots \ldots \ldots \ldots \ldots \ldots \ldots \ldots$

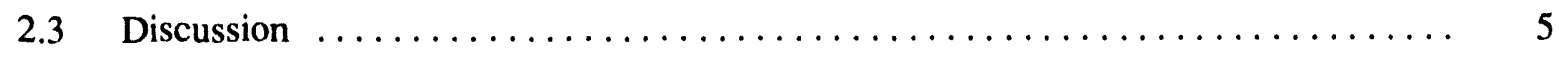

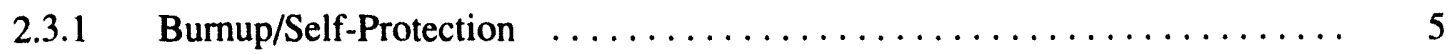

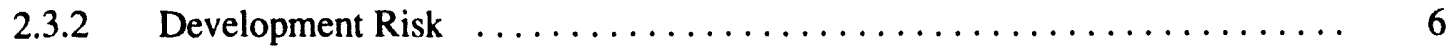

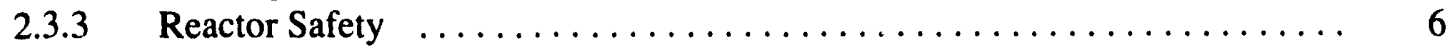

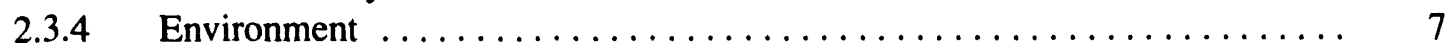

3. REACTOR CONCEPT OVERVIEW $\ldots \ldots \ldots \ldots \ldots \ldots \ldots \ldots \ldots \ldots \ldots \ldots \ldots \ldots$

3.1 Concept Description $\ldots \ldots \ldots \ldots \ldots \ldots \ldots \ldots \ldots \ldots \ldots \ldots \ldots \ldots \ldots \ldots \ldots \ldots$

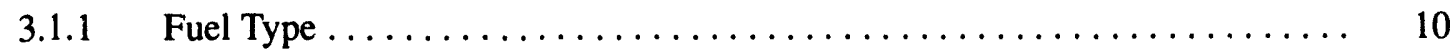

$3.1 .2 \quad$ Neutronics $\ldots \ldots \ldots \ldots \ldots \ldots \ldots \ldots \ldots \ldots \ldots \ldots \ldots \ldots \ldots \ldots \ldots$

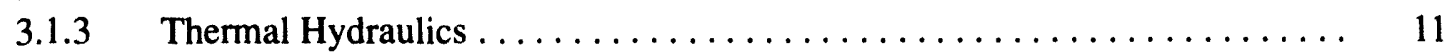

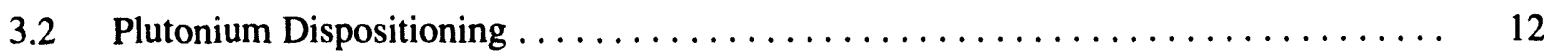

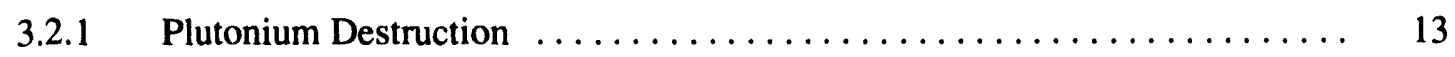

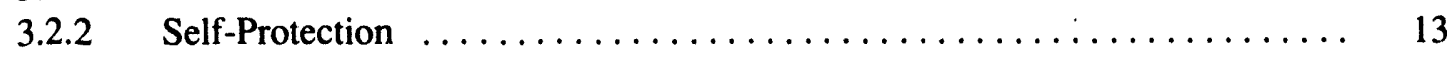

3.3 Source Term Evaluation $\ldots \ldots \ldots \ldots \ldots \ldots \ldots \ldots \ldots \ldots \ldots \ldots \ldots \ldots \ldots \ldots$

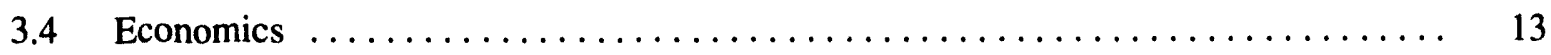

4. CONCLUSIONS AND RECOMMENDATIONS $\ldots \ldots \ldots \ldots \ldots \ldots \ldots \ldots \ldots \ldots \ldots$

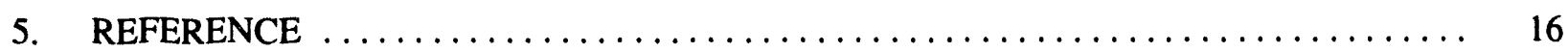

Appendix A-Plutonium Destruction Rates and Isotopics for Different Neutron Spectra . . . . . . A-1

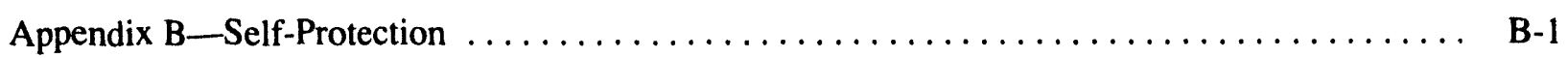

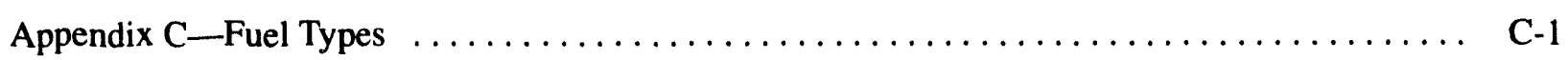

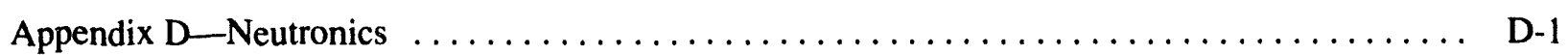


Appendix E-Thermal-Hydraulic Considerations

E-1

Appendix F-Evaluation of Offsite Releases

F-1

Appendix G-Economics

G-1

Appendix $\mathrm{H}$-Other Reactor Concepts

$\mathrm{H}-1$

Appendix I-Federal Standards, Codes, Regulations, and Requirements

I-1 


\section{ACRONYMS}

ALARA as low as reasonably achievable

ALMR Advanced Liquid Metal Reactor

ANL

ANS

BOC

BWR boiling water reactor

CANDU Canadian deuterium-uranium (reactor)

CISAC Committee on International Security and Arms Control

CSAR Conceptual Safety Analysis Report

DNBR departure from nucleate boiling ratio

DOE Department of Energy

FIMA Fissionable Isotope Mass Analysis

GDC General Design Criteria

GWD/MT gigawatt day per metric ton

GWD/MTIF gigawatt day per metric ton of initial heavy metal

HTGR High Temperature Gas-Cooled Reactor

INEL

\section{Idaho National Engineering}

Laboratory
LANL

Los Alamos National Laboratory

LCO limiting condition of operation

LMR liquid metal reactor

LOC limiting operating condition

LWR light water reactor

MHTGR Modular High Temperature Gas-Cooled Reactor

MT

metric ton

MTC

moderator temperature coefficient

MTR Materials Test Reactor

MWD megawatt day

MW/MTHM megawatt per metric ton of initial heavy metal

MW(t) megawatt thermal power

NAS National Academy of Sciences

NRC Nuclear Regulatory Commission

PNL Pacific Northwest Laboratory

PWR pressurized water reactor

QA quality assurance

SDC Supplemental Design Criteria

SRS Savannah River Site 


\section{A New Reactor Concept Without Uranium or Thorium for Burning Weapons-Grade Plutonium}

\section{INTRODUCTION}

Changing world conditions will result in significant reductions in the number of nuclear warheads in existing arsenals. The Secretary of the Department of Energy (DOE) has been charged by the United States Congress to provide recommendations and options for dispositioning of excess weapons-grade plutonium resulting from reducing the world arsenals. The Secretary of Energy has chartered the National Academy of Sciences (NAS) Committee on International Security and Arms Control (CISAC) to review and compare relative merits of plutonium disposal options ranging from simple storage through space disposal to consumption in reactors or accelerator-based systems. The CISAC Reactor Panel is tasked with examination of plutonium disposal options using either existing reactors or special purpose reactors dedicated to plutonium burning.

The Idaho National Engineering Laboratory (INEL) staff is supporting the committee's work by providing technical analyses in three specific areas identified by the Reactor Panel:

1. Provide a preconceptual analysis for a reactor specifically designed for destruction of weapons-grade plutonium.

2. Evaluate the feasibility of using plutonium fuels (without uranium) for disposal in existing commercial light water reactors (LWRs).

3. Assist in evaluation of proposals submitted by sponsors of reactor and accelerator concepts by providing a basis from which objective comparisons can be made.

This volume of the report presents the current status and results of the activities in the first area of focus. Separate volumes of this report address the other two areas.
Weapons-grade plutonium consists mostly of ${ }^{239} \mathrm{Pu}$. Plutonium is an excellent reactor fuel from the standpoint of core reactivity. All reactors are capable of burning plutonium. Furthermore, without any fertile materials in the system, all pure plutonium-burning reactors at the same power level and capacity factor destroy plutonium at the same rate, and this rate is faster than the rate of any reactor containing fertile materials (e.g., ${ }^{238} \mathrm{U}$ and thorium).

The NAS has requested that only reactor concepts that do not contain any uranium or thorium be examined. Eliminating ${ }^{238} \mathrm{U}$ from the reactor prevents the production of more ${ }^{239} \mathrm{Pu}$. Similarly, eliminating thorium from the reactor prevents the production of ${ }^{233} \mathrm{U}$. The main reason for not including fertile nuclides is to preclude the production of additional weapons materials. A plutonium-only based fuel provides the highest plutonium destruction rate.

The destruction of weapons-grade plutonium could be accomplished in a variety of reactor types operating in a variety of neutron spectral regimes. Selection of a preferred reactor type must include consideration of several important constraints. One important safety aspect is the reduction of the negative prompt Doppler reactivity coefficient when fertile materials are removed. The reactor must be designed such that the core reactivity drops as the fuel temperature increases. In addition, the delayed neutron fraction for plutonium is smaller than that of uranium. As a result, reactors without fertile materials are more difficult to control. However, certain materials can be added to the fuel to improve the reactivity coefficients.

Concepts that rely on passive safety, including low power densities, low coolant velocity, low temperature, and low pressure can be very safe. If a plutonium-burning reactor can meet its design 
goal while operating at a much lower power density than existing commercial reactors, then significant reliability, safety, and operability improvements can be attained.

A major advantage of a new plutonium burner is the possibility for elimination of terrorist threats during plutonium transportation by siting the reactor at the location where the excess plutonium is reconfigured. Mixed-oxide fuel use in several existing LWRs would lead to transporting weapons-grade material to several civilian sites. The development and construction costs and the construction time frame for a new plutonium burner may be disadvantages. However, the costs of the safeguards services would be lower, and these services would be more easily carried out in dedicated government operations than in the commercial power industry. A dedicated, colocated system avoids the perception that plutonium use will be supported by large numbers of commercial reactors at many locations.

Burning weapons-grade plutonium in a fission reactor is an effective dispositioning option offering adequate safeguards and diversion resistance. Plutonium is also a valuable resource that could be used to produce electricity, district heating, tritium, and medical isotopes. The NAS requested that the INEL examine concepts that focus only on the main mission: destruction of total plutonium as rapidly as possible. Not considering other missions eliminates the paradigms and constraints used by proponents of other dispositioning concepts.

For example, high reactor coolant temperatures are required to produce electricity efficiently. Removing this constraint allows the development of concepts that are safer than similar concepts that produce electricity. And, although revenue from the sale of electricity is lost, capital costs are reduced by eliminating turbines, generators, some support facilities, some backup safety systems, and a thick-walled pressure vessel. Reactor containment costs are reduced. Reactor design becomes simpler and more flexible, which also reduces costs. The reactor would not consume large quantities of electricity as the acceleratorbased concepts do. Finally, the mission of destroying plutonium is not impeded by electricity demand concerns and delays caused by maintenance of electrical systems.

Although the INEL has strived to achieve these requirements, the general consensus among the report authors is that plutonium is a valuable resource for electricity generation. Furthermore, it is hoped that this plutonium is used in existing commercial reactors to benefit society. Fuel reprocessing and breeder reactors should be used to extend the benefit of this resource. High priority should be given to examining ways to prevent proliferation without wasting this resource. The INEL concept meets NAS requirements, but does not fulfill all hopes.

The objective of this study is to develop reactor concepts, without uranium or thorium, that destroy all plutonium isotopes as rapidly as possible. The INEL has developed concept ideas that should be considered. Reactors that achieve this objective can be designed, constructed, and operated safely in a reasonable time frame.

Section 2 presents the assumptions and requirements upon which the INEL concept was developed. Section 3 contains an overview of the reactor concept. Section 4 lists the conclusions and recommendations. Most of the technical details and discussions are contained in the appendices. The first task was to examine plutonium destruction rates and isotopics for different neutron spectra, as discussed in Appendix A. This study lead to the adoption of a thermal reactor concept instead of reactors with fast or epithermal neutron spectra. The second lask was to study the addition of seed materials for selfprotection from materials diversion. Appendix B illustrates that fission products provide the best self-protection, and seed materials are not needed for the INEL concept. Various fuel types were investigated and are described in Appendix C. The core neutronics studies presented in Appendix $D$ and thermal-hydraulics studies presented in Appendix E were performed concurrently. An evaluation of potential offsite radiation doses 
from hypothetical releases is discussed in Appendix F. Appendix G presents cost reduction ideas. During the initial INEL study, several other potential plutonium-burning concepts were examined. Appendix H summarizes these discussions. Finally, Appendix I lists Federal standards, codes, regulations, and requirements that are applicable to DOE reactors. 


\section{ASSUMPTIONS AND REQUIREMENTS}

The INEL staff developed the following assumptions and requirements in conjunction with NAS.

\subsection{Assumptions}

- Uranium or thorium will not be used in this reactor concept.

- Focus will be on the primary mission of plutonium destruction. No attempt will be made to produce electricity, district heating, or beneficial isotopes. However, the design may be able to satisfy some of these missions.

- Concept selection will be unbiased and based solely on technical grounds.

- The amount of weapons-grade plutonium available is $50,000 \mathrm{~kg}$. A composition of 95.5\% ${ }^{239} \mathrm{Pu}, 4.0 \%{ }^{240} \mathrm{Pu}$, and $0.5 \%{ }^{241} \mathrm{Pu}$ was assumed.

- The short duration of this work requires the use of approximate computations and limited design effort.

\subsection{Requirements}

- Destroy the plutonium or produce self-protecting fuel as rapidly as possible.

- For destruction, the total plutonium content after irradiation must be less than some fraction (such as $10 \%$ ) of the original plutonium loading.

- $\quad$ For self-protection, the spent fuel must be activated such that 10 years after removal from the core the radioactivity is still above $100 \mathrm{rem} / \mathrm{hr}$ at $3 \mathrm{ft}$ from a fuel assembly.

- Minimize development risk in order to successfully achieve objectives as rapidly as possible.
- Well-tested fuel types and geometries are desirable.

- Fuel reprocessing should not be required between cycles (a oncethrough system is desired).

- The reactor designs will draw from the most favorable features (fuel form, control, safety features) of existing reactor designs.

- Design a reactor as safe as current uraniumfueled commercial reactors.

- The reactor design must have a negative net reactivity coefficient at power. If possible, both the prompt fuel temperature coefficient and moderator coefficient should 'xe negative.

- Natural circulation and other passive safety features will be considered. For example, a low power density and, therefore, a large core volume is desired.

- The fuel should have a large heat transfer area and should be arranged to provide a high coolant-to-fuel volume ratio.

- $\quad$ A large margin should exist between the normal fuel operating temperature and the temperature at which fuel damage occurs.

- The design should be robust against fuel dimension and composition uncertainties.

- The plutonium source term should be minimized, or the plutonium should be well contained.

- The fuel and core should be amenable to inspection.

- Design a reactor as environmentally sound as current advanced reactor designs. 
- Minimize wastes throughout the fuel life cycle.

Select a fuel type that lends itself to disposal.

\subsection{Discussion}

See Appendix I for a more detailed set of requirements. Specific issues include mission requirements, potential burnup criteria, heat rejection, economic resources, environmental impact, safety, technology development risk, completion schedule, repository issues, social and political acceptance, and diversion and proliferation. In addition to these issues, others that need to be considered include plutonium handling, waste disposal, environmental regulations, safety regulations and analysis, safeguards and security, technology development, economic analysis, and government and public policies. A variety of reactor concepts exists, and each concept has unique and specific concerns. The intent is not to present a complete set of requirements, but to briefly discuss a few selected issues.

2.3.1 Burnup/Self-Protection. Several potential burnup criteria exist, two of which are contained in the first main requirement. The primary goal of burnup criteria is to ensure sufficient destruction or denaturing to render weaponsgrade plutonium fuel unattractive and difficult to use in the construction of nuclear weapons. Selection of an acceptable burnup criterion could, together with the mission time requirement, determine the number and type of plutoniumburning reactors. The potential for diverting material that could be used in producing nuclear weapons must be minimized during the time that the option is being readied for operation, during the processing of plutonium, and after final dispositioning of the denatured product.

When this study was begun, it was believed that rapid denaturing of ${ }^{239} \mathrm{Pu}$ by producing ${ }^{240} \mathrm{Pu}$ was a good method for dispositioning. However, a recent report ${ }^{1}$ concludes the following:
- Reactor-grade plutonium with any level of irradiation is a potentially explosive material.

- The difficulties of developing an effective, simple, weapon design are about the same for reactor-grade plutonium as for weaponsgrade plutonium.

- The hazards of handling reactor-grade plutonium, though somewhat greater than those associated with weapons-grade plutonium, are of the same type and can be met by applying the same precautions.

- The need for safeguards to protect against the diversion and misuse of separated plutonium applies to all grades of plutonium.

In view of these facts, the INEL modified the requirements to allow only two options: destruction of all plutonium isotopes or production of self-protecting fuel. The self-protection criterion is only a temporary solution to a longer-term problem. All plutonium must eventually be destroyed; therefore, the INEL has focused on this goal. However, it may be more proliferation resistant to run the entire plutonium stockpile through a reactor quickly to render it self-protecting. Subsequently, the plutonium would then be returned to a reactor for further burning.

Fuel elements that have been irradiated in a reactor pose less of a risk for diversion than fresh unburned fuel elements because of the fission product radiation hazard. Other hazardous isotopes could also be bred into the spent fuel. Such isotopes and their daughter decay products, as well as fission products, emit gamma radiation that would pose a radiological threat to humans and would provide a strong gamma signal for detection.

The plutonium cannot be completely burned in a once-through cycle because of fuel burnup limits and the statistical improbability of all plutonium being struck by a neutron. However, with the right fuel choice perhaps $70-95 \%$ can be burned. The remaining 5-30\% could then be extracted via reprocessing and returned to a reactor. Thus, a fraction of the entire plutonium stockpile could be burned in one concept in a couple of 
decades, then, following reprocessing, the remainder would be burned again in the same or a different reactor concept. For example, an LWR could perform the initial burn and a fast reactor built later could complete the job.

The approach is to develop concepts for the first burn cycle, because this will burn the most plutonium over the next three decades. Furthermore, the plutonium mass remaining in each fuel rod after the first burn cycle should be less than contained in a spent fuel rod from a commercial reactor. If direct disposal of commercial spent fuel is acceptable, then it seems appropriate that a second burn cycle would not be required. The need to reprocess material to ensure complete destruction is less desirable, because it provides additional opportunities for diversion. It must be possible to track the weapons-grade plutonium through all processes associated with a disposal option. Methods must be available to verify the quantity of plutonium present and location of all material. This is difficult when reprocessing is performed.

2.3.2 Development Risk. The second main requirement is to minimize development risk in order to successfully achieve objectives as rapidly as possible. Some of the dispositioning options will require significant technology development before they can be used on the scale necessary to dispose of $50 \mathrm{MT}$ of plutonium. Because failure to burn the plutonium prolongs proliferation concerns, uncertainties in the success of technology development efforts are considered to be very important. Technology development risk or uncertainty will likely be strongly dependent on the option. For example, reactor option uncertainties could include development of a new fuel form, core design, balance of plant, and disposal of waste. The INEL is focusing on using existing technology as much as possible. However, very few reactors have operated without any uranium, so some new technology development is required for this concept. Uncertainties in technology development will be minimized to provide assurance that the selected option will be effective with ${ }^{\circ}$... reasonable time frame.
To minimize technology development risk, the INEL has focused on LWR concepts similar to those in the commercial industry. This technology is considered to be the most mature and well established. In addition, LWRs are reliable, accepted, and licensable. A new concept has the best chance of being designed and constructed quickly and economically if it is based on LWR technology. Furthermore, nuclear facility management and operational infrastructures are well established.

The completion schedule issue is linked to the mission time, diversion and proliferation, safety, and economics. The time required from the beginning of the development phase to the end of the decontamination and decommissioning phase will have an influence on the overall success of the project to destroy plutonium. The longer the time required, the higher the potential for diversion of material or rearmament. The possibility of accidents and environmental damage would also be expected to be greater for longer mission times. In addition, longer project durations imply higher project costs. Using existing technology as much as possible will minimize development risk and reduce the technology development time.

2.3.3 Reactor Safety. The third main requirement is to design a reactor as safe as or safer than current uranium-fueled commercial reactors. All health and safety regulations must be met, and risk to the workers and the public must be minimized. As mentioned in the introduction, eliminating uranium from the reactor reduces the ability to control the reactor. The attainment of a design as safe as commercial reactors requires innovative uses of technology.

There may be unique safety risks associated with some of the proposed options that must be identified and considered early in the development phase. For example, current accident source term limits may severely restrict the mass of plutonium that could be loaded into some reactor concepts at any given time. These restrictions could result in increased processing time (mission time).

Passive safety features will be employed to ensure potential hazards to the public are as low 
as reasonably achievable. Appendix E contains a more detailed discussion of such passive safety features.

2.3.4 Environment. The fourth main requirement is to design a reactor as environmentally sound as current advanced reactor designs. Methods for disposing of the spent fuel must meet all environmental regulations and must have a minimal negative impact on the environment. Currently, no clear advantages or disadvantages from the waste disposal standpoint for the fuel types being considered are seen. In addition, a fuel type that precludes fuel reprocessing should not be used if the fuel must be burned twice.

The methods of heat rejection to the environment have changed over the years. In first generation plants, it was common to reject heat to a large body of water, such as an ocean, lake, or river. Over time the heat discharge has been moved from bodies of water to the atmosphere through the use of wet and dry cooling towers. For decay heat removal under accident conditions, disposal of a fraction of the full thermal power into relatively small bodies of water, such as lakes or manmade ponds, may be acceptable. Therefore, an additional concern in the site selection process will be the availability of water resource or supply for the cooling towers and ponds.

Burning ${ }^{239} \mathrm{Pu}$ will generate thermal energy (heat) that must be rejected to the environment. An environmentally acceptable method of heat rejection to the environment (ultimate heat sink) will be required for each disposal concept. For a concept with electric power generation capability, the rejected heat will be significantly reduced to about two-thirds of the total thermal power (33\% reduction). Thus, because the proposed concept does not produce electricity, the heat rejected to the local environment will be higher. If several of the proposed 1,000 MW(t) reactors are located at the same site, the high heat rejection would require environmental analysis. 


\section{REACTOR CONCEPT OVERVIEW}

Reactor design is driven by performance goals that vary according to the application. For example, a commercial power reactor is designed for optimum deposition of thermal power within the core coolant, while a test reactor might be designed for maximum neutron flux at a particular location within the core. For a plutoniumburning reactor, the design goal is unique: the destruction of plutonium. Plutonium destruction is totally dependent on the reactor power and capacity factor. Furthermore, a reactor fueled by plutonium and without the presence of other fertile materials (such as uranium or thorium) has an abundance of reactivity as compared with existing reactor designs. Because of its unique design goal, the designers of a plutonium-burning reactor have unusual flexibility in specifying reactor geometry and materials. In particular, the design goal of a plutonium-burning reactor appears to be achievable with a reactor that operates at a significantly lower thermal power density than is appropriate for reactors with other design goals. For example, commercial power reactors operate at a thermal power density of about $100 \mathrm{MW} / \mathrm{m}^{3}$ (based on total core fluid and structure volume); for the Advanced Test Reactor, this figure is $1,000 \mathrm{MW} / \mathrm{m}^{3}$.

To attain these goals, existing reactor designs typically employ neutronically efficient core geometries, elevated material operating temperatures, and forced-convection cooling of the core with a rapidly-flowing pressurized coolant. The thermal limits of fuel and other materials often limit the power density and thus overall reactor performance. Additionally, the need for fuel heat removal at high power densities leads to a forcedconvection core cooling scheme and a pressurized coolant.

The reliability, safety, and operability of existing reactors, although acceptable, are affected by these design features. Narrow coolant channels decrease the coolant volume available to receive heat from the core. Increased fuel rod failure rates and lower margins of safety are accepted because materials are operated at elevated temperatures. Reliance on forced-convection core cooling raises the need to ensure continued operation of coolant pumps during power operation. Reliance on a pressurized coolant for heat removal raises the need to ensure continued coolant system pressurization. Reactor operability is made more complex by all these issues, and complexity generally increases risk. If a plutonium-burning reactor can meet its design goal while operating at a much lower power density than existing reactors, then significant reliability, safety, and operability improvements over existing reactors can be attained.

\subsection{Concept Description}

This section presents an overview of the INEL concept. This concept is not completely defined because of the short duration of this project. Table 1 lists the design parameters that have been chosen. The ranges indicate the design flexibility for minimizing fuel fabrication costs within acceptable safety limits. The INEL selected a power level of 1,000 MW(t) to achieve an acceptable plutonium destruction rate with a low power density over a large, but reasonably sized core. Although the core has a low power density, the fuel is expected to remain in the reactor for several years to achieve high burnup. A few (three to six) reactors of this power level could burn most of the plutonium in a reasonable time frame ( $30-40$ years).

Section 2.3 discusses the main reason for adopting light water technology: to minimize technology development risk. LWRs have well established technology, and are reliable, accepted, and liccnsable. Water is cheap, easy to use, a good moderator, and a good coolant. Furthermore, operations personnel can see the fuel assemblies through the water, making refueling easier. 
Table 1. Plutonium burner reactor concept design parameters.

\begin{tabular}{lll}
\hline \multicolumn{1}{c}{ Parameters } & \multicolumn{1}{c}{ Baseline } & \multicolumn{1}{c}{ Possible range } \\
\hline General parameters & & - \\
Reactor power $[\mathrm{MW}(\mathrm{t})]$ & 1,000 & $\mathrm{PuO}_{2} / \mathrm{TRISO}^{\text {Fuel material }}$ \\
Cladding material & $\mathrm{PuAl}_{\mathrm{x}}$ & Stainless steel or zircaloy \\
Coolant type & Aluminum & - \\
Moderator type & Light water & - \\
Fuel cycle length $(\mathrm{yr})$ & Light water & $1-5$ \\
Batch resident time $(\mathrm{yr})$ & 3 & $5-12$
\end{tabular}

Core geometric data

Core total height $(\mathrm{m})$

3.66

Core total diameter $(\mathrm{m})$

5.90

$3.40-5.90$

Core height/diameter

0.62

$0.62-1.08$

Fuel volume fraction

0.34

$0.18-0.42$

Coolant volume fraction

0.55

$0.51-0.60$

Structure volume fraction

0.11

$0.06-0.22$

Core volume $\left(\mathrm{m}^{3}\right)$

100

$33-100$

Fuel volume $\left(\mathrm{m}^{3}\right)$

34

11-34

Total fuel element surface area in core $\left(\mathrm{m}^{2}\right)$

16,461

$6,360-19,100$

Fuel data

Fuel element shape

Clad rod

Fuel diameter (mm)

8.19

8-16

Cladding thickness (mm)

0.572

$0.5-2.0$

Fuel-cladding gap width (mm)

0.082

$0.0-0.1$

Fuel element height (m)

3.66

Fuel element pitch (m)

12.5

$12.5-22.0$

Fuel element pitch/diameter

1.53

$1.38-1.57$

Number of fuel rods

174,800

$58,200-174,800$

Number of rods per assembly

264

Total number of assemblies in core

620

224-672 
Table 1. (continued).

\begin{tabular}{lll}
\hline \multicolumn{1}{c}{ Parameters } & \multicolumn{1}{c}{ Baseline } & \multicolumn{1}{c}{ Possible range } \\
\hline Assembly dimensions $(\mathrm{m} \times \mathrm{m})$ & $0.21 \times 0.21$ & $(0.21 \times 0.21)-(0.39 \times 0.29)$ \\
Plutonium loading per rod $(\mathrm{g})$ & 28.6 & $20-70$
\end{tabular}

Core physics data

Average power density $\left(\mathrm{MW} / \mathrm{m}^{3}\right) \quad 10$

$0 \quad 10-30$

Core plutonium loading at BOC (MT) 5

Resonance absorber poison

Tungsten, erbium Tungsten, erbium, europium

Average capacity factor

0.75

$0.7-0.9$

Average plutonium batch burnup (\%)

67.6

$50-80$

Thermal-hydraulic data

Coolant outlet pressure (MPa)

0.20

Core pressure drop (MPa)

0.0027

Coolant velocity $(\mathrm{m} / \mathrm{s})$

0.75

Coolant bulk inlet temperature $(\mathrm{K})$

325

Coolant bulk outlet temperature (K)

347

Average heat flux

0.0523

$0.0523-0.1572$

Average power density in fuel $\left(\mathrm{MW} / \mathrm{m}^{3}\right)$

29.7

$29.4-88.5$

Peak hot element centerline temperature (K)

409

$400-500$

Heat rejection method

Cooling towers

Also to minimize technology development risk, the basic geometry and dimensions of LWR fuel assemblies are probably acceptable. Fuel in the form of rods (as opposed to plates) is acceptable because of the low power densities that are proposed. Adoption of LWR technology reduces costs and development time. Fabricated fuel assemblies facilitate item accountability. Fuel assemblies cannot be removed from the reactor without observable activity. Both of these issues improve safeguards and security.

3.1.1 Fuel Types. The plutonium-based fuel form to be used in plutonium-burning reactors is closely coupled to a particular reactor design. However, several general criteria apply to all circumstances. Fuel forms chosen for use in any type of plutonium-burner should (a) possess high burnup capability, (b) provide a high degree of operational safety, (c) offer cheap and easy fabrication methods with minimum hazardous waste generation, and (d) offer cheap and easy end-oflife disposal.

Only two plutonium-only fuel forms have been tested for any length of time in a nuclear reactor: $\mathrm{PuAl}_{4}$ dispersed in aluminum, and $\mathrm{PuO}_{2}$ embedded in carbon and sealed in a silicon carbide shell (TRISO coated $\mathrm{PuO}_{2}$ ). The INEL has examined these and a few advanced solid fuels that have not been tested.

The reactor could possibly operate with several fuel types: $\mathrm{PuAl}_{\mathrm{x}}, \mathrm{PuZr}, \mathrm{PuO}_{2} / \mathrm{ZrO}_{2}$, $\mathrm{PuO}_{2} / \mathrm{ZrO}_{2} / \mathrm{Ca} 0, \mathrm{PuO}_{2} / \mathrm{C}$ (TRISO), or $\mathrm{PuZrH}_{1.6}$. 
The current top fuel choice is the $\mathrm{Pu}-\mathrm{Al}$ composite. Appendix $C$ presents the advantages and disadvantages of each fuel type. Some of these fuels are able to withstand very high exposures. As discussed in Appendix D. plutonium in these fuels provides ample core reactivity and must be diluted with other materials. Appendix $C$ presents the advantages and disadvantages of each fuel type.

These fuels will be clad in aluminum, zircaloy. or stainless steel. Present calculations indicate that all are acceptable. Tungsten, erbium, or europium will be added to the fuel to provide a negative Doppler reactivity feedback, as stated in Appendix D. These or other poisons such as boron or gadolinium will also be required to hold down the core reactivity at beginning of cycle (BOC). The poisons could be mixed in the fuel or cladding, or be separate rods in the reactor. All of these poisons appear to be compatible with the fuels being examined.

Fabrication processes, such as extruding $\mathrm{PuAl}_{\mathbf{x}}$, are discussed in greater detail in Volume 4 of this report. The traditional fabrication methods for the aluminum-based fuels are fairly simple. The fuel fabrication waste volumes can be minimized. Several variations of the fabrication method of aluminum-based fuel form have been successfully applied to produce $\mathrm{Pu}-\mathrm{Al}$ composite fuel elements. Plutonium fabrication facilities currently exist at the Los Alamos National Laboratory (LANL) and the Savannah River Site (SRS). These facilities could be used to produce $\mathrm{Pu}$-Al composite fuel elements in sufficient quantities to verify fuel designs and prove the fuel performance. The Advanced Test Reactor at the INEL could be used to test these fuels.

3.1.2 Neutronics. Eliminating ${ }^{238} \mathrm{U}$ from the reactor prevents the production of more ${ }^{239} \mathrm{Pu}$ and accelerates plutonium destruction. A major disadvantage of removing ${ }^{238} \mathrm{U}$ is the reduction or elimination of a prompt negative Doppler reactivity coefficient and a negative moderator temperature coefficient. A pure plutonium fuel type is not desirable in LWRs because of the low allowable mass loading per fuel rod (yielding short fuel cycles) and strong positive temperature coefficients. Any workable fuel composition must have a negative prompt temperature coefficient (i.e.. reactor power decreases as temperature increases) for safety and control purposes. Plutonium cores in LWRs can have negative isothermal temperature coefficients if enough tungsten, erbium, or other resonance absorbers are added. The addition of burnable poison is also needed to hold down the core reactivity.

Because a large excess reactivity is available, the cycle lengths can be greater than one year, and probably several years. With about $30 \mathrm{~g} \mathrm{Pu} / \mathrm{rod}$, 5 MT of plutonium would be present in the core initially. Confining a large amount of weaponsgrade plutonium in a reactor limits proliferation.

More dilute fuel could be burned more completely in shorter cycles. However, capacity factors would likely be higher with longer cycles. The fuel could be managed similar to a commercial LWR. Cycles could last one or two years, then one-third or one-fourth of the core could be replaced with fresh fuel. Thus, the typical fuel assembly would remain in the core several years, until a high exposure level is achieved. Commercial LWR fuel management strategies could be used to maintain relatively flat power distributions.

Appendix D gives a detailed explanation of the core neutronic aspects of this concept.

\subsubsection{Thermal Hydraulics. The proposed} reactor will have a low power density $\left(10-30 \mathrm{MW} / \mathrm{m}^{3}\right)$ and be cooled by water with a low flow velocity. Appendix $\mathrm{E}$ discusses these passive safety features and the thermal hydraulics of the INEL concept. As a result of the low-power densities, the reactor pressures and temperatures are very low compared to a commercial LWR. This enhances safety by reducing stresses on various components and by providing wider margins between steady-state fuel temperature and maximum allowable fuel temperature. Low coolant velocities, low pressures, and low temperatures also reduce capital costs as discussed in Appendix G. With low pressure coolant, a thick pressure vessel is not needed, and the core can be quite 
large (approximately 5 meters in diameter). Cores with low power densities are less sensitive to uncertainties in fuel content. This reduces inspection requirements, which could be a major concern for mixed oxide fuel in LWRs because remote inspections are required.

The core cooling flow is provided by pumps, but even greater safety advantages would be attained if a natural circulation cooling system could be employed. Preliminary analysis indicates that such a system is feasible, but further study is needed.

This reactor concept has multiple thermalhydraulic and safety advantages over most existing test and commercial reactor designs: (a) the margin to critical heat flux is very large, (b) the times required to raise fuel temperatures to damage and melting points are long, (c) coolant flowing vertically upward in the core ensures initiation and continuance of natural circulation core cooling should the primary coolant pumps fail, (d) the open, nonchannelized, core flow arrangement avoids safety issues associated with flow instability in parallel channels, (e) the low energy stored in the coolant and structure minimizes the requirements placed on the containment, and (f) the low pressure coolant system significantly reduces the safety risk due to lossof-coolant accidents and is compatible with passive safety injection systems.

\subsection{Plutonium Dispositioning}

All reactors without fertile materials at the same power level and capacity factor destroy plutonium at the same rate. In addition, this rate is faster than the rate of any reactor containing fertile materials (uranium or thorium), because fertile materials produce more weapons materials. All plutonium isotopes release about the same amount of energy per fission (within $2 \%$, and nearly independent of the incident neutron energy). Without fertile nuclides in the system, all of the fission energy comes from plutonium. Therefore, if the reactor is operated at a certain power level, the total amount of plutonium will decrease linearly in time. Thus, all reactors destroy the same amount of plutonium per megawatt. It is also clear that if any fertile materials are present in the system, some will fission and produce energy. If the same power level is used, less plutonium will be consumed. Thus, the rate of plutonium destroyed per megawatt is less if the reactor contains fertile material.

The above information allows us the freedom to explore a variety of reactor designs. A high capacity factor is needed to maximize the absolute quantity of plutonium consumed over a long period. Continuous operation during refueling is desirable, eliminating the need to shut the reactor down for refueling. The next best design would probably have long cycles with short refueling and maintenance outages. Fuel exposures greater than $700 \mathrm{GWD} / \mathrm{MT}$ are possible from a core reactivity standpoint. The remaining design drivers include security, safety, licensing, economics, and the environment. For example, plutonium located in the core for a long period is an impediment to diversion because it is surrounded by fission products and cannot be handled easily. Thus, long cycles may be desirable.

If the main burnup criterion becomes selfprotection, then the design could evolve in a different direction. In this case it would be advantageous to have continuous refueling or short cycles with short refueling and maintenance outages. Or, as stated earlier, all of the plutonium inventory could undergo a short burn for selfprotection, and then be placed back in the reactor for a long burn. For self-protection concepts, the plutonium feed rate through the system is a measure of irradiation rate.

If the goal is to achieve a specified absorber content, such as a specified fraction of ${ }^{240} \mathrm{Pu}$ in total plutonium, operation in a thermal spectrum is superior to operation in a fast spectrum. Notable exposure-dependent isotopic composition differences are observed between the thermal and fast spectra, as shown in Appendix A. Operation in a thermal spectrum yields a specified parasitic absorber content at much lower exposures. Thus, although this is not currently a goal, a thermal reactor concept is advantageous if such a goal were adopted. 
3.2.1 Plutonium Destruction. The total heat energy available from the fission of $50 \mathrm{MT}$ of ${ }^{239} \mathrm{Pu}$ is approximately $4.2 \times 10^{18}$ joules or 48,600,000 megawatt days (MWD). Burnup times are inversely proportional to power rating, number of reactors, and capacity factor, and are directly proportional to the percent ${ }^{239} \mathrm{Pu}$ burnup. For example, four reactors operating at $1,000 \mathrm{MW}(\mathrm{t})$ each and having a capacity factor of 0.75 would burn up 33.8 MT of plutonium (67.6\% of the total inventory) in 30 years. The full $50 \mathrm{MT}$ of plutonium would be burned in 44.4 years.

Building one giant 4,000 $\mathrm{MW}(\mathrm{t})$ reactor may reduce the probability of overall mission success, may produce a high fission product source term, and has less ability to adopt passive safety features. Building ten $400 \mathrm{MW}(\mathrm{t})$ reactors is more diverse, and the impact on the environment could be distributed. However, the capital costs for several smaller reactors could be higher than for a few moderate-sized reactors. As a starting point, the INEL investigated reactor designs at a power level of $1,000 \mathrm{MW}(\mathrm{t})$ as a reasonable middle ground. A few reactors of this size could destroy most of the plutonium in a reasonable time frame.

3.2.2 Self-Protection. Irradiated materials can be potent sources of gamma radiation, which reduces the likelihood of material diversion by terrorists. An intense gamma environment can provide a certain degree of self-protection in the form of high biological dose rate levels. Fission products in spent fuel provide a high amount of gamma radiation. Photon source strengths could be increased further by seeding the plutonium. Seeding is the addition of materials that will produce photon-emitting nuclides following irradiation and decay. Seeding offers the potential of enhancing the photon emission of the plutonium following irradiation.

The most attractive self-protection seed candidates are europium and cobalt. Cobalt could be incorporated into the plutonium fuel proper or employed by using a cladding material with high cobalt content. Europium is especially attractive because it may also be used for reactor control purposes. The degree to which any seed material can enhance fuel self-protection will depend primarily on the specific power level of the plutonium burner reactor. The most significant self-protection enhancements will occur for low plutonium exposures accumulated at high power density. For the proposed low-power density concept, generation of fission products provides the best option for self-protection, and seed materials are not used. Appendix B discusses self-protection in greater detail.

\subsection{Source Term Evaluation}

Potential offsite doses from hypothetical releases are of concern for any plutonium-based reactor facility. Offsite dose consequences may result from release of both fission products and heavy metals, especially uranium and plutonium. To compare differences in offsite dose impacts of ${ }^{235} \mathrm{U}$ and ${ }^{239} \mathrm{Pu}$ fueled reactors without developing specific reactor accident scenarios, simple aerosol releases were assumed. Appendix F presents an evaluation of offsite releases from a plutonium-burning reactor. Equivalent quantities of ${ }^{235} \mathrm{U}$ and ${ }^{239} \mathrm{Pu}$ were assumed to be released along with the fission products associated with those heavy metals. In both cases the calculated dose impact from all pathways is dominated by the fission products. The total dose consequence from ${ }^{239} \mathrm{Pu}$ release is less than $1 \%$ of the fission product dose.

\subsection{Economics}

Costs associated with construction, operation, decontamination and decommission, and waste processing and disposal, must be considered for all facilities. These nuclear facility costs demand that methods, processes, and requirements be critically reviewed and improved if these facilities are to be affordable in the future. Cost reduction ideas for these concepts have been developed and are discussed in Appendix G. When several of the cost reduction ideas are implemented, the overall cost of designing, constructing, and operating a reactor can be reduced significantly. 


\section{CONCLUSIONS AND RECOMMENDATIONS}

A reactor concept without uranium or thorium that destroys plutonium quickly has been developed. This concept is very safe and could be designed, constructed, and operated in a reasonable time frame.

Light water technology was adopted to minimize technology development risk, ensure the greatest chance of success, and reduce costs. Low power densities, temperatures, pressures, and coolant flow velocities were selected to enhance reactor safety. Electricity production was not considered at the request of NAS, thus allowing focus on the main mission of plutonium dispositioning. A few (three to six) reactors of this type [1,000 MW(t)] would be able to burn a large fraction of the weapons-grade plutonium in $30-40$ years.

The following preconceptual design studies are recommended:

- Reactor physics/neutronics

- Determine an acceptable weaponsgrade plutonium loading in the fuel elements. A range of plutonium loadings for candidate fuel forms acceptable from a core neutronics standpoint should be determined.

- Select a burnable poison and determine its loading in the fuel elements. The reactivity effects of the poison over the life cycle, as its concentration decreases, burnable plutonium decreases, and fission products increase, should be determined.

- Perform fuel cycle optimization and isotope concentration studies. Investigate incore fuel management and fuelloading schemes in order to achieve the desired burnup.

- Investigate reactor kinetics and control. Perform full core calculations and assembly calculations with the proposed fuel forms and loadings, pin dimensions and pitches, and reactivity/shutdown control mechanisms. Determine the core reactivity coefficient at design power levels for the complete cycle.

- Materials

- Establish a credible list of fuel composition candidates along with candidate cladding materials. Plutoniumdestruction performance and safety can be optimized. Burnable poison additions should be considered as an integral part of this study.

- Define and evaluate all existing U.S. plutonium fabrication facilities to estimate their potential for fabricating fuel elements. Reactor designs that can use existing fabrication facilities for fuel elements should be given the greatest attention.

- Outline a fuel development plan, including cost and schedule estimates.

- Select component materials to define a credible conceptual design.

- Thermal transport system

- Evaluate thermal-hydraulic safety parameters for core configurations consistent with the reactor physics studies.

- Develop conceptual designs of primary and secondary coolant loops. The feasibility of natural circulation for both should be investigated in more detail.

Propose concepts for an emergency core cooling system. 
- Examine the use of alternative coolants and concepts such as the Modular High Temperature Gas-Cooled Reactor (MHTGR) and the Advanced Liquid Metal Reactor (ALMR). There was not time in the preliminary design work to study in detail the possibility of use of other coolants. Alternative coolants should be evaluated considering both core neutronics and thermal hydraulics.

- Develop a list of thermal-hydraulic testing needs.

- Study various accident scenarios. Loss-ofcoolant, inadvertent reactivity insertion, control rod ejection, fission product release, fuel handling, and other accident scenarios should be investigated. Safety margins should be determined. Passive safety options should be examined.
- Characterize the spent fuel so that methods of handling and storage can be developed.

- Economics

- Examine reactor costs from reactor design, licensing, siting, and construction, fuel fabrication, safeguards, security, and processing, to waste handling and storage, and reactor decontamination and decommissioning. Suggest ideas and methods to reduce the costs. Develop a baseline cost estimate for this reactor.

- Investigate other uses of the reactor. Flux traps could be designed into the reactor for the production of medical isotopes, tritium, or ${ }^{238} \mathrm{Pu}$, or for burning actinides. 


\section{REFERENCE}

1. J. Mark, "Explosive Properties of Reactor-Grade Plutonium," Science and Global Security, 3, 1, 1992. 


\section{Appendix A \\ Plutonium Destruction Rates and Isotopics for Different Neutron Spectra}




\section{Appendix A}

\section{Plutonium Destruction Rates and Isotopics for Different Neutron Spectra}

\section{A-1. INTRODUCTION}

The destruction or denaturing of weaponsgrade plutonium could be accomplished in a variety of reactor types operating in a variety of neutron spectral regimes. Potential strategies range from maximum use of existing technology and facilities designed for electrical power production through new concepts designed and developed specifically for plutonium destruction. Eventual selection of a preferred reactor type must ultimately include consideration of a significant number of important or potentially important technical and political aspects described elsewhere in this document.

Initial investigations have been focused on two important characteristics crucial to any plutonium-burning reactor design and/or assessment activity. The influence of reactor type (essentially neutron spectrum) on the potential life of the plutonium fuel and the influence of reactor type on the exposure dependent isotopic compositions must be understood. The main limits on fuel exposure are reactivity and materials. To date, this study has examined only the reactivity limit.

Definitive answers to reactivity life and isotopic composition questions require a reasonably mature design and substantial reactor physics efforts. The methods employed for this assessment are described below. Although preliminary, these results provide a reasonable perspective on trends that could be expected from different reactor types. 


\section{A-2. ASSESSMENT METHODOLOGY}

The Oak Ridge National Laboratory ORIGEN2 isotopic generation and depletion code ${ }^{1}$ was employed to assess both isotopic compositions and changes in fuel reactivity. The ORIGEN 2 code is a zero-dimensional isotopic generation and depletion code. The code uses cross-section libraries developed for a variety of particular reactor designs. The libraries include spectrum-averaged, one-group cross sections for the heavy metals (including plutonium), fission products, and structural materials. Exposuredependent fission and radiative-capture cross sections are included for a number of heavy metals, including the plutonium isotopes of interest to this assessment.

Reactivity changes and plutonium isotopic compositions were first examined for a commercial pressurized water reactor (PWR) operating on a low enrichment (3.2 wt\% $\left.{ }^{235} \mathrm{U}\right)$ equilibrium fuel cycle. The results aided in understanding the significance of a number of approximations made in this assessment. The results also provided some perspective on the plutonium composition in spent commercial reactor fuels.

Typical analyses to determine reactivity changes would normally include isotopic generation and depletion in the heavy metals generated from the initially loaded uranium fuels, in the fission products, and in activation of structural materials. Exposure-dependent, cross-section sets would also normally be employed. Exposure-dependent, cross-section sets require significant development effort and are only available for selected reactor types. Existing sets are not suitable for the high exposure plutonium irradiations of interest. It is also convenient if the effects of absorption in structural materials can be ignored. This is not a serious omission because one of the important criteria employed in the selection of suitable structural materials is that they be neutronically benign.

Four specific cases were examined to assess the impact of not using exposure-dependent cross sections and of ignoring structural materials. The fuel was assumed to operate at a specific power of $37.5 \mathrm{MW} / \mathrm{MT}$ for a total of $\mathbf{8 8 0}$ days, yielding an exposure of $33 \mathrm{GWD} / \mathrm{MT}$. Results of the four cases examined are shown in Figure A-1. The upper figure illustrates the calculated infinite multiplication factor $\left(\mathrm{k}_{\mathrm{inf}}\right)$. The calculated reactivity, defined as $(k-1) / k$, is illustrated in the lower figure.

The curve labels employ the abbreviations $\mathrm{HM}, \mathrm{FP}$, and $\mathrm{L}$ representing heavy metals, fission products, and light (structural) materials, respectively. The case including heavy metals, fission products, and structurals (labeled "HM+FP+L") represents the best estimate calculation. Exposure-dependent cross sections were employed for all cases, except the one labeled "Constant XS." These results clearly illustrate that the fission products must be included and that the structurals may be excluded with only small errors. Use of the constant cross-section set introduces a small, but acceptable, exposure-dependent error in the calculated reactivity.

The calculated plutonium isotopic compositions are shown in Figure $\mathrm{A}-2$. The ${ }^{240} \mathrm{Pu}$ isotopic content reaches $20 \%$ of total plutonium at an exposure of about $18 \mathrm{GWD} / \mathrm{MT}$. The parasitic absorber $\left({ }^{240} \mathrm{Pu}\right.$ plus ${ }^{242} \mathrm{Pu}$ ) content reaches $20 \%$ at a slightly lower exposure of about $16 \mathrm{GWD} /$ MT. Although these values can be considered representative, the plutonium content is dependent on the initial enrichment and the particular fuel management schemes employed. Current LWR operations employ initial enrichments in excess of $4 \%{ }^{235} U$ to achieve exposures in excess of $40 \mathrm{GWD} / \mathrm{MT}$.

One metric ton of ${ }^{239} \mathrm{Pu}$ was selected as the basis for all plutonium irradiations. Weaponsgrade plutonium will in fact contain some small fraction of higher plutonium isotopes (primarily ${ }^{240} \mathrm{Pu}$ ). Using pure ${ }^{239} \mathrm{Pu}$ as the starting composition is acceptable for these evaluations because equivalent higher plutonium isotopic "contamination" will be achieved at low exposure in any reactor irradiation. 

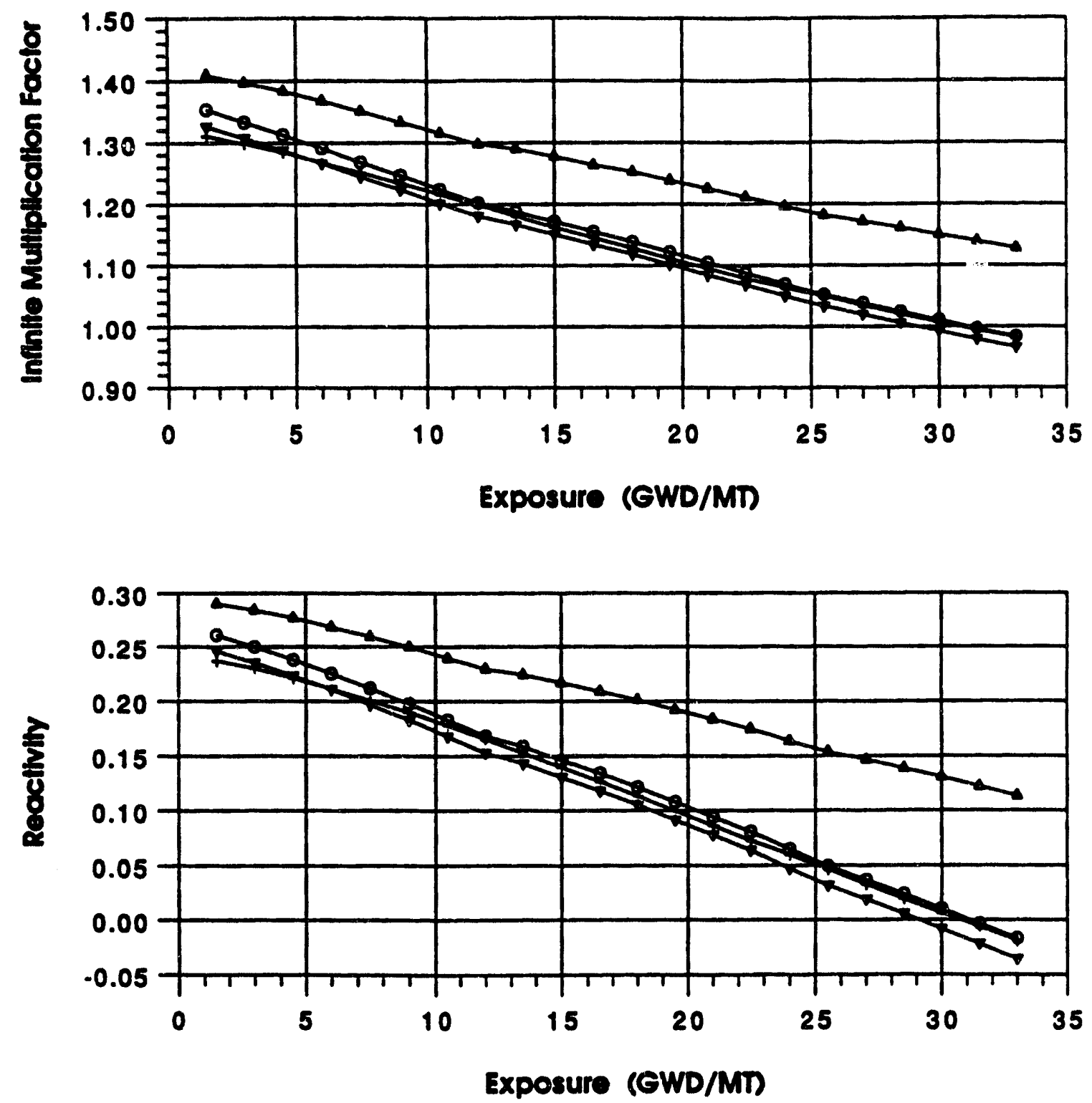

Figure A-1. Exposure dependent infinite multiplication factor and reactivity in a generic PWR equilibrium cycle. 


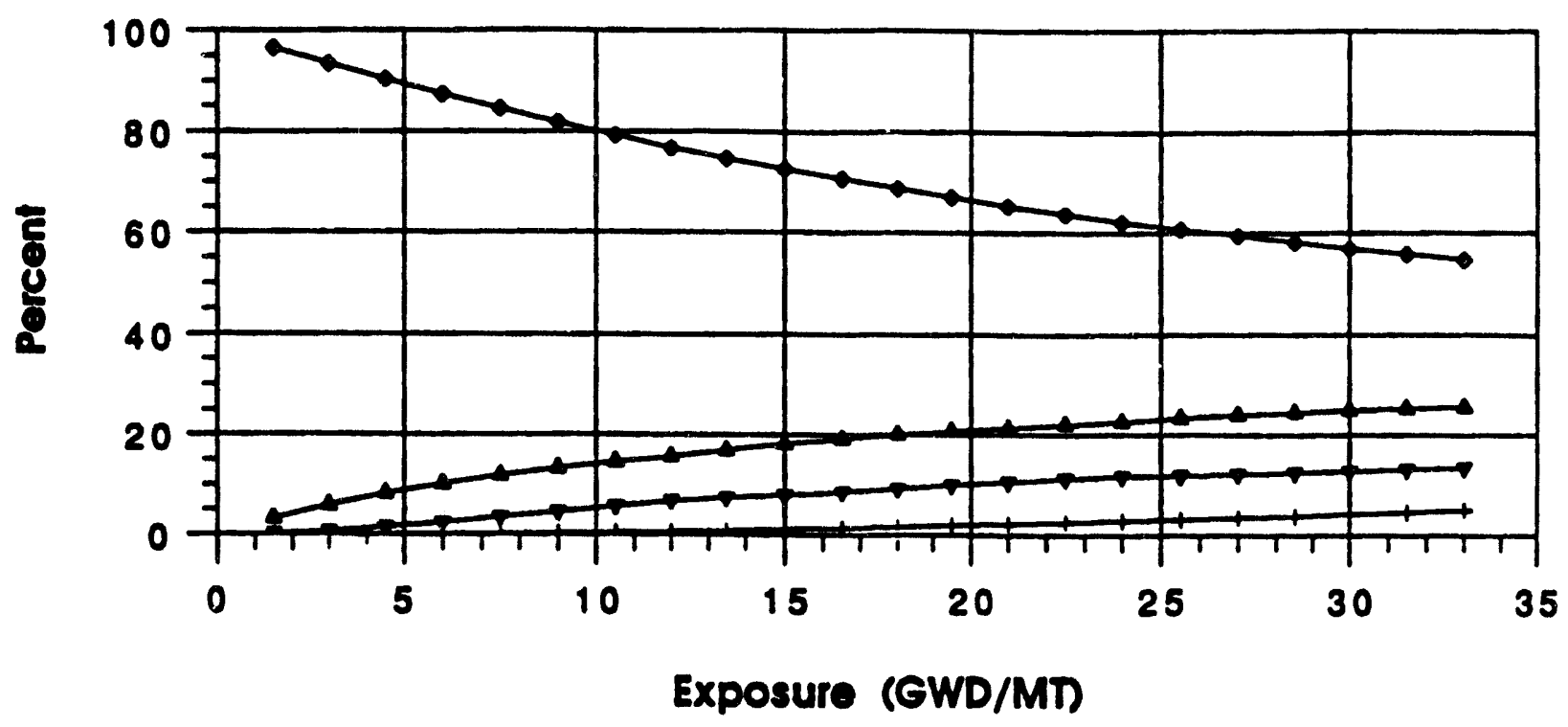

Figure A-2. Exposure dependent isotopic composition in a $3.2 \mathrm{wt} \%{ }^{235} \mathrm{U}$ generic PWR equilibrium cycle.

Five existing reactor types were selected for consideration to cover a broad range of possible neutron spectral characteristics. In alphabetical order, the types examined are a boiling water reactor (BWR), a Canadian deuterium-uranium (CANDU) reactor, a high-temperature gas-cooled reactor (HTGR), a liquid metal reactor (LMR), and a PWR.

All irradiations were assumed to be performed at a nominal specific power of $1,000 \mathrm{MW} / \mathrm{MT}$. This specific power is consistent with, for example, a current generation PWR, if the power is normalized to the fissile content rather than to the total uranium content. Isotopic compositions and reactivity changes should be only weakly dependent on the assumed specific power. The plutonium irradiations were continued until the material could no longer support irradiation from a reactivity standpoint. 


\section{A-3. RESULTS}

The reactivity changes with exposure for pure plutonium irradiations (no uranium present) in five reactor spectra are illustrated in Figure A-3. The exposure at which zero reactivity is reached is a reasonable first-order indicator of the maximum useful fuel life. Irradiation in a CANDU spectrum reaches zero reactivity soonest, and irradiation in an LMR spectrum reaches zero reactivity last. All cases are fairly tightly grouped with a maximum difference of about $12 \%$ in achievable exposure. There is little justification for preference of any particular reactor type, based on achievable exposure.

\section{Boiling Water Reactor (BWR)}

The exposure-dependent isotopic compositions of one metric ton of plutonium, irradiated in a BWR spectrum, are shown in Figure A-4. Moles of total plutonium and the ${ }^{239} \mathrm{Pu},{ }^{240} \mathrm{Pu}$,
${ }^{241} \mathrm{Pu}$, and ${ }^{242} \mathrm{Pu}$ components are shown in the upper figure. The lower figure illustrates the fractional contribution of each isotope to the total plutonium inventory. The same graphic format is used for all five reactor types.

The isotopic content reaches $20 \%{ }^{240} \mathrm{Pu}$ at an exposure of about $300 \mathrm{GWD} / \mathrm{MT}$. The zero reactivity point is reached at an exposure of about $750 \mathrm{GWD} / \mathrm{MT}$. At the zero reactivity point, the total plutonium inventory has been reduced to about $228 \mathrm{~kg}$ with $77.2 \%$ of the initial loading destroyed. The parasitic plutonium $\left({ }^{240} \mathrm{Pu}\right.$ plus ${ }^{242} \mathrm{Pu}$ components) is about $53 \%$ at the zero reactivity point. The residual plutonium is subcritical after the zero reactivity point and would have to be externally driven to achieve greater exposure. At an exposure of $925 \mathrm{GWD} / \mathrm{MT}$, the residual plutonium is less than $10 \mathrm{~kg}$ of the initial $1,000 \mathrm{~kg}$.
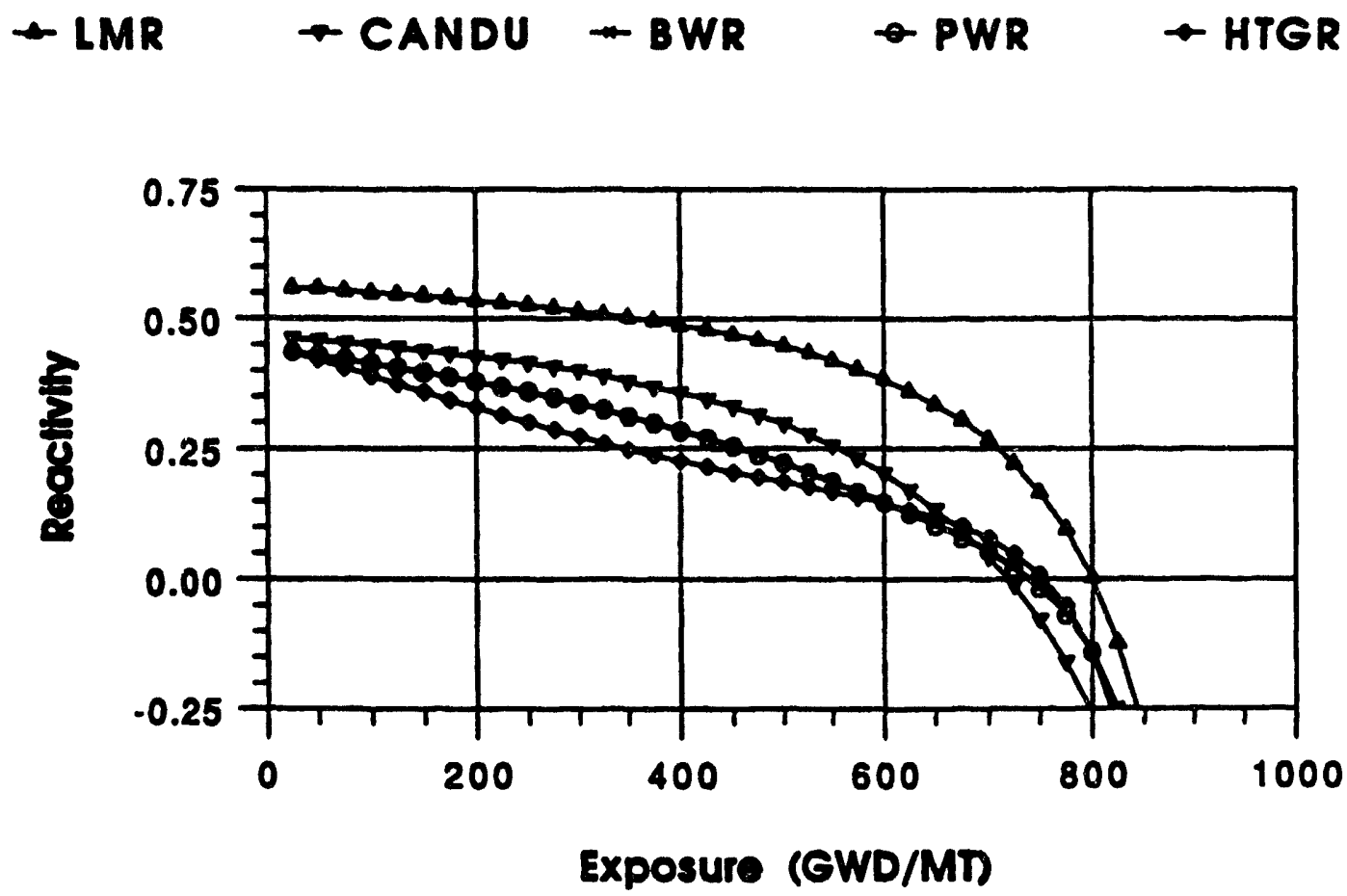

Figure A-3. Reactivity as a function of exposure for plutonium irradiated in selected reactor spectra. 
- All Pu $\rightarrow$ Pu-239 $-\mathrm{Pu}-240 \rightarrow \mathrm{PU}-241+\mathrm{Pu}-242$
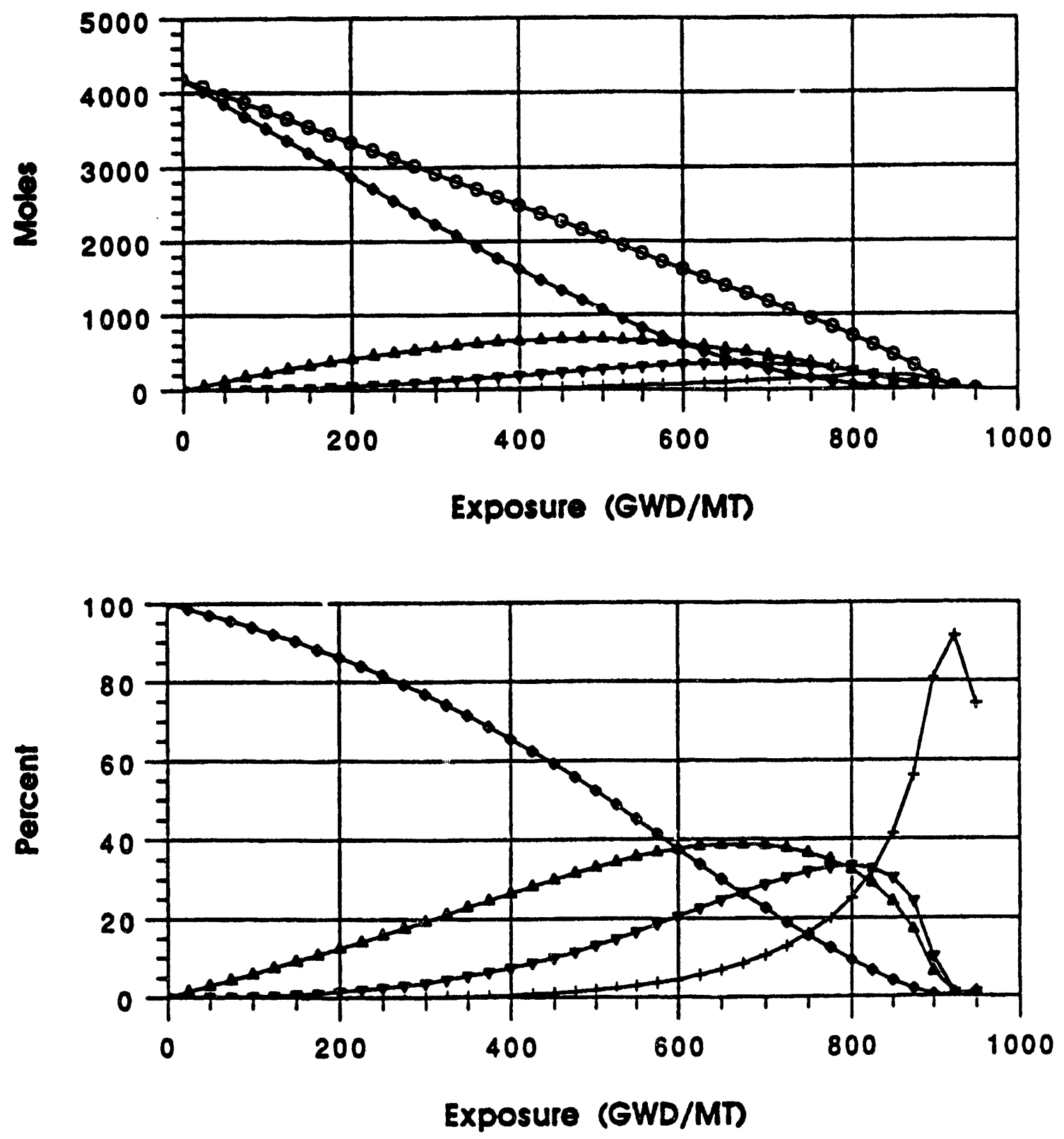

Figure A-4. Exposure dependent isotopic composition of plutonium irradiated in a boiling water reactor (BWR) spectrum. 


\section{Canadian Deuterium-Uranium (CANDU) Reactor}

Results for irradiation in a CANDU spectrum are shown in Figure A-5. The $20 \%{ }^{240} \mathrm{Pu}$ composition is reached at a slightly higher exposure of $325 \mathrm{GWD} / \mathrm{MT}$. The zero reactivity point is reached at a slightly lower exposure of about $725 \mathrm{GWD} / \mathrm{MT}$. At the zero reactivity point, the total plutonium inventory is slightly higher at $262 \mathrm{~kg}$ or $73.8 \%$ of the initial loading destroyed. The parasitic plutonium is higher at $63 \%$ at the zero reactivity point. At an exposure of $925 \mathrm{GWD} / \mathrm{MT}$, the residual plutonium is less than $26 \mathrm{~kg}$ of the initial $1,000 \mathrm{~kg}$.

\section{High-Temperature Gas-Cooled Reactor (HTGR)}

Isotopic compositions during irradiation in an HTGR spectrum are plotted in Figure A-6. The ${ }^{240} \mathrm{Pu}$ composition reaches about $20 \%$ at an exposure of about $500 \mathrm{GWD} / \mathrm{MT}$. The zero reactivity point is reached at an exposure of about $750 \mathrm{GWD} / \mathrm{MT}$. The total plutonium inventory at the zero reactivity point is $213 \mathrm{~kg}$. At the zero reactivity point, the parasitic plutonium content is about $32 \%$. At an exposure of $925 \mathrm{GWD} / \mathrm{MT}$, the residual plutonium is about $3 \mathrm{~kg}$ of the initial $1,000 \mathrm{~kg}$.

\section{Liquid Metal Reactor (LMR)}

The LMR spectrum results are shown in Figure A-7. A composition of $20 \%{ }^{240} \mathrm{Pu}$ is not reached until an exposure in excess of $475 \mathrm{GWD} / \mathrm{MT}$. The zero reactivity point is at an exposure of $800 \mathrm{GWD} / \mathrm{MT}$, the highest of the five reactor types, plutonium content is about $53 \%$ at the zero reactivity point. At an exposure of $925 \mathrm{GWD} / \mathrm{MT}$, the residual plutonium is about $59 \mathrm{~kg}$ of the initial $1,000 \mathrm{~kg}$.

\section{Pressurized Water Reactor (PWR)}

Results for irradiation in a PWR spectrum are shown in Figure A-8. The results are essentially indistinguishable from those obtained for the BWR case.

\section{Net Plutonium Destruction Rates}

The two primary removal mechanisms for fissile plutonium $\left({ }^{239} \mathrm{Pu}\right.$ and ${ }^{241} \mathrm{Pu}$ ) are fission and radiative capture. Net fissile destruction rates are shown in Figure A-9 for irradiations in the five reactor spectra. At low exposure, the net fissile rates are somewhat higher in thermal spectrum reactors. At exposures in excess of about $650 \mathrm{GWD} / \mathrm{MT}$, higher fissile destruction rates are achieved in fast (LMR) or epithermal (HTGR) spectrum reactors.

Total plutonium destruction as a function of exposure is illustrated in Figure A-10 for the five reactor types considered. The very slight differences observable only at high exposure are not significant.

\section{Plutonium Compositions}

Figure A-11 illustrates the growth in parasitic absorber plutonium isotopes with exposure in the five reactor spectra. The three thermal spectrum reactor types (BWR, CANDU, and PWR) all achieve about $20 \%$ parasitic absorber fraction at an exposure of about $300 \mathrm{GWD} / \mathrm{MT}$. The epithermal spectrum HTGR achieves a $20 \%$ parasitic absorber fraction at an exposure of about $450 \mathrm{GWD} / \mathrm{MT}$. The fast spectrum LMR achieves $20 \%$ parasitic absorber fraction at an exposure of about 475 GWD/MT. 

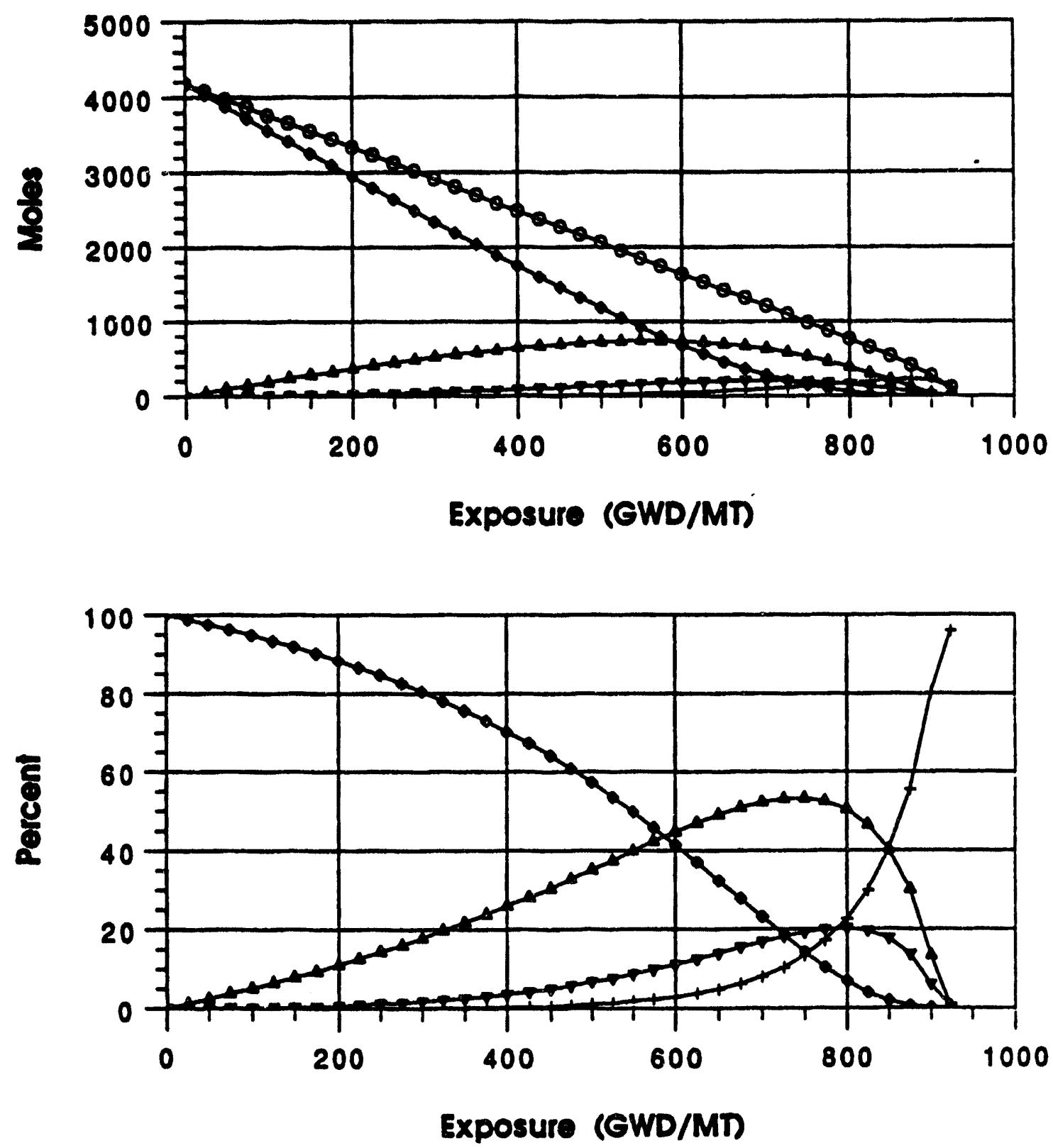

Figure A-5. Exposure dependent isotopic composition of plutonium irradiated in a CANDU reactor spectrum. 
$\rightarrow$ All Pu $\rightarrow \mathrm{Pu}-239+\mathrm{Pu}-240+\mathrm{Pu}-241+\mathrm{Pu}-242$
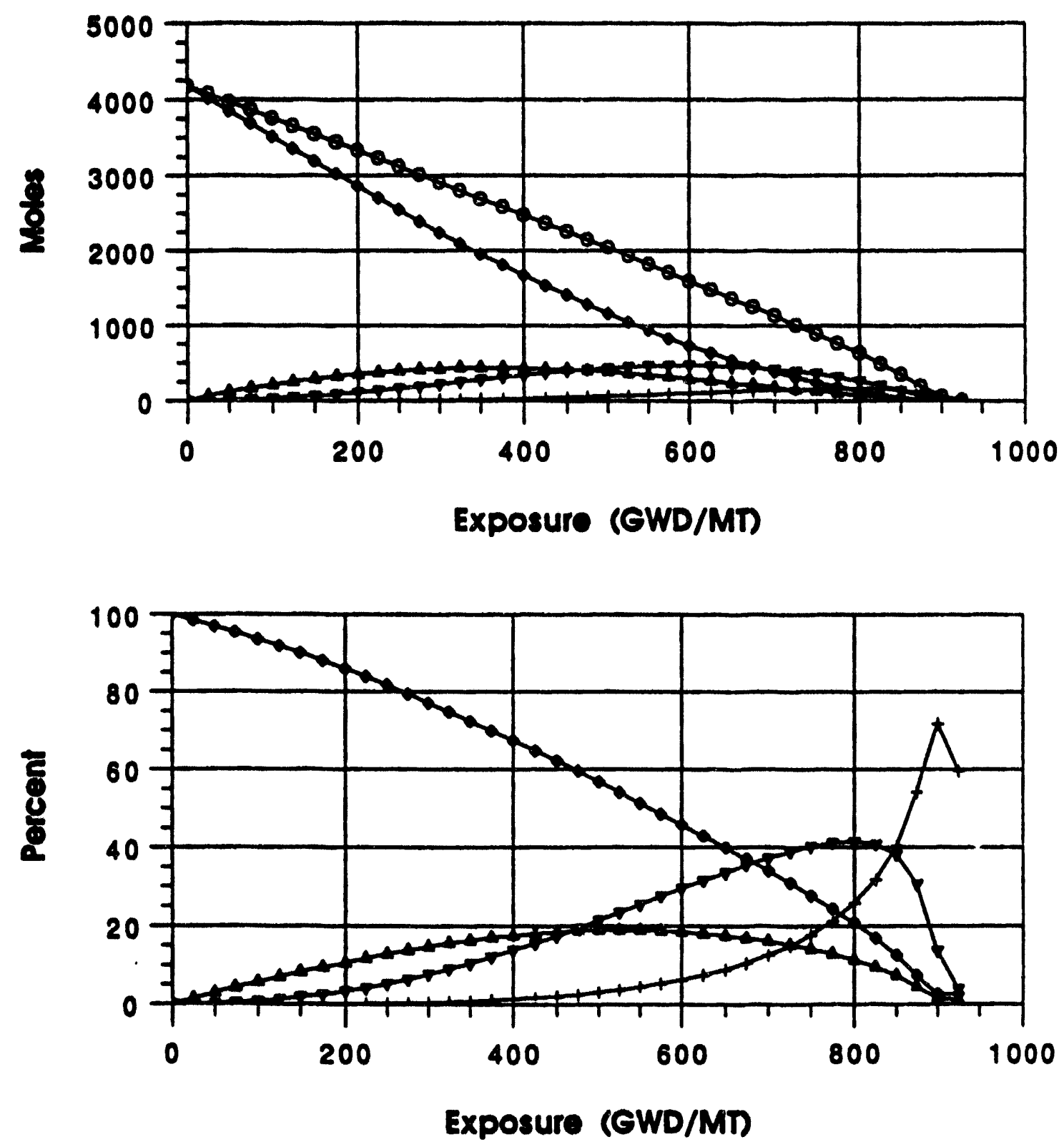

Figure A-6. Exposure dependent isotopic composition of plutonium irradiated in an HTGR spectrum. 
- All Pu $\rightarrow$ Pu-239 $\leftarrow$ Pu-240 $-P u-241+P u-242$
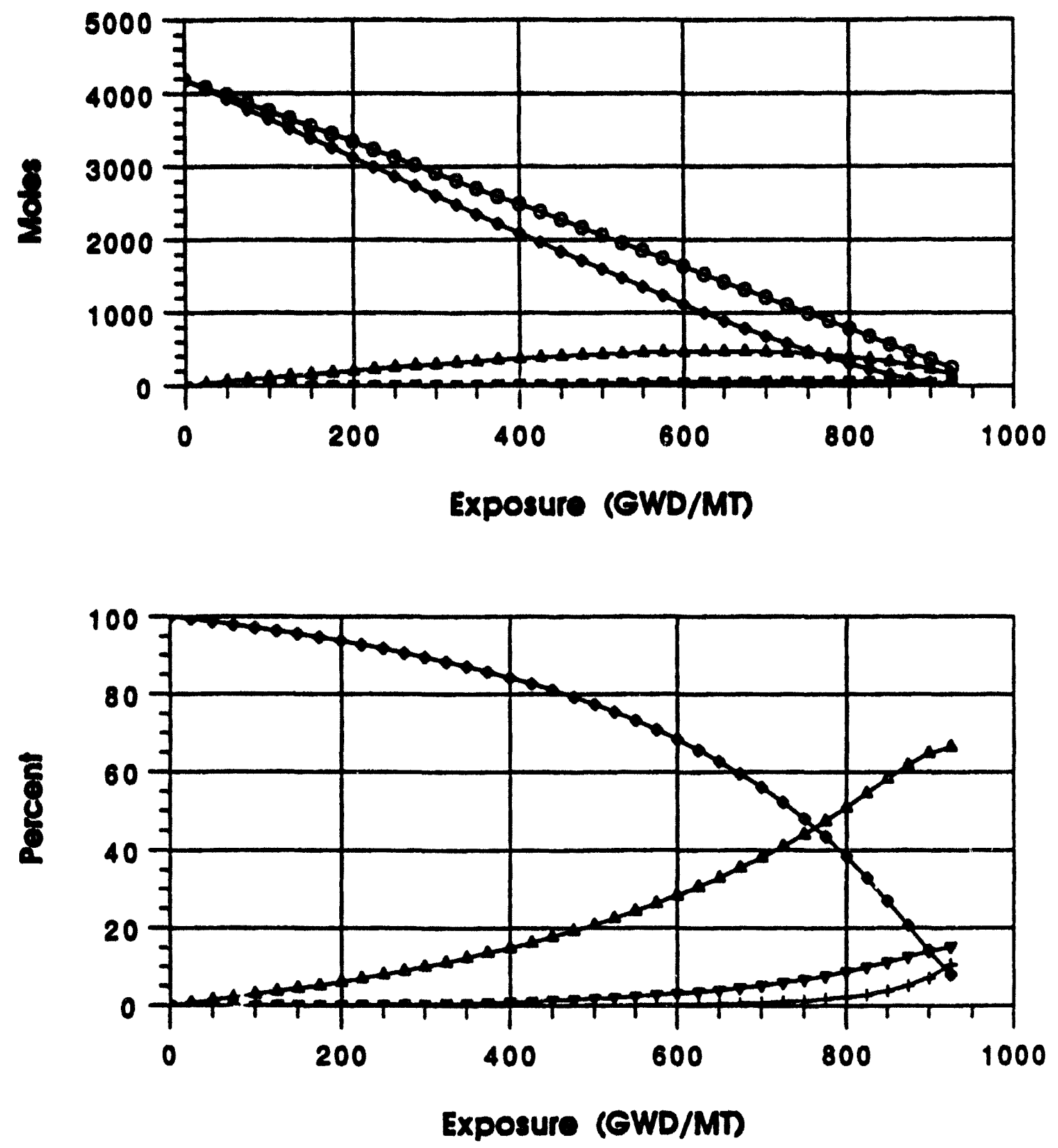

Figure A-7. Exposure dependent isotopic composition of plutonium irradiated in a liquid metal reactor spectrum. 
- All Pu $\rightarrow$ Pu-239 $\rightarrow P u-240 \rightarrow P U-241+P U-242$
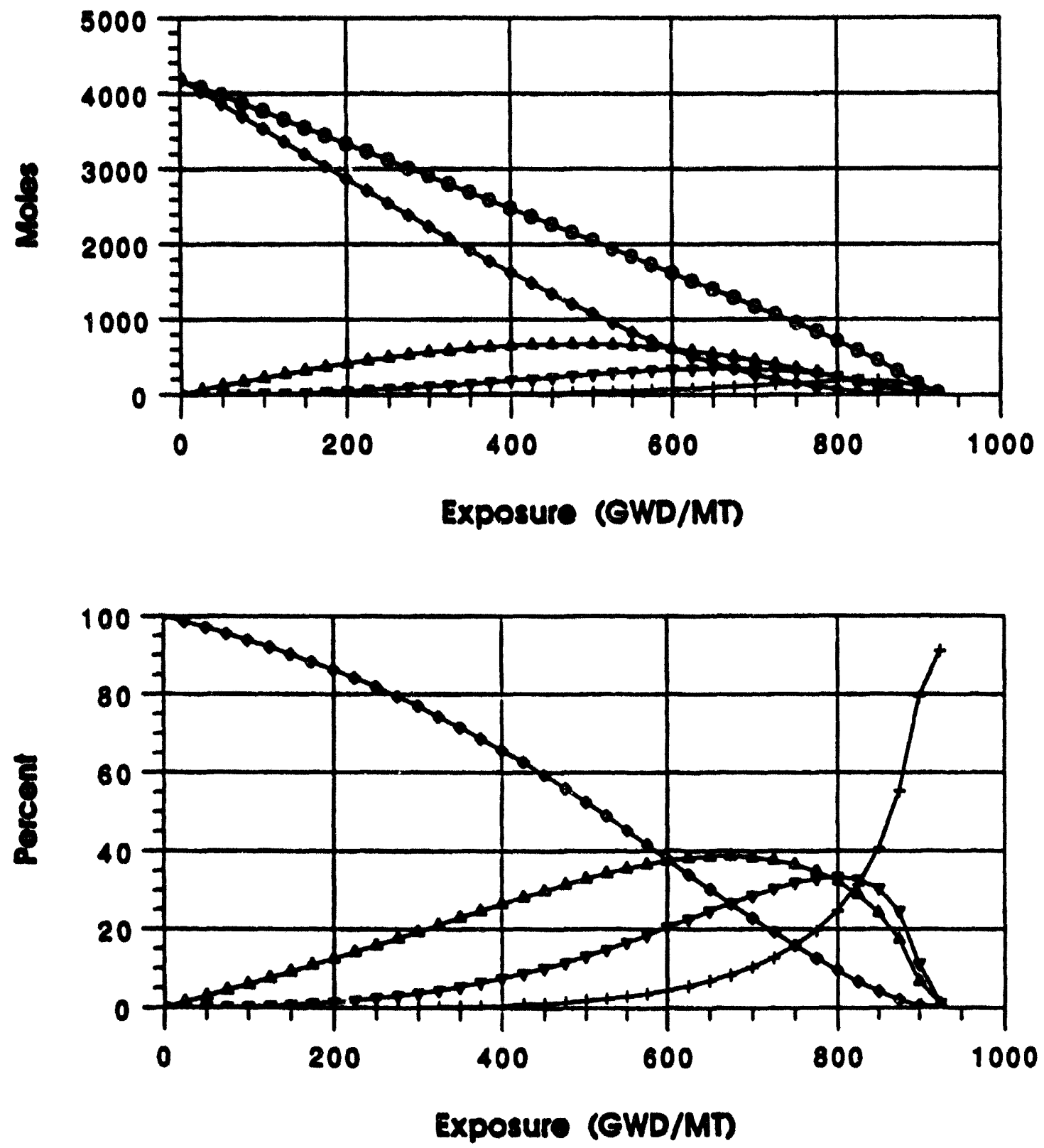

Figure A-8. Exposure dependent isotopic composition of plutonium irradiated in a PWR spectrum. 
- BWR $\rightarrow$ PWR $\rightarrow$ HTGR - CANDU - LMR

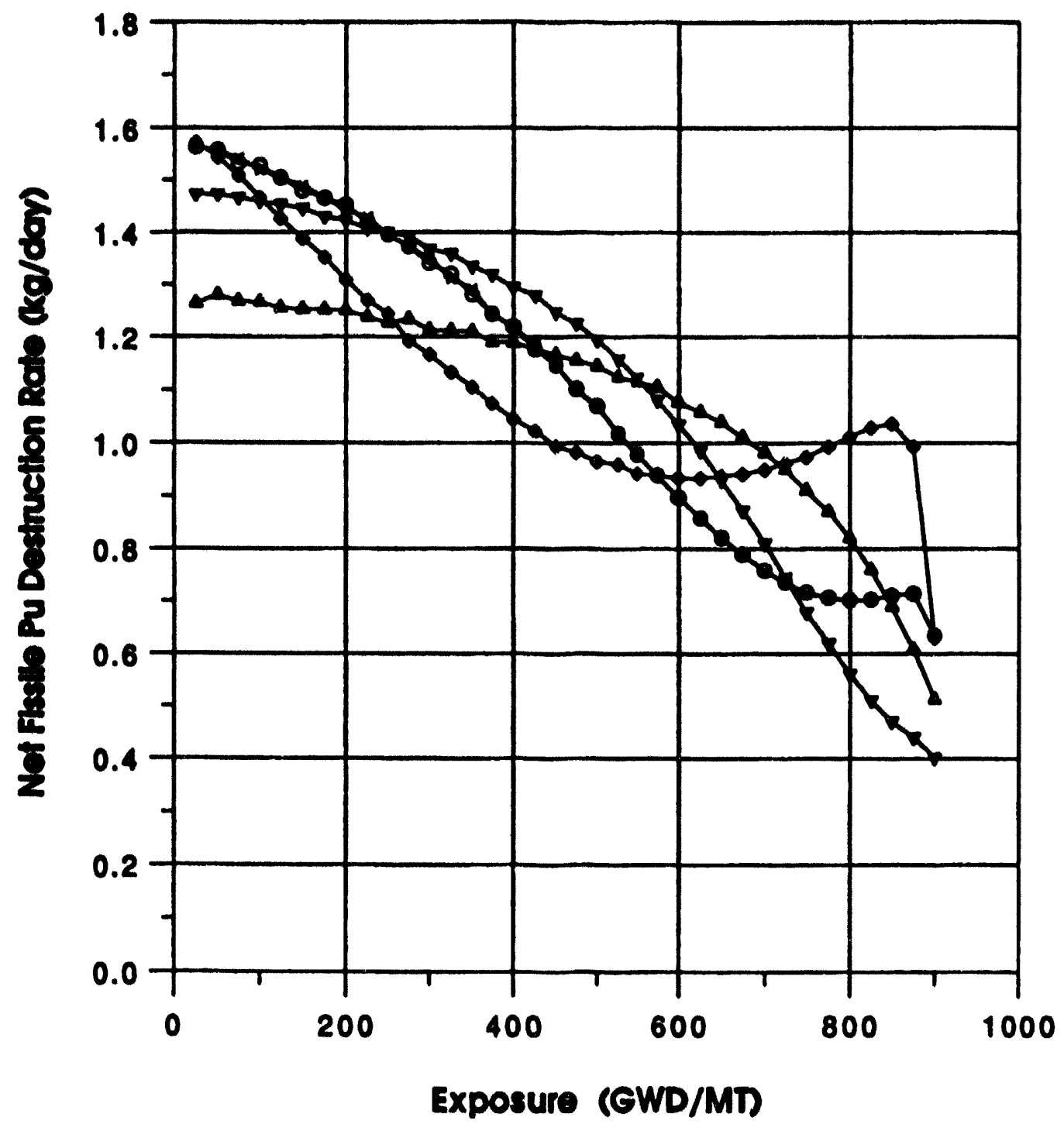

Figure A-9. Exposure dependent net fissile destruction rates for one metric ton of ${ }^{239} \mathrm{Pu}$ irradiated in selected reactor spectra. 
- BWR - PWR $\rightarrow$ HTGR $\rightarrow$ CANDU $\rightarrow$ LMR

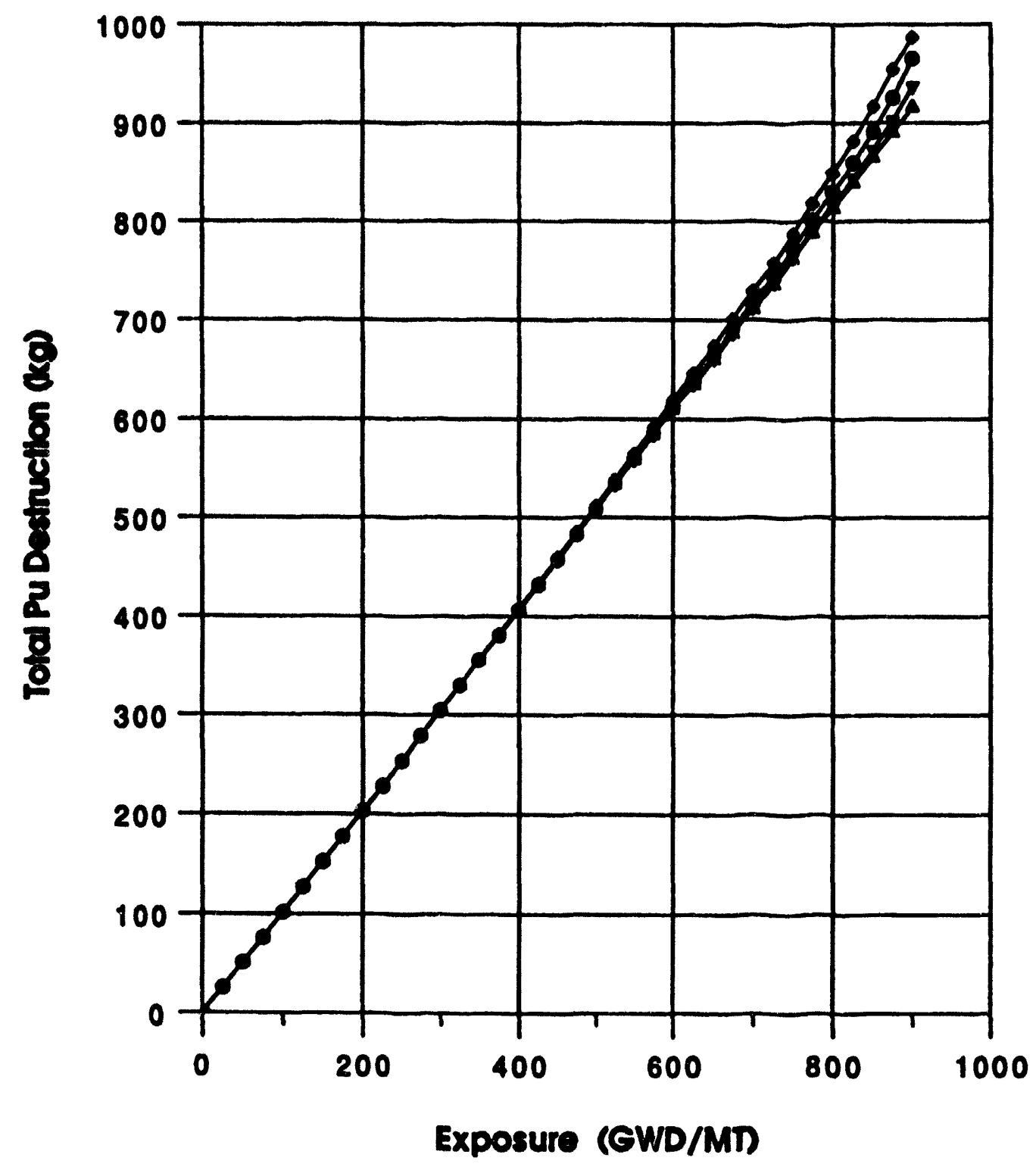

Figure A-10. Exposure dependent total plutonium destruction for one metric ton of ${ }^{239} \mathrm{Pu}$ irradiated in selected reactor spectra. 

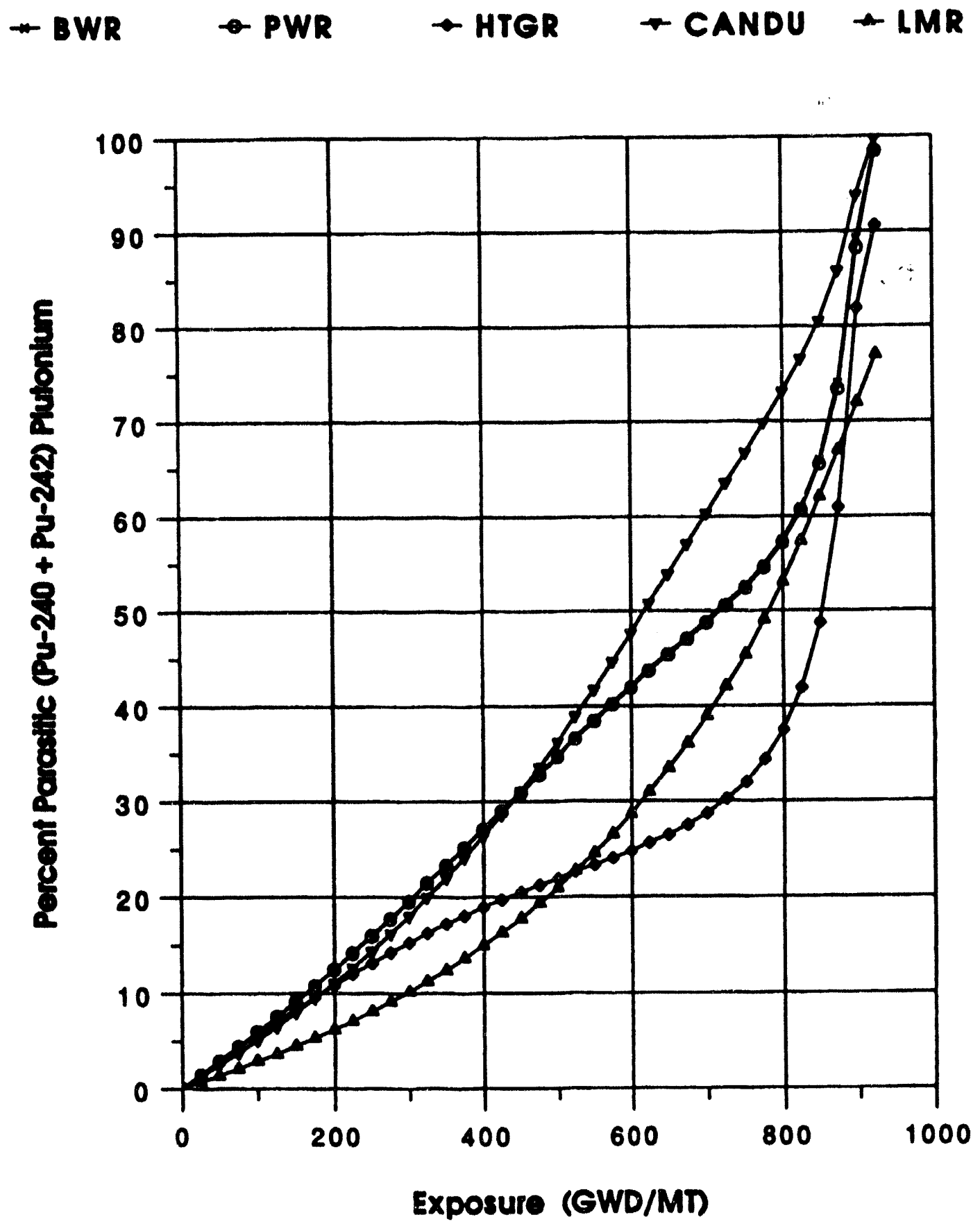

Figure A-11. Exposure dependent plutonium parasitic fraction for one metric ton of ${ }^{239} \mathrm{Pu}$ irradiated in selected reactor spectra. 


\section{A-4. CONCLUSIONS}

All five reactor types operating on nominal weapons-grade plutonium appear capable of achieving very high fuel exposures based solely on reactivity loss considerations. Plutonium irradiated i $r_{i}$ all five reactor spectra maintains a positive reactivity to exposures in excess of $700 \mathrm{GWD} / \mathrm{MT}$. A positive reactivity is maintained to about $800 \mathrm{GWD} / \mathrm{MT}$ in the LMR spectrum.

All five reactor types have comparable total plutonium destruction rates. If the goal is the total destruction of all plutonium isotopes, there is little to distinguish among the five reactor types considered in this assessment.

If the goal is achieving a specified absorber content, operation in a thermal spectrum offers significant advantages over operation in a fast spectrum. Notable exposure-dependent isotopic composition differences are observed between the thermal and fast spectrum cases. Operation in a thermal spectrum allows achieving a specified parasitic absorber content at much lower exposures.

Some care must be taken in interpretation of these results. The study methodology unavoidably incorporates the assumption that any plutonium-burning reactor operating in a given spectral regime will possess spectral characteristics identical to the commercial reactor type from which the cross-section sets were derived. The results of this study should not be construed as establishing plutonium isotopic compositions and destruction rates for any particular plutonium burner reactor design. Rather, the composition studies are useful in selecting a spectral regime in which to concentrate reactor design efforts. 


\section{A-5. REFERENCE}

1. A. G. Croff, ORIGEN2-A Revised and Updated Version of the Oak Ridge Isotope Generation and Depletion Code. ORNL-5621, Oak Ridge National Laboratory, Oak Ridge, TN, July 1980. 


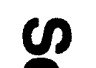

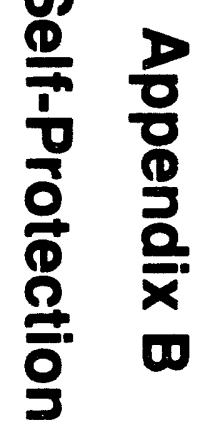




\section{Appendix B}

\section{Self-Protection}

Irradiated special nuclear materials can be potent sources of gamma radiation. The intense gamma environment can provide a certain degree of self-protection in the form of high biological dose rate levels. The dose rate needed to render a material self-protecting is somewhat arbitrary. Very intense sources producing very high radiation fields can be safely handled within a facility and transported offsite with adequate planning, handling equipment, and shielding. Such activities are routinely accomplished within both the letter of the regulatory law and the spirit of the as-low-as-reasonably-achievable (ALARA) philosophy.

The Code of Federal Regulations (10 CFR 73.6) establishes requirements for the physical protection of special nuclear materials of moderate and low strategic significance. Current practice allows only for some reduction in the level of physical security at some facilities if the special nuclear material provides a dose rate in excess of $100 \mathrm{rem} / \mathrm{hr}$ at a distance of $3 \mathrm{ft}(91.44 \mathrm{~cm})$ from any accessible surface without intervening shielding.

Guidelines for self-protection of any special nuclear material (including weapons-grade plutonium) must be established within the context of the strategic and perceived importance of the material, the physical form, the quantity of material, the susceptibility to diversion, the level of physical security provided, and possibly international agreements. For the purposes of this assessment, the biological dose rates from weapons-grade plutonium fuels were considered in relation to the $100 \mathrm{rem} / \mathrm{hr}$ at 3 - $\mathrm{ft}$ criterion and to the dose rate level provided by commercial spent fuels.

Fission product decay is the dominant source of photons in irradiated fuels. Fission product beta decay is also responsible for some photon production via bremsstrahlung in the fuel materials, but these contributions are concentrated at lower photon energies that are less effective for self-protection. Contributions from activated structural materials are usually relatively sinall.

Photon source strengths could be increased by seeding or spiking the special nuclear material. In this context, spiking is the addition of radioactive photon-emitting materials. Spiking is not considered in this assessment. Seeding is the addition of materials that will produce photon-emitting nuclides following irradiation and decay. Seeding offers the potential of enhancing the photon emission of the special nuclear material following irradiation. 


\section{B-1. ASSESSMENT METHODOLOGY}

Evaluation of biological dose rates from irradiated fuels is a three-step process requiring determination of the photon source strength, determination of the resulting energy flux at selected dose point locations, and conversion of the energy flux to biological dose rate. The methods employed to perform these assessments are summarized below.

The Oak Ridge National Laboratory ORIGEN2 isotopic generation and depletion code ${ }^{1}$ was employed to calculate isotopic compositions and resulting photon source strengths. Isotopic compositions are a function of initial composition, reactor type (neutron spectrum), total exposure, the manner in which the exposure is accumulated, and decay time. A pressurized water reactor (PWR) spectrum was assumed for all irradiations, and decay time is explicitly treated in the calculations. An initial composition and irradiation history typical of a current generation PWR was assumed for the PWR baseline calculations. For all plutonium irradiations the initial composition was assumed to be $100 \%$ ${ }^{239} \mathrm{Pu}$. A specific power of $1 \mathrm{MW} / \mathrm{kg}$ of initial fissile plutonium was assumed for the plutonium irradiations. Seeding was evaluated by including small quantities of potential seed materials in the fuel irradiations. The seed mass was assumed to be $0.1 \mathrm{wt} \%$ of the plutonium mass. All seed material cross sections are based on very dilute concentrations in the fuel. The effective cross section of the seed material will be lowered as the seed concentration is increased because of self-shielding. Irradiated seed photon strengths are more dependent on specific power than are the fission product source strengths. Effective production cross sections should be evaluated later for specific plutonium-burning reactor fuel geometries, operating power levels, and seed concentrations.

Photon transport from the irradiated fuel to the dose point was evaluated using previously calculated photon transport factors for a single TRIGA fuel pin. Reference 2 contains photon transport factors developed for 16 different research and test reactor fuel elements using the three-dimensional point-kernel shielding code QAD. ${ }^{3}$ In all cases the dose point was located at a distance of $3 \mathrm{ft}(91.44 \mathrm{~cm})$ from the element surface at the axial midplane of the element. The validity of the QAD uncollided flux solution was verified using RAFFLE $\mathrm{V},{ }^{4}$ a general purpose Monte Carlo transport code. The RAFFLE-calculated total photon fluxes (uncollided plus scattered) also provided a sound basis for the selection of iron dose buildup factors for the QAD calculation. The TRIGA pin photon transport factors should be considered representative. Photon transport should be evaluated later for specific plutonium burner reactor fuel geometries.

Photon flux-to-dose conversions factors were calculated using the analytic expression provided in ANSI/ANS-6.1.1.5 The energy group structure, photon transport factors, and flux-to-dose conversions are listed in Table B-1. 
Table B-1. Photon transport factors and flux-to-dose conversion factors.

\begin{tabular}{ccccc}
\hline $\begin{array}{c}\text { Energy } \\
\text { group }\end{array}$ & $\begin{array}{c}\text { Group } \\
\text { midpoint } \\
\text { energy } \\
(\mathrm{MeV})\end{array}$ & $\begin{array}{c}\text { Energy flux per } \\
\text { unit source } \\
\left(\frac{\mathrm{MeV} / \mathrm{cm}^{2} \mathrm{~s}}{\mathrm{MeV} / \mathrm{s}}\right)\end{array}$ & $\begin{array}{c}\text { Flux-to-dose } \\
\text { conversion } \\
\left(\frac{\mathrm{rem} / \mathrm{hour}}{\mathrm{MeV} / \mathrm{cm}^{2} \mathrm{~s}}\right)\end{array}$ & $\begin{array}{c}\text { Dose rate per } \\
\text { unit source } \\
\text { rem/hour }\end{array}$ \\
\hline 1 & 0.225 & $5.00 \times 10^{-6}$ & $2.51 \times 10^{-6}$ & $1.26 \times 10^{-11}$ \\
2 & 0.375 & $5.70 \times 10^{-6}$ & $2.49 \times 10^{-6}$ & $1.42 \times 10^{-11}$ \\
3 & 0.575 & $6.80 \times 10^{-6}$ & $2.29 \times 10^{-6}$ & $1.56 \times 10^{-11}$ \\
4 & 0.850 & $7.35 \times 10^{-6}$ & $2.07 \times 10^{-6}$ & $1.52 \times 10^{-11}$ \\
5 & 1.25 & $7.65 \times 10^{-6}$ & $1.86 \times 10^{-6}$ & $1.42 \times 10^{-11}$ \\
6 & 1.75 & $7.70 \times 10^{-6}$ & $1.67 \times 10^{-6}$ & $1.29 \times 10^{-11}$ \\
7 & 2.25 & $7.70 \times 10^{-6}$ & $1.54 \times 10^{-6}$ & $1.19 \times 10^{-11}$ \\
8 & 2.75 & $7.65 \times 10^{-6}$ & $1.44 \times 10^{-6}$ & $1.10 \times 10^{-11}$ \\
9 & 3.50 & $7.55 \times 10^{-6}$ & $1.32 \times 10^{-6}$ & $9.97 \times 10^{-12}$ \\
10 & 5.00 & $7.40 \times 10^{-6}$ & $1.16 \times 10^{-6}$ & $8.58 \times 10^{-12}$ \\
11 & 7.00 & $7.20 \times 10^{-6}$ & $1.04 \times 10^{-6}$ & $7.49 \times 10^{-12}$ \\
12 & 11.0 & $7.00 \times 10^{-6}$ & $9.33 \times 10^{-7}$ & $6.53 \times 10^{-12}$ \\
\hline
\end{tabular}




\section{B-2. RESULTS}

\section{Commercial Spent Fuels}

Time-dependent biological dose rates were evaluated for a representative commercial spent fuel form to provide a basis for comparison. A $3.2 \mathrm{wt} \%{ }^{23.5} \mathrm{U}$ fuel was assumed to operate at a specific power of 37.5 megawatts per metric ton of initial heavy metal (MW/MTHM) for a total of 880 days, providing a total exposure of 33 gigawatt-days per metric ton of initial heavy metal (GWD/MTHM). This corresponds to an exposure of 1,031 GWD/MTIF. Dose rates were evaluated for a single fuel rod at the $3-\mathrm{ft}$ dose point. Dose rates were evaluated for a fuel exposure of $3.2 \mathrm{GWD} / \mathrm{MTHM}$ or $100 \mathrm{GWD} / \mathrm{MTIF}$. This exposure represents approximately $10 \%$ of design exposure for the fuel. The relative timedependent dose rate contributions from fission products, heavy metals, and structural material activation products are shown in Figure $B-1$. The dose rate is dominated by contributions from the fission products at all decay times of interest. The heavy metals contribute less than $10 \%$ of the total dose rate over the first three days and then drop rapidly to the millirem-per-hour level at about 45 days. Contributions from activated structural materials (zircaloy and 304 stainless steel for these cases) are approximately two orders of magnitude lower than the fission products.

The total dose rates for three different fuel exposures are shown in Figure B-2. At short decay times, the dose rates are dominated by short-lived fission products and are comparable because they are primarily a function of the specific power at which the exposure was accumulated. At longer decay times, the dose rates are dominated by long-lived fission products and scale approximately with the total accumulated exposure.

The dose rates shown in both Figures B-1 and B-2 are for a single pin. Dose rates from even a near full exposure single pin decay to less than $100 \mathrm{rem} / \mathrm{hr}$ at the 3 -ft dose point after only about three years. If the pins are left in a complete assembly, the 100-rem/hr level is reached at considerably longer decay times. Photon transport from a complete bundle has not yet been examined, but a 264-pin bundle is expected to yield 50 to 100 times the dose rate of a single pin. For the complete bundle, the 100-rem/hr level would not be reached for approximately 100 years.

\section{Potential Seed Materials}

Potential seed materials were first screened by examining the ORIGEN2 library of known radionuclides. Nuclides with a half-life of less than one year were rejected because of relatively rapid loss of self-protection by decay. Nuclides with a halflife of greater than 1,000 years were rejected because of relatively low specific activity. The remaining nuclides are shown in Table B-2 along with values of half-life.

Most of the nuclides shown in Table B-2 must be rejected as potential seed materials because of some combination of little or no photon yield, poor production by neutron irradiation, and poor chemical form such as a noble gas. The list was narrowed to the four potential seed materials shown in Table B-3, along with selected characteristics of interest for fuel self-protection.

\section{Commercial Fuels Seeded with Co-59}

Time-dependent dose rates were evaluated for the representative $3.2 \mathrm{wt} \%{ }^{23.5} \mathrm{U}$ fuel case with cobalt as a seed. Dose rates were evaluated at $10 \%$ of design exposure (3.2 GWD/MTHM). Natural cobalt $\left(100 \%{ }^{59} \mathrm{Co}\right)$ was included in the fuel at $0.1 \mathrm{wt} \%\left(1 \mathrm{~kg}{ }^{59} \mathrm{Co}\right.$ per metric ton of initial heavy metal). The relative time-dependent dose rate contributions following shutdown are shown in Figure B-3. For the 0.1 wt $\%$ case, the ${ }^{6()} \mathrm{Co}$ dose contribution is only slightly larger than that of the fission products at decay times between 2 and 10 years. For the 1 wt $\%$ case, the ${ }^{60}$ Co dose contribution exceeds that of the fission products for decay times between about 0.5 and 30 years. 


\section{$3200 \mathrm{MWD} / \mathrm{MT}$ Initial Uranium \\ 100 GWD/MT Initial Fissile \\ Three-Foot Dose Point}
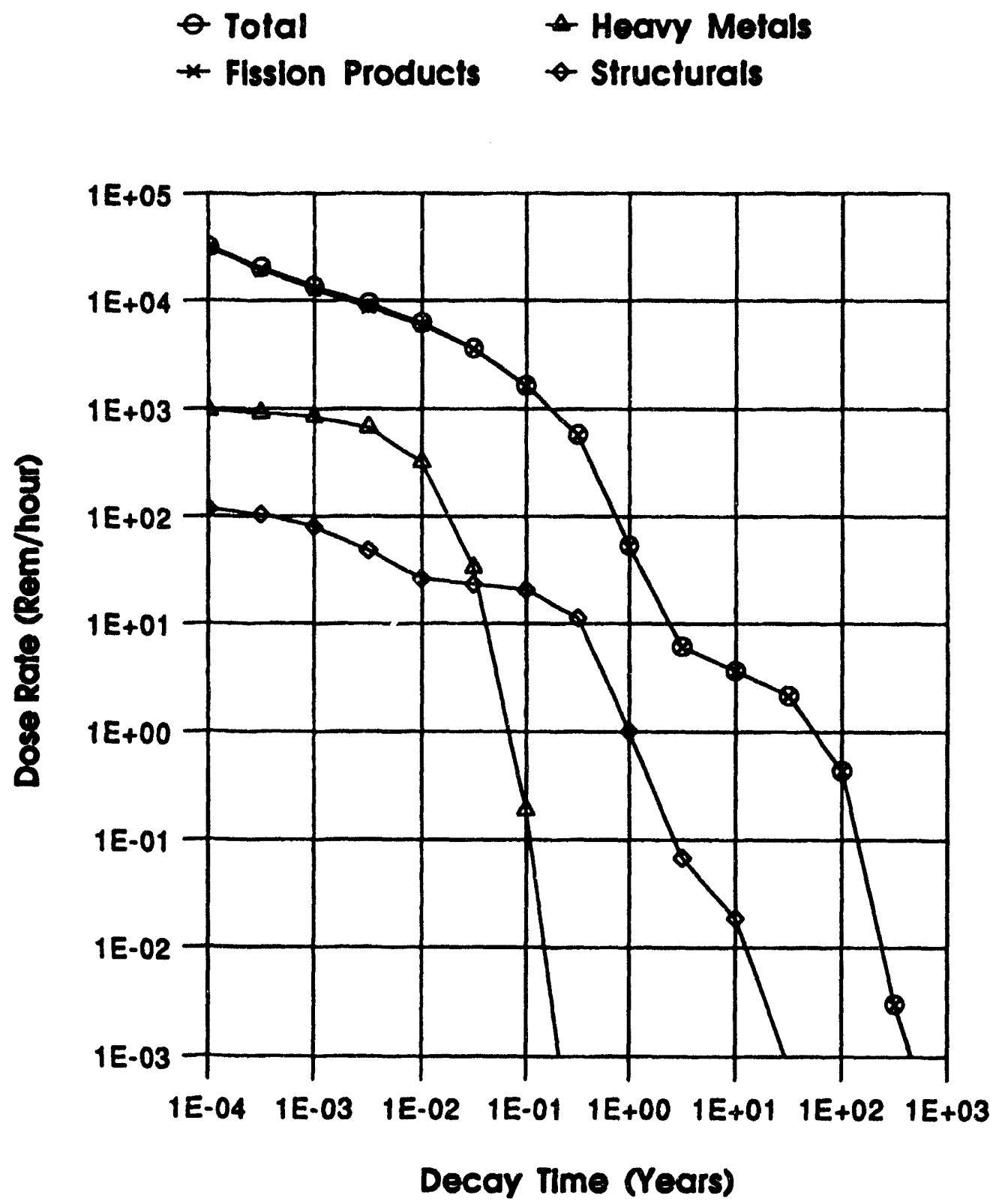

Figure B-1. Relative biological dose rate contributions at $3 \mathrm{ft}$ from a PWR pin irradiated to approximately $10 \%$ of design exposure. 
Design Exposure $=33 \mathrm{GWD} / \mathrm{MT}$ Initial Uranium Design Exposure $=1000 \mathrm{GWD} / \mathrm{MT}$ Initial Flssile Three-Foot Dose Point
- 950 GWD/MT Initial Fissile (95\% Design Exposure)
- 100 GWD/MT Intilal Fisslie (10\% Desion Exposure)
- 10 CWD/MT Initial Fisslle (1\% Desion Exposure)

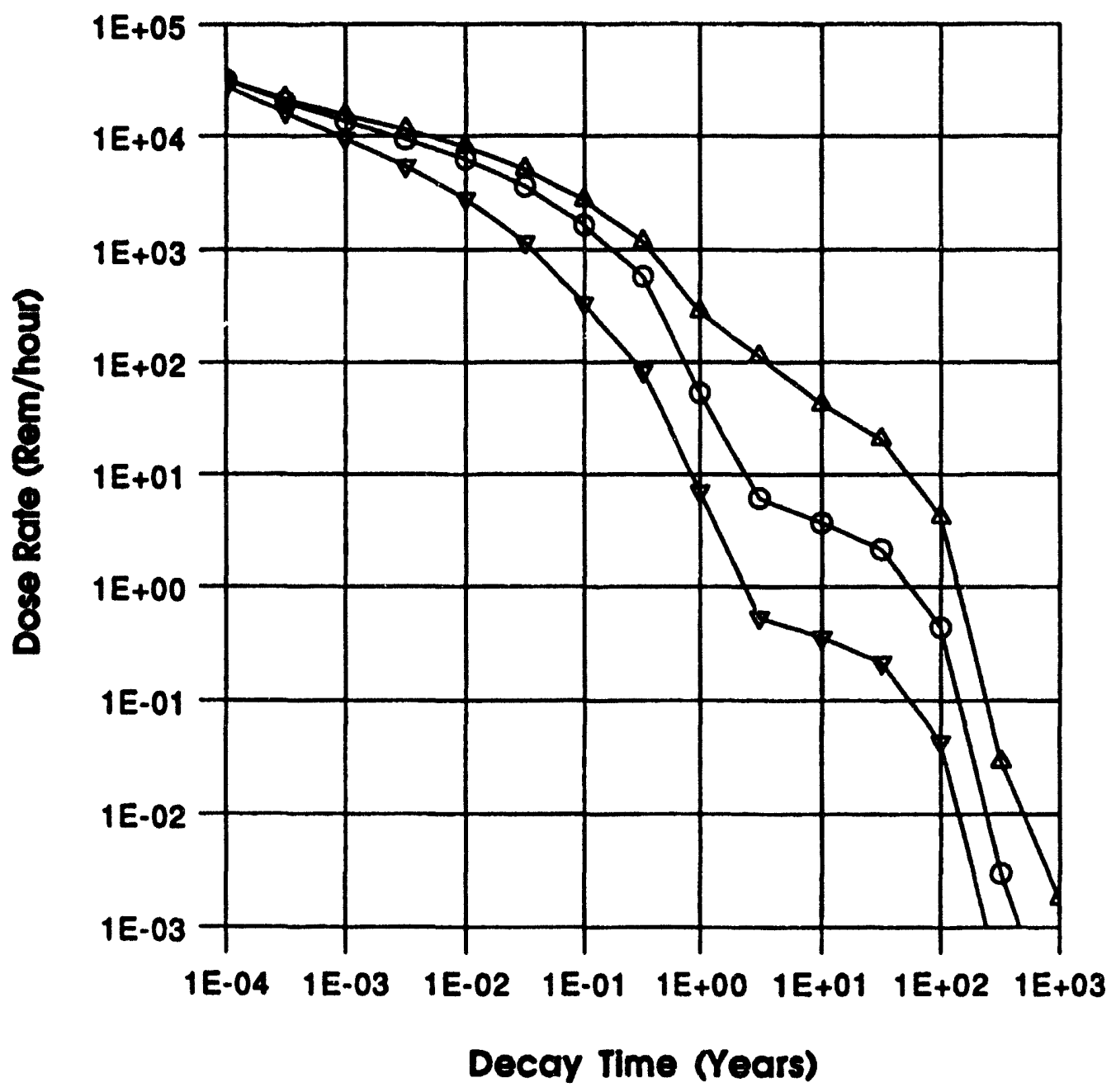

Figure B-2. Relative biological dose rate contributions at $3 \mathrm{ft}$ from a PWR pin for selected fuel exposure levels. 
Table B-2. Potential self-protection radionuclides with half-lives between 1 and $1,(0)(0)$ years.

\begin{tabular}{|c|c|c|}
\hline Nuclide & Half-life (yr) & Comments \\
\hline $\mathrm{Si-32}$ & $\approx 650$ & Reject-beta only \\
\hline Pt-193 & $\approx 500$ & Reject-beta only and poor production path \\
\hline $\operatorname{Ar}-39$ & 269 & Reject-noble gas and beta only \\
\hline Ir- $192 \mathrm{~m}$ & 241 & Possible-photon yield from Ir-192 \\
\hline Tb-157 & 150 & Reject-no production path \\
\hline $\mathrm{Ag}-108 \mathrm{~m}$ & 127 & Possible-photon yield from $\mathrm{Ag}-108 \mathrm{~m}+$ weak $\mathrm{Ag}-108$ \\
\hline $\mathrm{Ni}-63$ & 93.0 & Reject-beta only \\
\hline Sm-151 & 90.0 & Reject-low photon yield \\
\hline $\mathrm{Sn}-121 \mathrm{~m}$ & 50.0 & Reject-low photon yield \\
\hline Ar- 42 & 33.0 & Reject-noble gas \\
\hline Ho- 163 & 33.0 & Reject-beta only and no production path \\
\hline Cs-137 & 30.0 & Spike only-no production path except fission yield \\
\hline Sr-90 & 29.1 & Spike only-no production path except fission yield \\
\hline$P m-145$ & 17.7 & Reject-no production path \\
\hline Eu-152 & 13.6 & Good photon yield \\
\hline $\mathrm{Nb}-93 \mathrm{~m}$ & 13.6 & Reject-no production path \\
\hline H-3 & 12.4 & Reject-gas and beta only \\
\hline Ba-133 & 10.7 & Reject-no production path \\
\hline $\mathrm{Kr}-85$ & 10.7 & Reject-noble gas \\
\hline Eu-154 & 8.6 & Good photon yield \\
\hline Os-194 & 6.00 & Reject-poor production path and low photon yield \\
\hline Co-60 & 5.27 & Good photon yield \\
\hline Eu-155 & 4.96 & Incidental via Eu-153 (n, $\gamma$ ) Eu-154 low photon yield \\
\hline T1-204 & 3.8 & Reject-no photon yield \\
\hline Sb-125 & 2.77 & Fair photon yield but poor production path from $\mathrm{Sn}-124$ \\
\hline$P m-147$ & 2.62 & Reject-poor photon yield \\
\hline $\mathrm{Na}-22$ & 2.60 & Reject-no production path \\
\hline $\mathrm{Fe}-55$ & 2.60 & Reject—no photon yield \\
\hline Cs-134 & 2.06 & Good photon yield \\
\hline Tm-171 & 1.92 & Reject_poor photon yield \\
\hline Cd-109 & 1.27 & Reject-good photon yield and no production path \\
\hline $\mathrm{Ru}-106$ & 1.01 & Spike only-no production path except fission yield \\
\hline
\end{tabular}




\section{GWD/MT Inlital Fiselle \\ Three-Foot Dose Point \\ Cobali Soed}
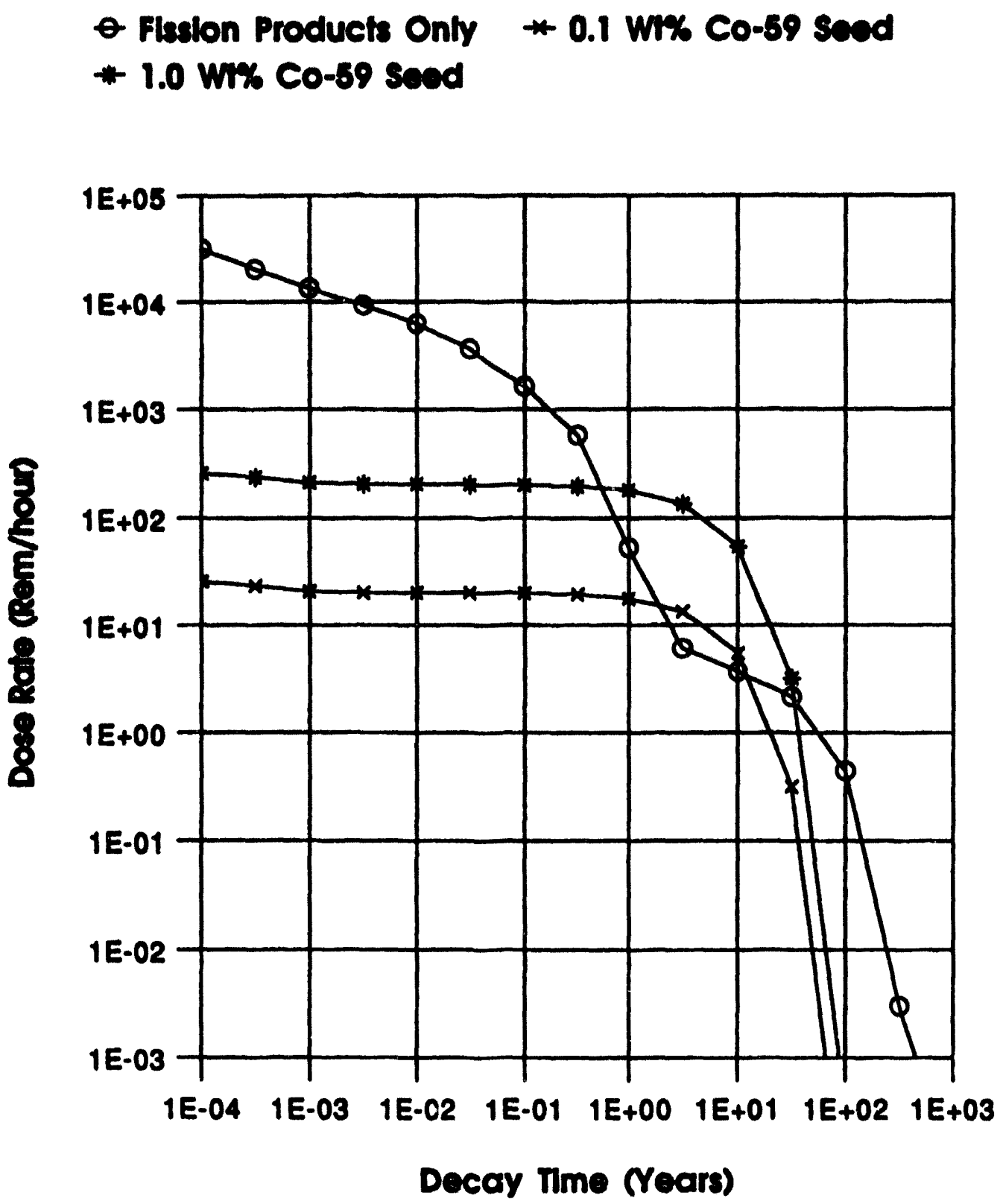

Figure B-3. Relative biological dose rate contributions at $3 \mathrm{ft}$ from a PWR pin at $10 \%$ design exposure with cobalt self-protection seed. 
Table B-3. Potential self-protection seed materials.

\begin{tabular}{|c|c|c|c|c|c|c|}
\hline Nuclide & $\begin{array}{c}\text { Half-life } \\
\quad(y r)\end{array}$ & $\begin{array}{l}\text { Method of } \\
\text { production }\end{array}$ & $\begin{array}{c}\text { LWR } \\
\text { spectrum } \\
\text { pioduction } \\
\text { cross } \\
\text { section } \\
\text { (barns) }\end{array}$ & $\begin{array}{l}\text { LWR } \\
\text { spectrum } \\
\text { removal } \\
\text { cross } \\
\text { section } \\
\text { (barns) }\end{array}$ & $\begin{array}{c}\text { Approximate } \\
\text { cost } \\
(\$ / \mathrm{kg})\end{array}$ & $\begin{array}{l}\text { Photon yield } \\
\text { (Mev/decay) }\end{array}$ \\
\hline Eu-152 & 13.6 & $\mathrm{Eu}-151(\mathrm{n}, \gamma)$ & 740 & 191 & 50,000 & 1.146 \\
\hline Eu- 154 & 8.6 & $\mathrm{Eu}-153(n, \gamma)$ & 71.8 & 129 & $50,0 \times 0$ & 1.228 \\
\hline $\mathrm{Co}-60$ & 5.27 & $\operatorname{Co-59}(n, \gamma)$ & 4.83 & 0.268 & $?$ & 2.500 \\
\hline Eu-155 & 4.96 & Eu-154 (n, $\gamma)$ & 129 & 366 & 50,000 & 0.061 \\
\hline Sb-125 & 2.77 & $S n-124(n, \gamma)+\beta$ & 0.402 & 0.762 & 13 & 0.431 \\
\hline Cs-134 & 2.06 & $\operatorname{Cs}-133(n, \gamma)$ & 11.8 & 22.9 & 25,000 & 1.553 \\
\hline
\end{tabular}

Slightly higher seed concentrations would probably be required to obtain the indicated dose levels because of self-shielding in the heavier cobalt loadings.

\section{Seeded Plutonium Fuels}

Time-dependent dose rates were evaluated for plutonium-based fuels using ${ }^{59} \mathrm{Co},{ }^{133} \mathrm{Cs}$, natural tin, or natural europium as seed materials. Seed concentrations of $0.1 \mathrm{wt} \%$ were assumed for all cases. All fuels were assumed to be irradiated at a specific power of $1 \mathrm{MW} / \mathrm{kg}$ of initial fissile material. Dose rates were examined as a function of decay time for fuel exposures of 10,100, and 950 GWD/MTIF. These exposures correspond to approximately $1 \%, 10 \%$, and $95 \%$ initial plutonium burnup, respectively.

Time-dependent relative biological dose rates for the fission products and the four possible seed materials are shown in Figure B-4 for the 10\% burnup case. Natural tin can be rejected because of the very low dose rate contribution. The combination of relative volatility and a two-year halflife limits the attractiveness of cesium. Europium and cobalt are the most attractive of the four seed materials, but they only add less than $10 \%$ to the dose rate relative to the unseeded fuel.
Seed materials could either be alloyed with the plutonium fuel or used in the clad or other structural material. Cobalt is attractive because cobaltbearing steels could be substituted for the more traditional stainless steel clad materials.

Europium seeding provides somewhat higher dose rates for the cases examined. Europium is attractive because it is also one of the candidate materials for providing a prompt negative temperature coefficient for the plutonium fuels. The primary disadvantage of europium is the higher (but probably acceptable) cost. At a $0.3 \mathrm{wt} \%$ loading, the europium cost for $50 \mathrm{MT}$ of weapons-grade plutonium would be less than $\$ 8$ million.

The seed performance is generally poorer for the plutonium fuels examined than for the ${ }^{235} \mathrm{U}$ low enrichment commercial fuel examined. This is due primarily to lower fluxes for any given power level in the plutonium-based fuels. Seed activation rates are a strong function of flux level, and flux levels are generally lower for the plutonium fuels. Low power density plutoniumburning reactor designs will further aggravate this problem. Flux levels at any particular power level are also dependent on the fissile concentration in the fuel. Plutonium-burning reactor designs using 


\section{Relative Blological Dose Rates From A Single PIn Plutonlum to 100 GWD/MT Initial Fisslle (10\% Burnup) Selected Seli-Profection Seed Materials Three-Foof Dose Point}

- Fisalon Products

* Natural Europlum

- Ceslum-133
* Cobali-59

* Natural Tin

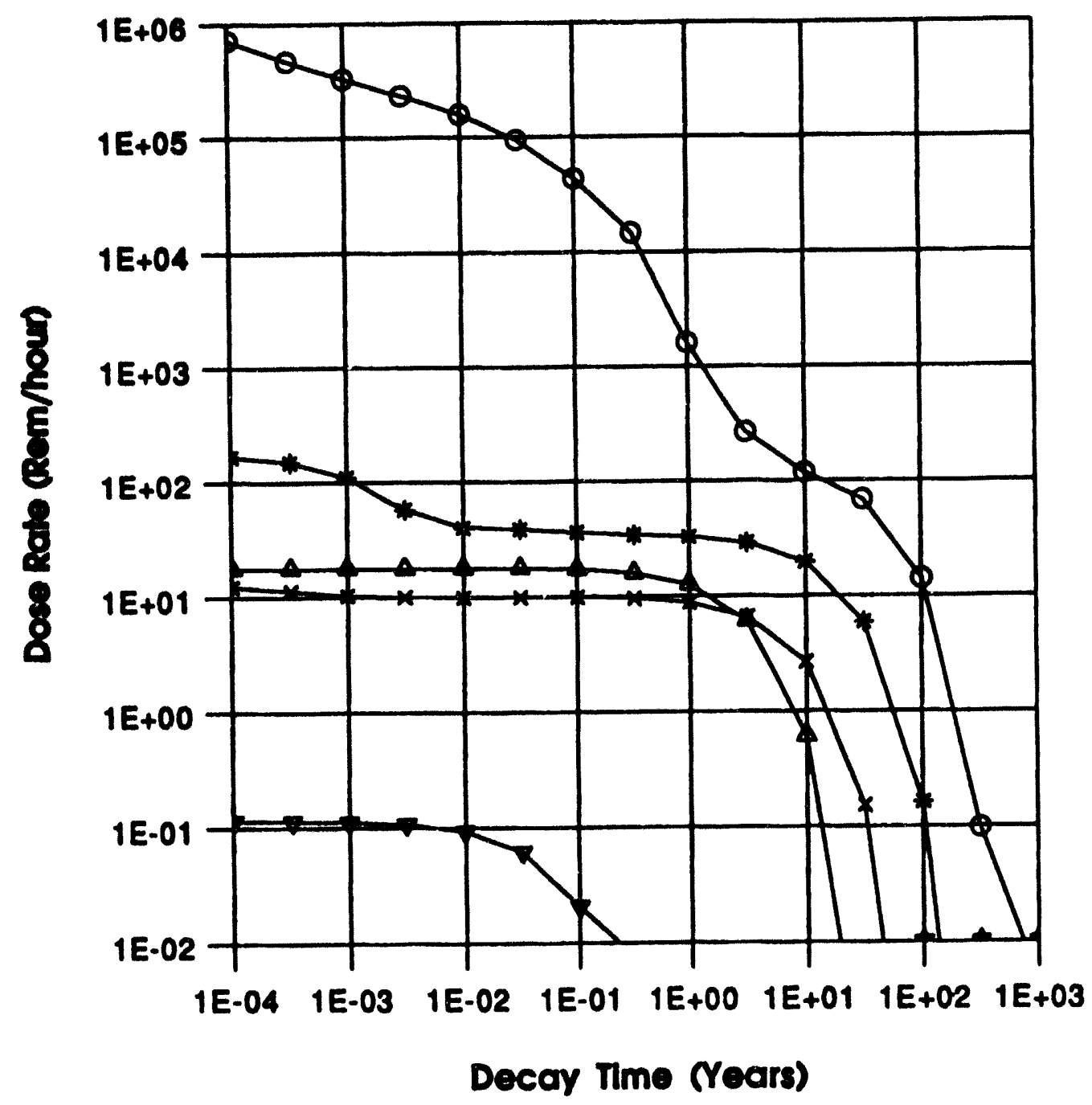

Figure B-4. Relative biological dose rates for a plutonium fuel pin irradiated to $10 \%$ burnup with selected self-protection seed materials. 
low plutonium content fuels will exhibit higher flux levels. Specific designs must be analyzed to determine which of the competing effects will dominate.

Effectiveness of the europium seed at different levels of plutonium burnup is illustrated in Figure B-5. The dose rate contributions from fission products and from the europium seed materials are shown at exposure levels corresponding to plutonium burnup values of $1 \%, 10 \%$, and $95 \%$. At decay times of longer than one year, the fission product dose levels scale approximately with plutonium burnup. The rather complex europium dose rate behavior is due to the mixture of europium isotopes and the relatively high europium radiative capture cross sections. The europium seed material is severely depleted in the high $(95 \%)$ burnup case. The europium dose rate contributions are al" ays less than the corresponding fission product dose rate contributions for the seed concentration, specific power, and plutonium burnup combinations examined. Europium dose rates can be increased by raising the seed concentration in the fuels, but additional analyses are required. The europium seed performs hest for low plutonium exposures accumulated at high specific power levels. 


\section{Relative Blological Dose Rates From A Single Pin Plutonium Fission Products and Europium Seed \\ At $1 \%, 10 \%$, and $95 \%$ Plutonium Bumup Three-Foot Dose Point}
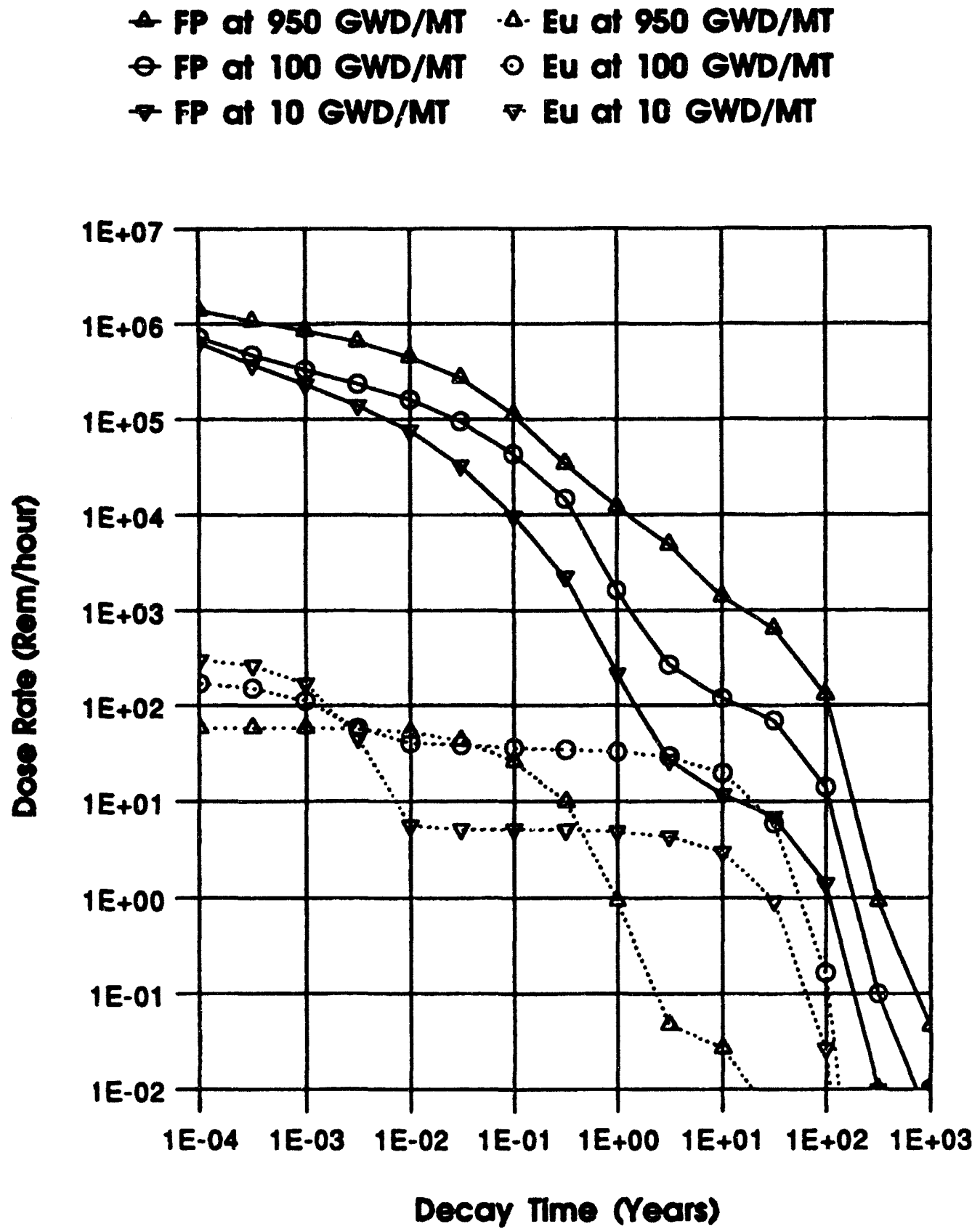

Figure B-5. Relative biological dose rates at $3 \mathrm{ft}$ from a europium-seeded plutonium pin at selected plutonium burnup levels. 


\section{B-3. CONCLUSIONS}

Fission products in high-exposure fuel provide a high level of self-protection. The most attractive self-protection seed candidates are europium and cobalt. Cobalt could be incorporated into the plutonium fuel itself or employed by using a cladding material with high cobalt content. Europium is especially attractive because it may be needed for reactor control purposes. The degree to which any seed material can enhance fuel self-protection will depend primarily on the specific power level of the plutonium burner reactor. The most signifi- cant self-protection enhancements will occur for low plutonium exposures accumulated at high power density. Seeding will need to be evaluated for specific plutonium burner designs. The benefit from using seed materials is limited, especially considering added costs for testing and fabrication of these fuel types. For the proposed lowpower density concept, generation of fission products provides the best option for self-protection, and seeding is not needed. 


\section{B-4. REFERENCES}

1. A. G. Croff, ORIGEN2-A Revised and Updated Version of the Oak Ridge Isotope Generation and Depletion Code, ORNL-5621, Oak Ridge National Laboratory, July 1980.

2. B. G. Schnitzler, A Calculational Method for Determining Biological Dose Rates from Irradiated Research Reactor Fuel, NUREG-CR-4203, April 1985.

3. R. E. Malanfant, QAD: A Series of Point-Kernel General-Purpose Shielding Programs, LA-3572, Los Alamos National Laboratory, April 1967.

4. F. J. Wheeler, The RAFFLE V General Purpose Monte Carlo Code for Neutron and Gamma Transport, EGG-PHYS-6003, EG\&G Idaho, Inc., Idaho National Engineering Laboratory, August 1982.

5. ANSI/ANS 5.1.1, "Neutron and Gamma-Ray Flux-to-Dose Rate Factors," American Nationai Standards Institute/American Nuclear Society, 1977. 
Appendix C Fuel Types

C-1 


\section{Appendix C}

\section{Fuel Types}

The plutonium-based fuel form to be used in plutonium-burning reactors is closely coupled to a particular reactor design, but there are several general criteria that apply to all circumstances. Fuel forms chosen for use in any type of plutonium burner should (a) possess a high burnup capability, (b) provide a high degree of operational safety, (c) offer the cheapest and easiest fabrication methods with minimum hazardous waste, and (d) offer the cheapest and easiest endof-life disposal. Candidate fuel forms considered in this study for use in a plutonium burner do not include uranium or thorium as a constituent.

The amount of plutonium that can be fissioned before the fuel has to be removed from the reactor for either loss of reactivity, fuel element swelling, or irradiation damage that threatens reactor safety must be considered. Weapons-grade plutonium generates approximately one noble gas atom for every four fissions. At very high burnups, this will cause the fuel to swell to volumes that are unaccéptable for most traditional fuel forms.

The fabrication methods must be as inexpensive as possible, but a cheap fabrication method that generates large quantities of hazardous waste may not be inexpensive overall. The spent fuel must be disposable with inexpensive methods and facilities that are in place now or will be available when the reactor starts to burn up the plutonium.

Very little practical reactor experience exists with fuel forms that contain plutonium as the only fissile element. Some fuel testing will be required to verify the fabrication, performance, and safety of any fuel form selected. A pilot fuel fabrication and test program will have to be initiated at the earliest possible date to prevent undue delay in starting the burning of plutonium.
The fabrication of plutonium-bearing fuels from weapons components, plutonium scrap, and other sources of weapons-grade plutonium will be a major hurdle in providing fuel elements for any reactor design. Fuel form choices (and reactor design choices) should be made based on the existence or ease of modification of existing fabrication facilities capable of producing and handling plutonium fuel. These facilities will have to be both safe and environmentally acceptable. All fabrication and interim storage facilities should reside on a highly secure DOE reservation. Security from theft and diversion is essential and will be a major component and operating cost of any fabrication facility. Because of cost and schedule considerations, it will be very difficult to build a new fabrication facility to produce fuel for a plutonium-burner. A plutonium production facility sufficiently large and secure could easily cost $\$ 1$ billion and take at least eight years to design, finance, build, and make operational.

The operational costs of a plutonium-fuel fabrication facility are expected to be two to three times those currently encountered for the uranium-based fuel fabrication facilities, because of such considerations as personnel safety, physical security, and environmental restraints. Plutonium-fuel fabrication times are also expected to be increased by factors of 2 or 3 when compared to uranium-fuel fabrication times for similar reasons.

This brief study addresses only the very basic issues related to plutonium-burner fuel, and the list of viable candidates is not inclusive. However, the processes and criteria defined in this report for selecting plutonium fuel forms can be applied to the consideration of any candidate. More discussion on fuels and materials is contained in Volume 4 of this report. 


\section{C-1. PLUTONIUM-BURNER CANDIDATE FUELS}

The following discussion of plutonium-burner fuel candidates is divided according to whether the fuel form has been fabricated and tested, and other fuel forms that do not have extensive testing but may be attractive for an advanced reactor design.

\section{Fuels with Operating Experience}

There appears to be only two plutonium-only fuel forms that have been tested for any length of time in a nuclear reactor: $\mathrm{PuAl}_{4}$ dispersed in aluminum, and $\mathrm{PuO}_{2}$ embedded in carbon and sealed in a silicon carbide shell (TRISO-coated $\mathrm{PuO}_{2}$ ). Data relevant to these two fuel forms are summarized in Table C-1.

\section{Plutonium Fuel Experiences}

A literature review has identified reports from the Phoenix Fuel Program ${ }^{1-4}$ and the Plutonium Recycle Program ${ }^{5,6}$ conducted by the Pacific Northwest Laboratory (PNL) in the early 1970s.

The Phoenix program experiments were conducted in the Materials Test Reactor (MTR) at the INEL, the Plutonium Recycle Critical Facility at PNL, and the Physical Constants Testing Reactor at PNL.

The Plutonium Recycle Program concentrated mainly on mixed oxide fuels (uranium and plutonium); however, some efforts were devoted to the fabrication and testing of zircaloy-cladded, plutonium-aluminum fuels in the Plutonium Recycle Test Reactor and the Experimental Boiling Water Reactor at the INEL.

The Phoenix core in the light water MTR was composed of fuel plate bundles containing a $\mathrm{Pu}-\mathrm{Al}$ alloy fuel (aluminum clad) and was designed specifically for small, high power reactors. The MTR Phoenix core operated successfully with a peak steady state power level of
$24 \mathrm{MW}(\mathrm{t})$. The plutonium reactor-grade fuel was isotopically $67 \%{ }^{239} \mathrm{Pu}, 23 \%{ }^{240} \mathrm{Pu}, 6 \%{ }^{241} \mathrm{Pu}$, and $4 \%$ other plutonium isotopes (that is, not weapons-grade plutonium). The primary goal of the Phoenix program was to demonstrate extended core life reactivity by conversion of the initial high ${ }^{240} \mathrm{Pu}$ loading into fissile ${ }^{241} \mathrm{Pu}$.

\section{Pu-Al Composite Fuels}

$\mathrm{Pu}-\mathrm{Al}$ fuel forms fabricated to date have been composite plates to operate in low-temperature, water-cooled, thermal reactors such as the MTR or one of the Savannah River Site (SRS) production reactors. This fuel type has the limitations associated with all aluminide fuels, such as low melting temperatures and relatively low heat inputs required for melting, which are governed by the relatively low melting temperature of aluminum (933 K).

Because of the low temperature operation limit of this fuel form, compatible cladding materials are not necessarily limited to aluminum. As indicated in Table C-1, stainless steels or zircaloy could be used for cladding, especially because high heat rejection rates are not required.

A considerable amount of operating experience with $\mathrm{U}-\mathrm{Al}$ fuels in aluminum and aluminum alloy cladding exists. This should be at least partially applicable to the $\mathrm{Pu}$-Al fuels. The maximum burnup level expected with $\mathrm{Pu}-\mathrm{Al}$ fuels without a recycle step is based on the performance of $\mathrm{U}-\mathrm{Al}$ fuel plates irradiated in the Advanced Test Reactor. ${ }^{7}$ This burnup level (70\% FIMA) is based on fuel element swelling and fission product release limitations in a thin plate geometry under conditions of high fission rates. More robust geometries might be fissioned to safe burnup levels in excess of $90 \%$. Burnable poisons have been added to U-Al fuel plates with little difficulty, so burnable poisons could probably be added to a $\mathrm{Pu}$-Al fuel form. 
Table C-1. Candidate plutonium-burner fuels with operating experience.

\begin{tabular}{|c|c|c|}
\hline Fuel material & $\mathrm{Pu}-\mathrm{Al}$ & $\mathrm{PuO}_{2} / \mathrm{C}$ \\
\hline Form & $\mathrm{PuAl}_{4}$ dispersed in aluminum & TRISO-coated particles \\
\hline \multicolumn{3}{|l|}{ Practical maximum } \\
\hline $\mathrm{Pu}$ density (atoms $/ \mathrm{m}^{3}$ ) & $5 \times 10^{27}$ & $5 \times 10^{26}$ in compacts \\
\hline $\begin{array}{l}\text { Cladding(s): demonstrated } \\
\text { Possible or compatible }\end{array}$ & $\begin{array}{l}\text { Aluminum, aluminum alloys } \\
\text { Stainless steel, zircaloy }\end{array}$ & $\begin{array}{l}\text { Graphite/SiC } \\
\text { Stainless steel, aluminum }\end{array}$ \\
\hline Compatible coolant(s) & Water & $\begin{array}{l}\text { Helium, water (in metal } \\
\text { clad) }\end{array}$ \\
\hline $\begin{array}{l}\text { Practical maximum safe } \\
\text { operating temperature }\end{array}$ & $850 \mathrm{~K}$ & $1600 \mathrm{~K}$ \\
\hline $\begin{array}{l}\text { Maximum burnup } \\
\text { (\% of initial FIMA) }\end{array}$ & 70 & 75 \\
\hline $\begin{array}{l}\text { Element reactor } \\
\text { operating experience }\end{array}$ & MTR, SRS & Dragon, Peach Bottom \\
\hline $\begin{array}{l}\text { Fabrication: demonstrated } \\
\text { process(es) }\end{array}$ & $\begin{array}{l}\text { Rolled aluminum plates with cast } \\
\text { or powder fueled cores }\end{array}$ & $\begin{array}{l}\text { Fuel particles consolidated } \\
\text { into graphite compacts }\end{array}$ \\
\hline $\begin{array}{l}\text { Current capabilities on } \\
\text { DOE reservations }\end{array}$ & $\begin{array}{l}\text { SRS-powder metallurgy } \\
\text { processing and extrusion } \\
\text { LANL_plutonium alloy casting }\end{array}$ & None \\
\hline
\end{tabular}

a. For reasons other than loss of reactivity, such as fuel swelling, cladding irradiation damage, or cladding corrosion.

The traditional fabrication methods for the aluminide fuels are fairly simple. The fuel fabrication waste volumes can be made quite small. Several variations of fabrication of the aluminide fuel form having fuel meat encased in pure aluminum or aluminum alloys have been successfully applied to produce $\mathrm{Pu}-\mathrm{Al}$ composite fuel elements. Plutonium fabrication facilities currently exist at Los Alamos National Laboratory (LANL) and SRS that could be used to produce $\mathrm{Pu}-\mathrm{Al}$ composite fuel elements, using weapons-grade plutonium, in sufficient quantities to verify fuel designs and prove performance of such modifications as burnable neutron poisons. The feasibility of using these facilities for fabricating $\mathrm{Pu}-\mathrm{Al}$ fuel in large quantities is not established at this point, but they should be considered in any planning exercise.

\section{$\mathrm{PuO}_{2} / \mathrm{C}$ TRISO}

This fuel form has been successfully operated in reactors to very high burnups. The plutonium density limit, which is about an order of magnitude below that of the $\mathrm{Pu}-\mathrm{Al}$ system, is driven by the fact that a quantity of carbon is needed inside a TRISO particle to chemically stabilize the $\mathrm{PuO}_{2}$, in addition to all the other materials needed to make the fission product container parts of the particle and the compact graphite.

This fuel form would require a considerable development effort both in fabrication and optimization of performance. The addition of burnable poisons would probably be made directly to the $\mathrm{PuO}_{2}$, but studies would have to be performed to optimize the performance and reliability of this modified fuel form. 
This fuel form could be further contained in cladding materials such as stainless steel or aluminum for low temperature operation in a watercooled reactor. A water corrosion resistant cladding is necessary because the compact graphite is quite porous and cannot be expected to keep water from directly contacting and corroding the fuel particle surfaces.

The fabrication of $\mathrm{PuO}_{2}$ /TRISO fuel particles and their incorporation into graphite compacts is a complex process that requires a considerable effort to develop for the production of high quality fuel particles. No facilities currently exist for the fabrication of $\mathrm{PuO}_{2}$ /TRISO fuel particles and compacts, and several years would probably be required to develop capabilities for producing even small quantities for test purposes.

\section{Advanced Fuel Concepts}

A few advanced solid fuel concepts were considered in this study to indicate some of the improvements that might obtained in reactor design or operation. There are no operating data for these fuel forms, so only the perceived advantages of each fuel form considered are briefly presented. The feasibility of the fabrication of these advanced fuel forms was assumed mostly on the basis of the known feasibility of the fabrication of similar systems. Liquid fuel forms, such as molten salts, were also considered, but the containment of these highly corrosive materials was considered to be a major unsolved problem that would significantly delay their use in plutonium burning.

A list of advanced fuel forms studied is presented below; the neutronic acceptability of these various fuel forms has not been studied in detail:

- $\mathrm{PuO}_{2}$ with burnable poisons such as $\mathrm{Eu}_{2} \mathrm{O}_{3}$

- $\mathrm{PuO}_{2}-77$ wt\% $\mathrm{ZrO}_{2}-9$ wt\% $\mathrm{CaO}$

- $\quad 5 \mathrm{v} / \mathrm{o} \mathrm{PuO}_{2} / \mathrm{SS}$ cermet

- $\quad \mathrm{Pu}-\mathrm{Ni}$ composite

- $\quad \mathrm{Pu}-\mathrm{Fe}$ composite

- $\mathrm{Pu}-28 \mathrm{wt} \% \mathrm{Zr}$.
$\mathrm{PuO}_{2}$ can be mixed with the oxides of most burnable poison rare earth elements such as europium, erbium, or gadolinium. $\mathrm{PuO}_{2}$ can also be mixed with oxides such as $\mathrm{ZrO}_{2}$ and $\mathrm{Al}_{2} \mathrm{O}_{3}$ for purposes of dilution. These fuel forms could be clad in stainless steel for low temperature operation. These fuel forms should perform similar to the $\mathrm{UO}_{2}$-based fuels and would require minimal development. This has been assumed by Westinghouse (SRS) in a proposal to use $\mathrm{PuO}_{2}-77 \mathrm{wt} \%$ $\mathrm{ZrO}_{2}-9 \mathrm{wt} \% \mathrm{CaO}$ in a plutonium-disposing power reactor, even though the INEL is not aware of any reactor experience with this fuel form.

The 5 vol\% $\mathrm{PuO}_{2} / \mathrm{SS}$ cermet was considered because of the good in-pile performance demonstrated by $\mathrm{UO}_{2} / \mathrm{SS}$ cermets. These cermets can be loaded with fissile materials to densities only slightly below the aluminide fuel forms, and they have good thermal conductivity. $\mathrm{PuO}_{2}$ cermets have been successfully fabricated with other matrix materials, such as molybdenum.

The $\mathrm{Pu}-\mathrm{Fe}$ and $\mathrm{Pu}-\mathrm{Ni}$ composites are expected to be like the $\mathrm{Pu}-\mathrm{Al}$ composites, but more robust and capable of withstanding higher temperatures. Both iron and nickel form intermetallic compounds with plutonium, which should allow for the production of a composite structure as in the $\mathrm{Pu}-\mathrm{Al}$ fuel forms. Some neutronic advantages might be gained with the use of either nickel or iron from their resonance absorption properties.

The $\mathrm{Pu}-28 \mathrm{wt} \% \mathrm{Zr}$ alloy is being proposed for the advanced liquid metal reactor plutoniumburning power reactor. It appears attractive for fast reactor concepts, but considerably more dilution of the plutonium would be required in a thermal reactor. The melting temperature of this alloy system is roughly proportional to the atomic percentage of zirconium, which melts at $2130 \mathrm{~K}$ (plutonium melts at $915 \mathrm{~K}$ ). Fabrication could be achieved by melting and casting the alloy.

The $\mathrm{ZrH}_{1.6}-10 \mathrm{wt} \%$ plutonium fuel form was considered in this study, but neutronic calculations indicate that it would have a positive fuel temperature coefficient of reactivity. Consequently, the addition of burnable poisons must be explored if this fuel form is considered. 


\section{C-2. PLUTONIUM FUEL EVALUATION METHODOLOGY}

The plutonium fuel evaluation methodology is a multistep evaluation process designed to test and accept or reject a fuel composition based on its performance characteristics relative to a typical LWR fuel and core environment. The first step in the process is to establish mass loadings or volume fractions for a fixed reactivity level ( $k$-infinity). The second step is to evaluate the fuel against the following performance characteristics:

- Prompt fuel Doppler temperature coefficient

- Moderator temperature coefficient

- $\quad$ Plutonium burnup time (constant power)

- Fission power density

- Isotope reaction rates/depletion
- Lattice effects

- Materials characteristics.

A fuel composition can be eliminated or modified if any of the performance characteristics are deficient. For example, the plutonium mass loading should meet a minimum quantity per rod to burn for the desired cycle length at a specified average pin power. In addition, the net temperature coefficient must be negative and burnable poisons should burn at rates comparable to the plutonium.

The third step will evaluate fuel compositions with favorable characteristics for fabricability and availability and identify potential developmental risks.

Most of the work performed to date in this area is discussed in Volume 4 of this report. 


\section{C-3. REFERENCES}

1. R. I. Smith, The MTR-Phoenix Fuel Experiment: Burnup Analyses and Correlations, BNWL-1756. Battelle Northwest Laboratory, June 1973.

2. E. C. Davis, Critical Experiments in an MTR Mockup Using Phoenix Fuel, BNWL-11481, Battelle Northwest Laboratory, June 1970.

3. C. M. Heeb, Analysis of the Phoenix Fuel Experiments, BNWL-1514, Battelle Northwest Laboratory, October 1970.

4. J. W. Kutcher, The MTR-Phoenix Fuel Experiment: Critical Test and Burnup Results, BNWL-1593, Battelle Northwest Laboratory, June 1971.

5. C. H. Been, R. E. Sharp, and W. J. Baily, The EBWR Plutonium Recycle Demonstration Experiment, BNWL-SA-1199, Battelle Northwest Laboratory, April 1967.

6. M. D. Freshly and S. Goldsmith, Operating Experience with Plutonium Fuels in PRTR, BNWLSA-1204, Battelle Northwest Laboratory, August 1967.

7. L. G. Miller and J. M. Beeston, Extended Life Aluminide Fuel, Final Report, EGG-2441, EG\&G Idaho, Inc., Idaho National Engineering Laboratory, June 1986. 
Appendix D

Neutronics

D-1 


\section{Appendix D}

\section{Neutronics}

A companion team at the INEL is evaluating the feasibility of using plutonium fuels for disposal in existing commercial LWRs. Most of the results obtained by that team can be applied directly to the LWR concept. The companion team's findings are presented in Volume 4 of this report. Its pertinent findings are summarized in this appendix.

Eliminating ${ }^{238} \mathrm{U}$ from the reactor prevents the production of more ${ }^{239} \mathrm{Pu}$ and accelerates plutonium destruction. A major disadvantage of removing ${ }^{238} \mathrm{U}$ is the reduction or elimination of a prompt negative Doppler reactivity coefficient. As the plutonium fuel temperature rises, the plutonium fission resonances broaden, increasing the core reactivity. Without adequate control, this can lead to even higher fuel temperatures and cause a reactor accident. In addition, the delayed neutron fraction for ${ }^{239} \mathrm{Pu}(0.0022)$ is much smaller than that of ${ }^{238} \mathrm{U}(0.0069)$. This also makes a pure plutonium reactor more difficult to control. Removal of ${ }^{238} \mathrm{U}$ eliminates the primary reactivity holddown mechanism in LWRs.

Volume 4 of this report concludes that a pure plutonium fuel type is not desirable in LWRs because of the low mass loading per fuel rod (yielding short fuel cycles), relatively small prompt Doppler temperature coefficients, and strong positive isothermal temperature coefficients. Any workable fuel composition must have a negative prompt temperature coefficient (reactor power decreases as temperature increases) for safety and control purposes.

The isothermal temperature coefficient is a measure of the combined thermal reactivity feedback response to heating both the light water moderator and fuel uniformly. The isothermal temperature coefficient includes feedback mechanisms from (a) Doppler broadened resonances (prompt), (b) moderator thermal spectral shift to higher energies with increasing moderator temperature, (c) reduction in water moderator density with increasing temperature, and (d) dimension changes. The companion study indicates that plutonium cores in LWRs can have negative isothermal temperature coefficients if enough erbium or europium is added. Therefore, the concept will contain at least one of the burnable poisons. Additional calculations will be performed to determine the right amount of poison.

The addition of burnable poison is also needed to hold down the core reactivity at beginning of life and, thus, allow more plutonium in the fresh fuel. Other poisons such as boron or gadolinium could also be used in the fuel or cladding or as separate rods. Because the poisons and the plutonium are consumed over the cycle, it is not clear how the temperature coefficients change with exposure. This still needs to be examined.

Commercial LWRs typically depend on a combination of the fertile materials and burnable poisons to achieve the required safety characteristics, provide adequate holddown reactivity, and obtain desired cycle lengths. The proposed use of europium or erbium plus other poisons in plutoniumfueled devices should mimic the desired attributes of commercial reactors.

An alternative approach is the use of materials that exhibit thermal and resonance capture behavior similar to ${ }^{238} \mathrm{U}$. The added neo-fertile material would make the mixed plutonium fuels perform like the uranium fuels in LWRs but without the liability of additional fissile material production. Based on a preliminary survey, natural tungsten appears to have the desired characteristics.

Typical plutonium fuel loadings could range from around 50 grams for an 8-mm-diameter rod (nominal PWR size) to around $200 \mathrm{~g}$ for a larger 16-mm-diameter rod. On the order of $5 \mathrm{MT}$ of plutonium would be included in the initial core load. Lower plutonium loadings could allow 
higher burnup, but would shorten the cycle. Low plutonium densities produce less fission product accumulation and less subsequent deterioration of the fuel pin. Low plutonium densities also reduce the self-shielding effect, increasing burnup at a given fluence. Higher plutonium densities increase the cycle length and capacity factor, reduce the volume of waste, reduce fuel fabrication costs, and increase the concentration of the radioactive hazard in order to prevent diversion, but increase reactivity control requirements. An acceptable plutonium loading still needs to be determined based on these tradeoffs.

Fuel assembly dimensions and fuel management procedures would be similar to those of a commercial LWR. Calculations still need to be performed to ensure that assemblies with plutonium are undermoderated at typical rod diameters and pitches so that a negative moderator temperature coefficient exists. Cycles could last one to two years, then one-third or one-fourth of the core could be replaced with fresh fuel. Thus, the typical fuel assembly would remain in the core for several years until a high exposure level is achieved. Commercial LWR fuel management strategies could be used to maintain relatively flat power distributions. Shorter cycles with batch refueling provide higher fuel exposure because fresh fuel maintains the core reactivity longer while older fuel continues to burn. On the other hand, without batch refueling one core loading could burn over a long cycle to minimize the potential for material diversion. Better burnup criteria are needed before this tradeoff can be optimized. 


\section{D-1. CHOOSING THE BASIC LATTICE}

Because fertile material is not used in the concept, the LWR-type fuel design may require modification. The plutonium must be diluted to reduce excess reactivity. The diluting materials should be compatible with the plutonium. These materials should have some other technical advantages such as low cost, good thermal conductivity, thermal expansion, absorption resonances of suitable width and energy, and material strength. Aluminum, zirconium, iron, and nickel are primary diluent candidates. Ceramics, such as $\mathrm{PuO}_{2}$ and $\mathrm{ZrO}_{2}$, are also possible candidates and are addressed by others in the companion team from the INEL in Volume 4 of this report. Metals have high thermal conductivity and in general low thermal expansion properties. Many of these metals are among the resonance absorption candidates for a thermal spectrum (e.g., tungsten, molybdenum, dysprosium, europium, erbium, iridium, and antimony). The base metal has to have a lower melting temperature than the other components in the alloy, so that these would not precipitate out or melt off in various operating scenarios. For these reasons, and several others, $\mathrm{Pu}-\mathrm{Al}$ was chosen as a first candidate. $\mathrm{Pu}-\mathrm{Zr}$, $\mathrm{Pu}-\mathrm{Fe}, \mathrm{Pu}-\mathrm{Al}-\mathrm{W}$, and TRISO particles will be looked at as alternates. At this stage, $\mathrm{Pu}-\mathrm{Al}$ is taken as the base fuel. The preliminary neutronic analyses are made with $1,2,3$ and 4 vol\% ${ }^{239} \mathrm{Pu}$ in aluminum. These correspond to 8.21, 15.30, 21.49 , and $26.94 \mathrm{wt} \%{ }^{239} \mathrm{Pu}$, respectively.

The choice of cladding requires consideration of thermal and hydraulic requirements, material compatibility, and fission gas buildup. Aluminum, stainless steel, zircaloy, and molybdenum are possible candidates. The stainless steel and molybdenum alloys are acceptable based on their material strength and ability to withstand longterm irradiation as compared to the traditional zircaloys. For optimal heat removal, the design should minimize fuel-to-clad gaps at normal operating conditions. This can be achieved by selecting a cladding that has a thermal expansion coefficient less than or equal to than that of the fuel. Four candidates have thermal expansion coefficients less than or equal to that of the fuel. Table D-1 summarizes the expansion coefficient and other cladding properties. All four candidates can withstand temperatures equal to or higher than the allowed fuel centerline temperature.

For some preliminary calculations, the fuel pellet diameter and active core height are taken as $8 \mathrm{~mm}$ and $3.66 \mathrm{~m}$ (12 ft), respectively. Design considerations can change both of these dimensions when needed. Some of the considerations for the fuel shape are that it can be easily manufactured, as in an extrusion process, and that it has a reasonable diameter with uniform fuel density. The fuel height and diameter should be made such that the rod is structurally rugged and able to withstand flow induced vibrations. Finally, thermal considerations require that the fuel thickness be compatible with the power density and the available heat removal rate to avoid excessive fuel centerline temperatures.

A cladding thickness of $2 \mathrm{~mm}$ was assumed, mainly for safety consideration for high burnup fuel. These considerations include fission product release and high neutron and photon fluences. The thickness and material selections are open to change based on any of the above considerations, including cost.

Furthermore, there may be an overriding consideration because of the effect of relative material expansion on the instantaneous reactivity feedback effect, as explained below.

The next choice is for the type of coolant. As stated earlier, either spectrum will achieve the same burnup rate (see Appendix A). For the present, light water is chosen because of cost and cumulative experience considerations. 
Table D-1. Basic characteristics of fuel cladding options.

\begin{tabular}{lccccc}
\hline \multicolumn{1}{c}{ Clad } & $\begin{array}{c}\text { Fuel expansion } \\
\text { coefficient }\left(\mathbf{K}^{-1}\right)\end{array}$ & $\begin{array}{c}\text { Resonances/ } \\
\text { neutron } \\
\text { absorption }\end{array}$ & Strength & Experience & $\begin{array}{c}\text { Manufacturability/ } \\
\text { cost }\end{array}$ \\
\hline Aluminum & $26 \times 10^{-6}$ & Few/low & Moderate & High & Very easy/low \\
Stainless steel & $6 \times 10^{-6}$ & Many/high & High & High & Easy/low \\
Molybdenum & $5 \times 10^{-6}$ & Many/high & Very high & Low/none & Moderate/high \\
Zirconium & $5 \times 10^{-6}$ & Many/low & Moderate & High & Easy/moderate \\
\hline
\end{tabular}




\section{D-2. DETERMINING THE LATTICE PARAMETERS}

The first design task is to determine the allowable pin pitch for the chosen fuel and cladding specifications. The lattice must have a negative moderator temperature coefficient (MTC) and not be overmoderated. For this reason, several pin unit cell cases for a square lattice have been analyzed using the Monte Carlo code MCNP. ${ }^{1}$ The results given in Figures D-1 to D-3 are for Pu-Al pellets of $8-\mathrm{mm}$ diameter and clad with 2-mmthick aluminum, molybdenum, or stainless steel.

In Figure D-1, the curves 1, 2, and 6 show that an undermoderated region cannot be achieved in square lattices of this type when only fissile material is used $\left({ }^{239} \mathrm{Pu}\right.$ or $\left.{ }^{235} \mathrm{U}\right)$. At a pin pitch of $12 \mathrm{~mm}$, the fuel pins are touching. The atom ratio of ${ }^{235} \mathrm{U}$ to aluminum, or ${ }^{239} \mathrm{Pu}$ to aluminum in this lattice, is the same as that in a typical platetype test reactor fuel. When the 4.5 at $\%$ of ${ }^{240} \mathrm{Pu}$ (weapons-grade plutonium) is reintroduced, the undermoderated region reappears, Curve 3. Curves 4,5 , and 7 through 10 yield the additional effect of the introduction of small amounts of resonance absorbers. The resonance absorbers are intended to be integral with the fuel, and having resonance energies and widths that yield an acceptable Doppler coefficient.

Two candidate resonance absorbers were explored, natural europium and natural tungsten. Both are capable of producing the desired negative moderator temperature coefficient region. On a per atom basis, europium depresses the multiplication factor by over 100 times more strongly than tungsten. Several factors must be considered in the evaluation of these two representative absorbers. These include the self-protection potential of europium, the actual Doppler effect realizable, europium depletion rates, and cost.

Figure D-2 shows the effect of a good resonance absorber (molybdenum) in the cladding. However, this good influence on the fuel-to-moderator ratio may not also yield an adequate Doppler response because the cladding is not integral with the fuel, and temperature rise in the fuel requires a finite time to reach the cladding. Figure D-3 explores various cases of fuel clad in a modest resonance absorber (stainless steel) containing small amounts of resonance absorbers.

Preliminary evaluations were carried out for Pu-Al fuels containing natural tungsten. A typical LWR uranium enrichment is about $3 \%$. The effective capture cross section for natural tungsten is about 6.67 times higher than that of ${ }^{238} \mathrm{U}$. Scaling the effective ${ }^{238} \mathrm{U}$ volume fraction of $97 \%$ by a factor of 6.67 yields a tungsten effective volume fraction of about $14.5 \%$. A tungsten volume fraction of $12 \%$ was also examined to provide information on the sensitivity to this parameter. With an assumed plutonium volume fraction of $3 \%$, the remaining aluminum volume fractions are $82.5 \%$ and $85 \%$. The plutoniumfueled configurations that were evaluated consisted of an 8.9-mm-diameter fuel pellet, a $0.127-\mathrm{mm}$ gap, and a $0.7112-\mathrm{mm}$ thick aluminum cladding. A $3 \%{ }^{235} \mathrm{U}$ metal rod of the same dimensions was also evaluated to serve as a reference case.

The calculated results of the relation of infinite multiplication factor to pin pitch are shown in Figure D-4. The infinite multiplication factor curve shape of $\mathrm{Pu}-\mathrm{Al}$ plus tungsten looks very similar to the reference uranium metal lattices. The infinite multiplication factor maximum occurs at a pin pitch of about $19 \mathrm{~mm}$. This result agrees quite well with results for a $3.06 \%$ enriched uranium lattice reported in Reference 2.

The steep curve decline on the undermoderated side in Figure D-4 will ensure a strong negative moderator temperature coefficient. For a given fuel rod and cladding configuration, to maximize the reactor safety and fuel performance, one would like to choose the pin pitch on the undermoderated side and near the peak of the infinite multiplication factor to ensure negative moderator void and temperature coefficients. A suitable pin pitch for the mixed $\mathrm{Pu}-\mathrm{Al}$ plus tungsten lattices is $15 \mathrm{~mm}$. 


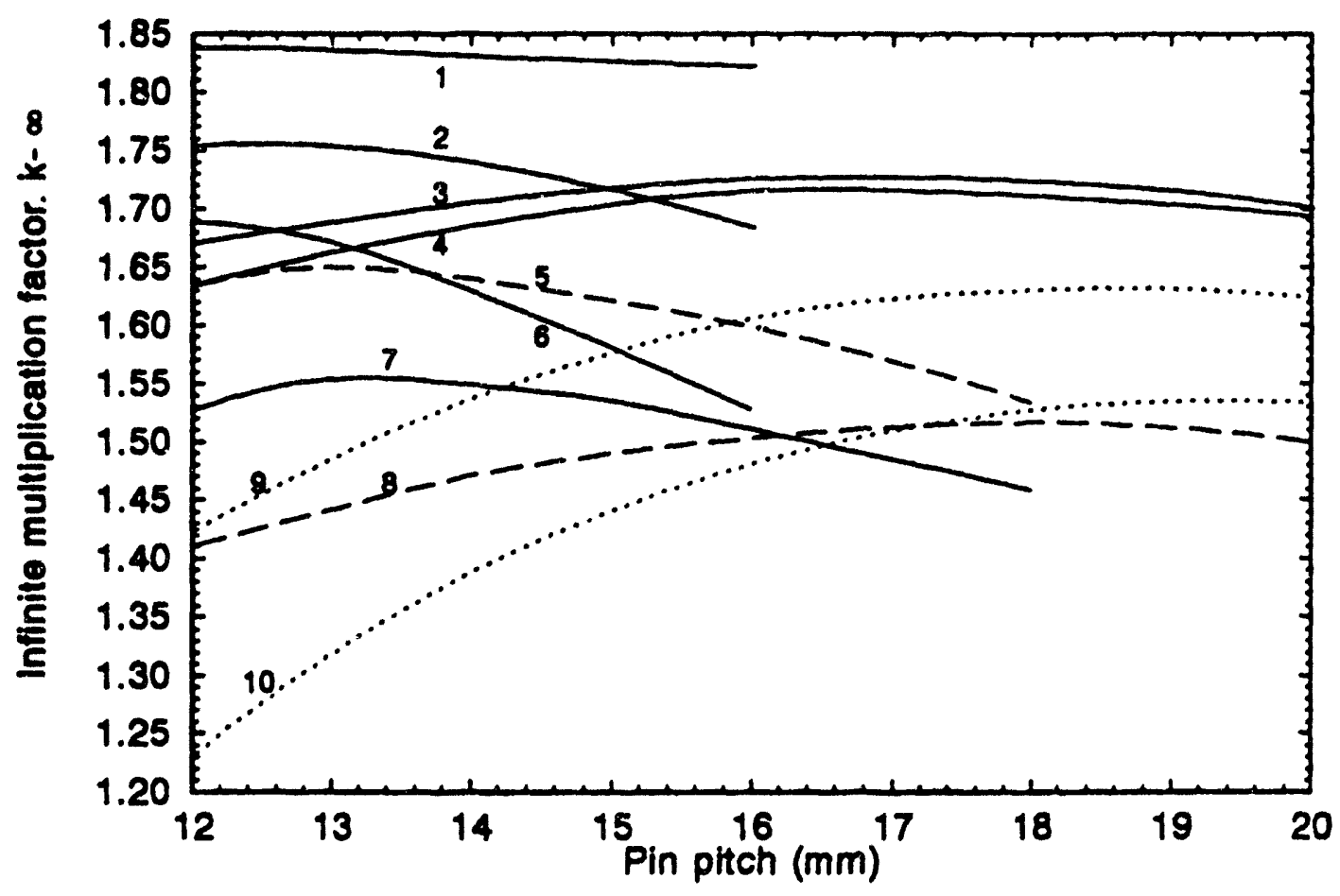

Fuel Composition

14 volume\% Pu-238-Al

21 volume $\%$ Pu-238-AI

34 volume $\% \mathrm{Pu}-\mathrm{Al}$

44 volume\% Pu-Ala , 4\% of Pu-239 is replaced with natural tungsten

51 volume $\%$ Pu-239-Al, $2 \%$ of Pu-239 is replaced with natural europium

61 volume $\%$ U-235-Al

71 volume\% Pu-239-Al, 4\% of Pu-239 is replaced with natural europium

84 volume\% Pu-Ala, $4 \%$ of $\mathrm{Pu}-239$ is replaced with natural europium

94 volume $\%$ Pu-Ala, $4 \%$ volume $\% \mathrm{~W}-92$ volume $\% \mathrm{Al}$

104 volume $\%$ Pu-Ala, $12 \%$ volume $\% \mathrm{~W}-84$ volume $\%$ Al

\section{a. Weapons-grade plutonium}

Figure D-1. The infinite multiplication factor as a function of pin pitch $(\mathrm{mm})$ in a square lattice. The $\mathrm{Pu}-\mathrm{Al}$ fuel is $8 \mathrm{~mm}$ in diameter, with an aluminum cladding of 2-mm thickness, and no fuel-clad gap. 


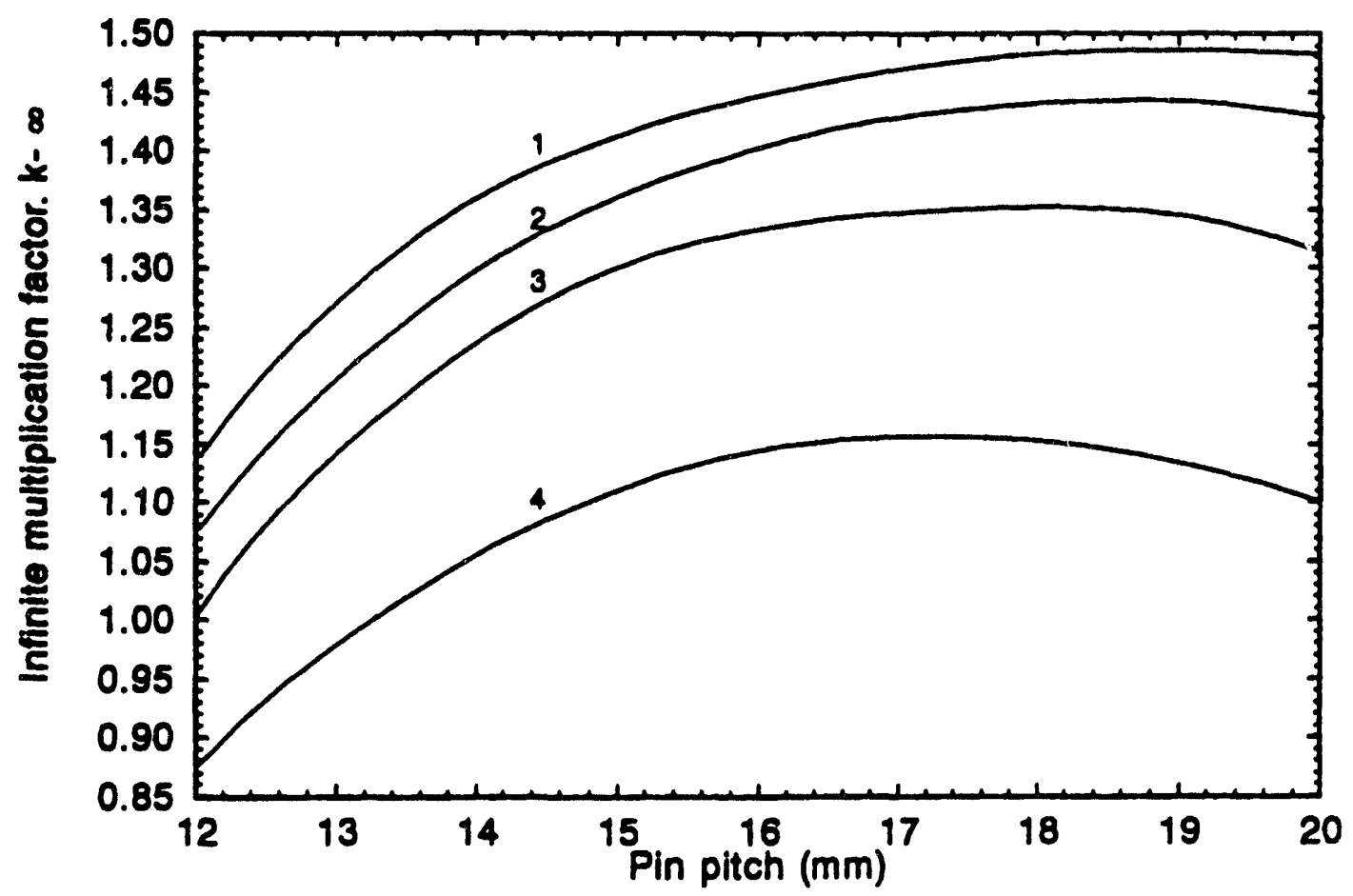

Fuel Composition

14 volume\% Pu-239-Al

23 volume\% Pu-239-Al

32 volume\% Pu-239-Al

41 volume\% Pu-239-Al

Figure D-2. The infinite multiplication factor as a function of pin pitch $(\mathrm{mm})$ in a square lattice. The $\mathrm{Pu}-\mathrm{Al}$ fuel is $8 \mathrm{~mm}$ in diameter, with a molybdenum cladding of 2-mm thickness, and no fuel-clad gap. 


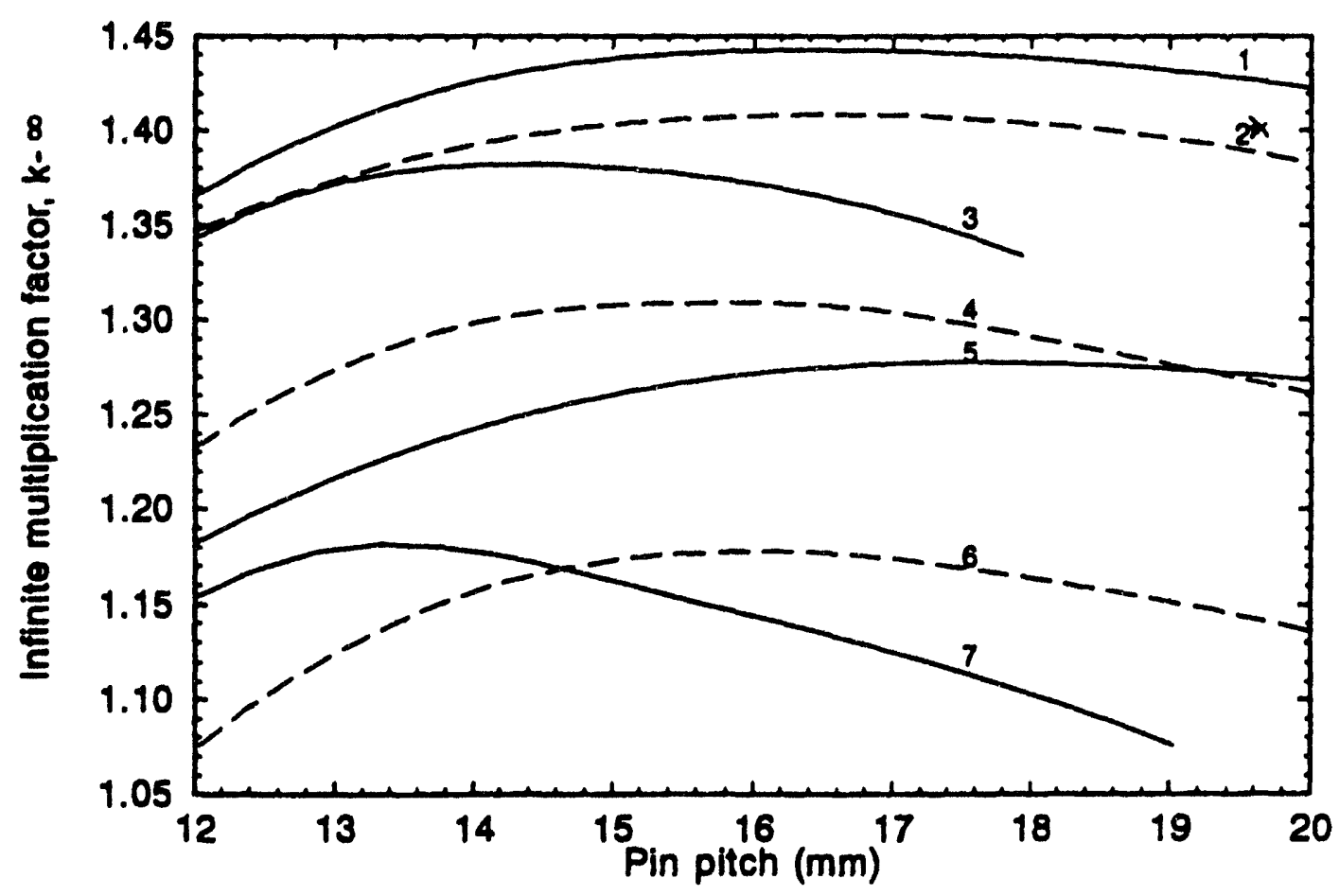

Fuel Composition

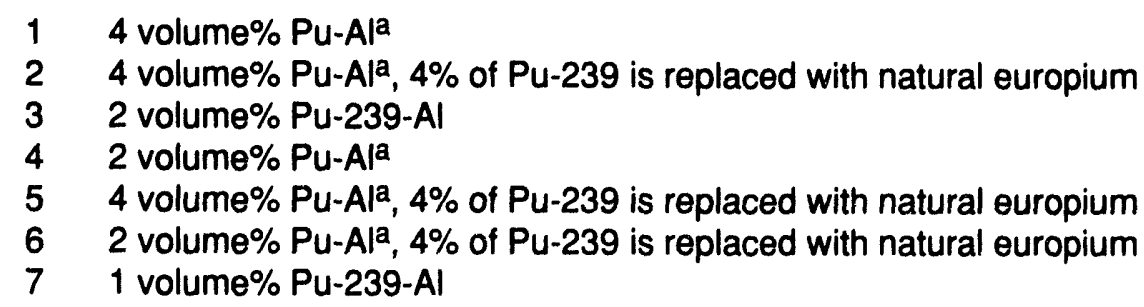

a. Weapons-grade plutonium

Figure D-3. The infinite multiplication factor as a function of pin pitch $(\mathrm{mm})$ in a square lattice. The $\mathrm{Pu}-\mathrm{Al}$ fuel is $8 \mathrm{~mm}$ in diameter, with stainless steel cladding of $2-\mathrm{mm}$ thickness, and no fuel-clad gap. 


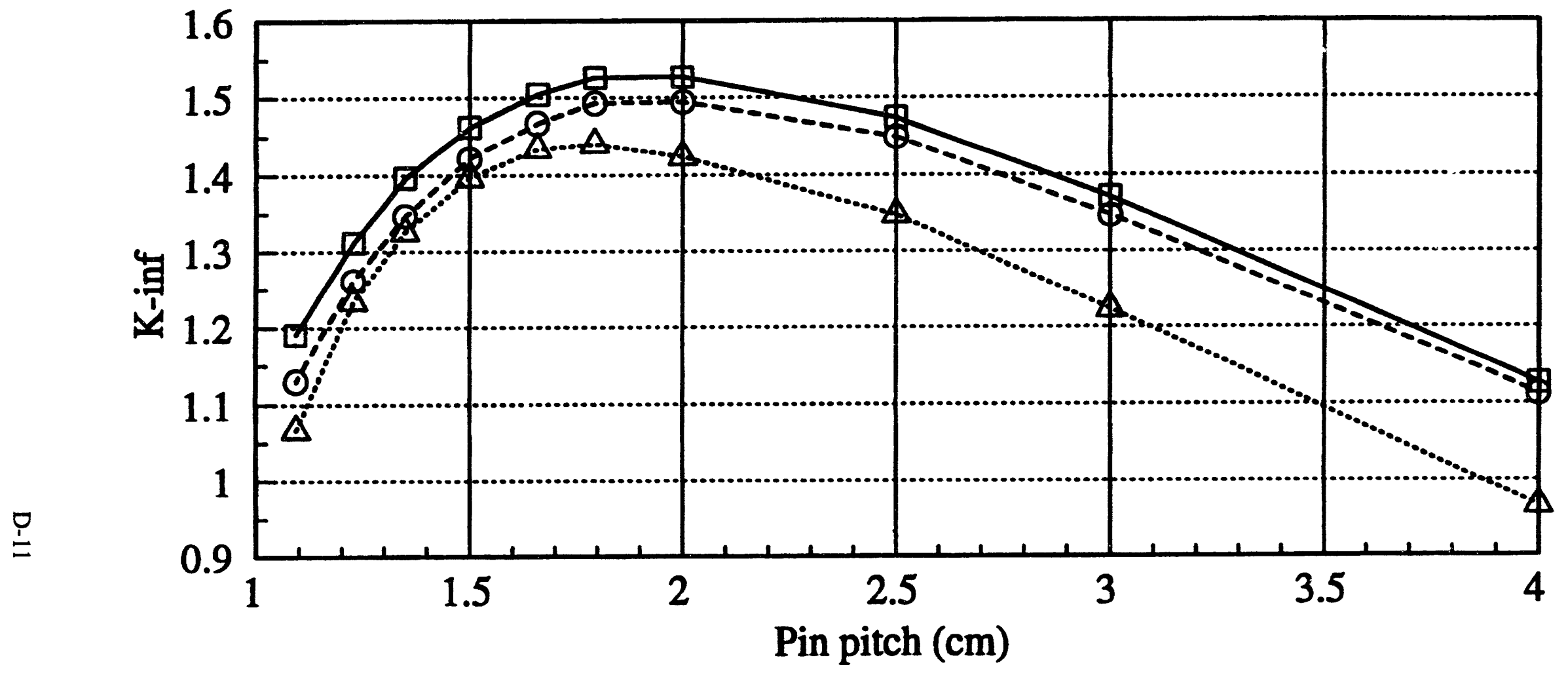

Tungsten VF=12\% Tungsten $\mathrm{VF}=14.5 \%$ U-metal rod

PU-239 VF=3\%, AL VF=85\% or $82.5 \%$.

$\mathrm{U}-235 \mathrm{VF}=3 \%, \mathrm{U}-238 \mathrm{VF}=97 \%$.

Pin diameter is $8.9 \mathrm{~mm}, \mathrm{Al}$ clad is $0.73 \mathrm{~mm}$ thick.

Figure D-4. Relation of $\mathrm{k}$-infinity to fuel pin pitch for $\mathrm{Pu}-\mathrm{Al}+\mathrm{W}$ and $\mathrm{U}-$-metal lattices. 
A mixed Pu-Al plus tungsten fuel without uranium or thorium for the plutonium burner reactor has been shown to have some of the same safety features of conventional uranium fuels. Compared to most burnable poisons used in current LWRs, tungsten has a very low thermal capture cross section.

Therefore, the depletion rate of tungsten is more compatible with plutonium-fueled reactors. Although detailed analyses have not been performed, this new mixed Pu-Al plus tungsten fuel exhibits characteristics comparable to LWR uranium fuels.

Several plutonium burner fuel and cladding combinations could be employed. The plutonium-aluminum composite was selected as the preferred fuel form. Possible cladding materials include aluminum, stainless steel, zircaloy, molybdenum, and tungsten. Aluminum and stainless steel are the preferred cladding materials. Aluminum is acceptable at the relatively benign operating conditions expected and may provide fabrication advantages, such as the ability to coextrude the $\mathrm{Pu}-\mathrm{Al}$ fuel and aluminum cladding. Stainless steel would provide superior containment.

Both the prompt Doppler reactivity coefficient and the moderator temperature coefficient must be negative. Because of low cladding absorption, the aluminum cladding configurations are expected to present the greatest challenge in achieving negative temperature coefficients. Preliminary evaluations have been performed for selected $\mathrm{Pu}-\mathrm{Al}$ in aluminum cladding configurations.

Three fuel rod diameters were examined. The first was a nominal pressurized water reactor (PWR) rod configuration with a fuel diameter of $8.19 \mathrm{~mm}$, a $0.082-\mathrm{mm}$ gap, and a $0.572-\mathrm{mm}$ aluminum cladding. The gap and thin cladding may not be representative of an eventual design, but these assumptions are conservative for the investigation of temperature coefficients. Sensitivity to rod diameter was investigated by examining configurations with $16-\mathrm{mm}$ fuel diameter and with 24-mm fuel diameter. The same gap and cladding dimensions were retained.

Natural europium $\left(47.8 \%{ }^{151} \mathrm{Eu}, 52.2 \%{ }^{153} \mathrm{Eu}\right)$ was added to provide a negative prompt Doppler coefficient. Numerous compositions were examined and one was selected for additional temperature coefficient evaluations. The composition (in atom percent) was $98.95 \%$ aluminum, $1 \%$ plutonium, and $0.05 \%$ europium. Plutonium weight fractions of $0.955{ }^{239} \mathrm{Pu}, 0.04$ ${ }^{240} \mathrm{Pu}$, and $0.005{ }^{241} \mathrm{Pu}$ were assumed. The plutonium content of a $8-\mathrm{mm}$-diameter rod of $3.66-\mathrm{m}$ length is about 50 grams.

Unit cell calculations were performed using the COMBINE- $V^{3}$ spectrum code. Several pin pitches in a square lattice were examined for each rod diameter in order to establish an acceptable (undermoderated) region of operation with a negative moderator temperature coefficient. Calculated effective multiplication factors for the unit cells are shown in Figure D-5. Undermoderated (left-of-peak) regions exist even with low absorption aluminum clad and very low europium content. A lattice configuration can be selected with a negative temperature coefficient, although the temperature coefficient magnitudes are small for the cases examined. The temperature coefficient magnitude could be increased by using a more absorbing cladding such as stainless steel, by additional europium absorber content, by addition of a nonresonance absorber to the fuel, or by some combination of these methods. Acceptable ranges of moderator temperature coefficient would need to be established as part of comprehensive safety evaluations.

Prompt temperature feedback and total temperature defect were examined at beginning-of-life for three configurations corresponding to conditions near the peaks of the three curves shown in Figure D-5. The $8-\mathrm{mm}$ rod was examined at a pitch of $12 \mathrm{~mm}$, the $16-\mathrm{mm}$ rod was examined at a 22-mm pitch, and the 24-mm rod was examined at a $31-\mathrm{mm}$ pitch. Unit cell effective multiplication factors were determined for three cases for each of the three configurations. Results of these evaluations are shown in Table D-2. 
Table D-2. Unit cell multiplication factors for selected $\mathrm{Pu}-\mathrm{Al}$ in aluminum-clad configurations.

\begin{tabular}{lccc}
\hline \multirow{2}{*}{ Configuration } & \multicolumn{3}{c}{$\begin{array}{c}\text { Unit cell effective multiplication factor } \\
\text { for selected fuel diameters/lattice rod pitches }\end{array}$} \\
\cline { 2 - 4 } Room temperature & $8 \mathrm{~mm} / 12 \mathrm{~mm}$ & $16 \mathrm{~mm} / 22 \mathrm{~mm}$ & $24 \mathrm{~mm} / 31 \mathrm{~mm}$ \\
Prompt jump & 1.4993823 & 1.4974456 & 1.4911421 \\
Temperature defect & 1.4977597 & 1.4957619 & 1.4893298 \\
\hline
\end{tabular}

\section{Plutonium - Europlum - Aluminum Lattice 1\% Pu, 0.05\% Eu, 98.95\% Al (Atom \%)}

\section{$\Delta 8 \mathrm{~mm}$ dlamoler $\theta 16 \mathrm{~mm}$ diameter $\nabla 24 \mathrm{~mm}$ diamotor}

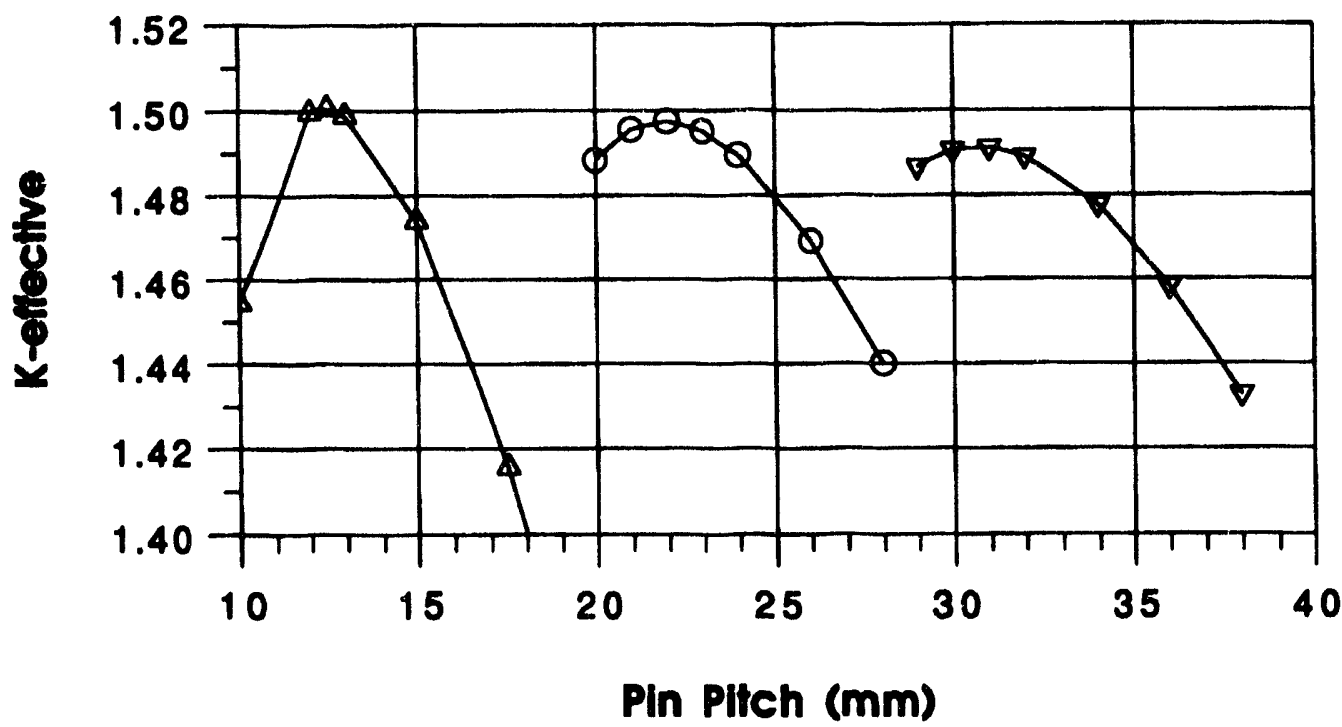

Figure D-5. Effective multiplication factor as a function of pin pitch for selected fuel pin diameters. 
The "Room Temperature" case corresponds to an isothermal unit cell at $296 \mathrm{~K}$. For the "Prompt Jump" case, the temperature assumed for the Nordheim resonance treatment was increased to the assumed operating fuel temperature of $500 \mathrm{~K}$. For the "Temperature Defect" case, the unit cell operating conditions were assumed. The fuel, clad, and moderator temperatures were assumed to be $500 \mathrm{~K}, 420 \mathrm{~K}$, and $350 \mathrm{~K}$, respectively. Radial expansion of the fuel and clad regions was modeled. The reduced moderator density was modeled and temperature dependent scattering kernels applied in the calculation.

The calculated prompt change is small, but negative, for all three configurations examined. The calculated negative response is due primarily to Doppler broadening in ${ }^{151} \mathrm{Eu}$ and ${ }^{240} \mathrm{Pu}$. This calculation underestimates the actual negative change because the available ${ }^{153} \mathrm{Eu}$ cross sections had been processed assuming infinite dilution, and Doppler broadening in ${ }^{153} \mathrm{Eu}$ could not be evaluated. When the ${ }^{153}$ Eu response is included, a more negative prompt change will be observed at this europium concentration, and even lower europium concentrations may prove acceptable.

The prompt Doppler reactivity coefficient and the moderator temperature coefficient must remain negative over the entire fuel exposure. The prompt change was evaluated only at one other exposure in an attempt to provide some insight into exposure-dependent behavior. The 16-mm-diameter rod was evaluated at an exposure of $500 \mathrm{GWD} / \mathrm{MT}$. Isotopic compositions were calculated using the ORIGEN2 isotopic generation and depletion $\operatorname{code}^{4}$ with appropriate plutonium, europium, ${ }^{135} \mathrm{Xc}$, and ${ }^{149} \mathrm{Sm}$ cross sections from the COMBINE results. At this exposure, approximately $50 \%$ of the initial plutonium and $23 \%$ of the europium have been consumed. Approximately $60 \%$ of the remaining europium is ${ }^{153} \mathrm{Eu}$. The remaining plutonium is approximately $23 \%{ }^{240} \mathrm{Pu}$. The COMBINE calculations were repeated with the 50) GWD/MT compositions and results are shown in Table D-3.

The calculated change is small but negative at this exposure. Again, the results should be riewed as conservative because Doppler broadening is not treated in ${ }^{153} \mathrm{Eu}$. The contributions from europium transmutation products (primarily gadolinium) have not yet been evaluated. Most of the observed negative contribution is from ${ }^{240} \mathrm{Pu}$.

Although certainly not conclusive, these results indicate it is probably feasible to design $\mathrm{Pu}-\mathrm{Al}$ fueled configurations with aluminum clad and relatively low europium content that exhibit both negative prompt temperature coefficients and negative moderator temperature coefficients over a wide range of exposures.

The lattice analyses are continuing to incorporate the design safety and performance requirements. For plutonium, the temperature feedback mechanism has to be chosen carefully. Regular examination of the neutron spectra is required as absorbers are added. Strong low-lying resonances exist in plutonium; for example, a ${ }^{239} \mathrm{Pu}$ resonance near $0.3 \mathrm{eV}$ and a ${ }^{240} \mathrm{Pu}$ resonance near $1.0 \mathrm{eV}$. These can interfere with the temperature feedback if they lie in the predominant region of the neutron distribution (the "Maxwellian").

Table D-3. Unit cell multiplication at $0 \mathrm{GWD} / \mathrm{MT}$ and $500 \mathrm{GWD} / \mathrm{MT}$ exposure.

\begin{tabular}{ccc}
\hline Configuration & \multicolumn{2}{c}{$\begin{array}{c}\text { Unit cell effective multiplication factor } \\
16-\mathrm{mm} \text { rod on } 22-\mathrm{mm} \text { square pitch }\end{array}$} \\
\cline { 2 - 3 } Room temperature & $0 \mathrm{GWD} / \mathrm{MT}$ & $500 \mathrm{GWD} / \mathrm{MT}$ \\
Temperature defect & 1.4974456 & 1.3754804 \\
\hline
\end{tabular}




\section{D-3. CONTROL AND SHUTDOWN CONSIDERATIONS}

Reactivity control may be described based on response time considerations. The longest time is associated with "permanent" reactivity holddown and can be achieved with borosilicate glass rods that can be placed in the lattice. The experience with borosilicate glass in the LWR industry is extensive and very satisfactory. Borosilicate glass is also relatively cheap. Boron- 10 is a $1 / v$ absorber and, thus, supplies reactivity holddown over a large neutron energy range, but without resonance absorption. Reactivity holddown with materials such as gadolinium or boron in the fuel complicates the material properties and burnup characteristics. Control rods made of a suitable material that covers a broad spectrum of neutron energies such as hafnium or $\mathrm{B}_{4} \mathrm{C}$ can be used, as shown in Table D-4. The insertion time for such rods is estimated to be in the tenths of a second, using available technology.

Short-term negative reactivity response on the order of milliseconds, but larger than the mean neutron lifetime, can be provided by the moderator coefficient, which is dependent on the variation of the moderator (water) density and scattering characteristics. Table D-5 presents a summary of these response times.

Reactivity control on the order of the mean neutron lifetime (e.g., $10^{-4}$ seconds) is achievable from material expansion from the fuel and from the integral resonance absorbers that can be included in the fuel.

The resonance absorbers provide negative feedback because of Doppler broadening of the resonances. As mentioned above, the resonance absorbers may be tungsten, dysprosium, iridium, europium, erbium, and other rare earth metals with resonances in the $\mathrm{eV}$ to tens of $\mathrm{eV}$ range. Specific neutronic analyses performed to obtain the temperature coefficient of reactivity and quantities needed in the fuel alloy are under way for several of the candidate resonance absorbers.
Metallurgical compatibility evaluations are also under way.

Two spatial control issues must be addressed for large reactors. The first is the potential for spatial fluctuations of the flux among loosely coupled (or decoupled) regions of the reactor. The strength (or weakness) of the coupling between the various regions of a reactor is a function of the ratio of the average neutron mean free path in the fast group to the average distance between the regions. The fast neutron mean free path in a light water moderated reactor, such as the proposed design, is much larger than the mean free path of the thermal neutrons. The interregion coupling will, therefore, be driven primarily by the fast neutron group. The fast neutron mean free path for the proposed design is expected to be of the same order of magnitude as that of existing nonboiling LWRs. Therefore, it is possible that power fluctuations similar to those occurring in PWRs might arise in the proposed reactor concept. The fluctuations because of the "decoupled regions" effect would not, however, be a serious concern. These concerns are likely to be significant only when the reactor is operated at very low power, and hence, the corresponding peaking would not lead to local temperatures above the operating envelope. This effect would also be countered by the negative temperature feedback built into the concept. An alternative measure of how tightly coupled the various regions of the core are is the ratio of the size of the reactor to the migration length. In the INEL reactor concept the ratio is expected to be large, and hence the reactor to be loosely coupled.

The second spatial control issue is that of xenon oscillations. When operating at high powers, a large reactor such as the one proposed in the conceptual design could be subject to xenon spatial oscillations and to the corresponding power oscillations. This effect is manageable using flux monitoring and real-time control equipment. 
Table D-4. Possible materials for control and shutdown systems.

\begin{tabular}{|c|c|c|}
\hline Material & Form & Remarks \\
\hline \multicolumn{3}{|l|}{ Shutdown material } \\
\hline Hafnium & $\begin{array}{l}\text { Rods } \\
\text { Cruciform blades } \\
\text { Drums }\end{array}$ & $\begin{array}{l}\text { Broad neutron absorption energy } \\
\text { range and extersive experience }\end{array}$ \\
\hline $\mathrm{B}_{4} \mathrm{C}$ & $\begin{array}{l}\text { Rods } \\
\text { Cruciform blades } \\
\text { Drums }\end{array}$ & $\begin{array}{l}\text { Broad spectrum, lower cost, and } \\
\text { extensive experience; for shut- } \\
\text { down, no concern with }{ }^{4} \mathrm{He} \text { off- } \\
\text { gassing. }\end{array}$ \\
\hline \multicolumn{3}{|l|}{ Control material } \\
\hline Hafnium & Rods & $\begin{array}{l}\text { No off-gassing and strong parasitic } \\
\text { capture. }\end{array}$ \\
\hline $\mathrm{Ag}-\mathrm{In}-\mathrm{Cd}$ & Rods & $\begin{array}{l}\text { Large industry experience, expen- } \\
\text { sive, may not be black enough for } \\
\text { plu,onium fuel, exhibits parasitic } \\
\text { capture over broad energy range. }\end{array}$ \\
\hline $\mathrm{B}_{4} \mathrm{C}$ & Rods & $\begin{array}{l}\text { Least expensive, off-gassing, } \\
\text { strong } 1 / \mathrm{N} \text { absorber, industry expe- } \\
\text { rience. }\end{array}$ \\
\hline \multicolumn{3}{|l|}{ Holddown material } \\
\hline Borosilicate or $\mathrm{B}_{4} \mathrm{C}$ & Rods & $\begin{array}{l}\text { Broad absorption range, extensive } \\
\text { experience, least expensive. Con- } \\
\text { siderably slower burnup than } \\
\text { gadolinium. No off-gassing con- } \\
\text { cern when clad and displacing fuel } \\
\text { pin in lattice. }\end{array}$ \\
\hline
\end{tabular}


Table D-5. Active (engineered) and inherent control requirements based on response time and relative reactivity magnitude.

\begin{tabular}{|c|c|c|c|c|}
\hline Purpose & Response time & Material & $\begin{array}{l}\text { Available } \\
\text { reactivity }\end{array}$ & Remarks \\
\hline Shutdown & Standby & $\mathrm{Hf}$ and $\mathrm{B}_{4} \mathrm{C}$ & Unlimited & \\
\hline Scram & $10^{-2} \mathrm{sec}$ & $\mathrm{Hf}$ and $\mathrm{B}_{4} \mathrm{C}$ & Unlimited & $\begin{array}{l}\text { Same system as } \\
\text { above; insertion } \\
\text { speed determined } \\
\text { by drive } \\
\text { mechanism }\end{array}$ \\
\hline \multirow[t]{2}{*}{ Control } & $10^{-2} \mathrm{sec}$ & Hf rods & Unlimited & Depletable \\
\hline & $10^{+1} \mathrm{~min}$ & Soluble boron & TBD & $\begin{array}{l}\text { May affect mod- } \\
\text { erator temperature } \\
\text { coefficient, may } \\
\text { be undesirable in } \\
\text { primary }\end{array}$ \\
\hline Holddown & Cycle length & Borosilicate rods & Unlimited & \\
\hline $\begin{array}{l}\text { Moderator } \\
\text { temperature } \\
\text { coefficient }\end{array}$ & & N/A & $<50 \mathrm{pcm}^{\mathrm{a}}$ & $\begin{array}{l}\text { Magnitude } \\
\text { depends reactor } \\
\text { pool temperature, } \\
\text { clad choice, core } \\
\text { loading, burnup, } \\
\text { presence of other } \\
\text { absorbers }\end{array}$ \\
\hline Doppler & $<10^{-4} \mathrm{sec}$ & $\begin{array}{l}\text { Resonance } \\
\text { absorber loading }\end{array}$ & TBD & $\begin{array}{l}\text { Depends on reso- } \\
\text { nance absorber } \\
\text { loading and } \\
\text { burnup rate, } \\
\text { fission product } \\
\text { production }\end{array}$ \\
\hline Fuel expansion & $<10^{-4} \mathrm{sec}$ & $\begin{array}{l}\text { Fuel, clad, } \mathrm{H}_{2} \mathrm{O} \\
\text { displacement }\end{array}$ & TBD & $\begin{array}{l}\text { Depends on } \\
\text { relative fuel-clad } \\
\text { expansion } \\
\text { coefficient }\end{array}$ \\
\hline $1 \mathrm{pcm}$ is $10^{-5} \times$ & & & & \\
\hline
\end{tabular}




\section{D-4. CRITERIA AFFECTING CLADDING CHOICE}

\section{Strength and Durability}

Because ample excess reactivity exists in plutonium-burning reactors, it is desirable to keep the cladding thick and strong to withstand high fluence (high burnups), corrosion, thermal cycling, and other fuel-cladding interaction mechanisms. The cladding thicknesses that have been examined range up to four times as thick as the cladding in commercial LWRs.

\section{Cost and Manufacturability}

Stainless steels and molybdenum or molybdenum alloy clads are manufacturable and at relatively low cost. Aluminum alloys seem more attractive because of even lower cost, and to being co-extrudable with the $\mathrm{Pu}-\mathrm{Al}$ fuel. There is a large body of satisfactory experience with aluminum cladding extending into high burnups, but not reaching $90 \%$ burnup. It is not clear, at present, if aluminum alloy cladding will be satisfactory for burnup approaching $90 \%$. More details on manufacturability are included in Volume 4 of this report.

\section{Thermal Expansion and Reactlvity Feedback}

The resonances in the cladding have a considerable effect on the relation of the infinite multiplication factor to the pin pitch, as seen in
Figures D-2 and D-3. Furthermore, the relative temperature expansions have another interesting effect. Assuming the fuel has an average expansion coefficient of aluminum $\left(20 \times 10^{-6} \mathrm{~K}^{-1}\right)$, while aluminum, stainless steel, or a molybdenum alloy cladding has average therrnal expansion coefficients of $26 \times, 6 \times$, and $5 \times 10^{-6}$ $\mathbf{K}^{-1}$, respectively, then as the temperature rises, the axial linear fuel density varies differently inside each of the three cladding materials. Correspondingly, the axial linear moderator density also varies in each of the three clad materials. Both of these linear density changes affect the moderator-to-fuel ratio and, hence, the degree of reactivity control that can be obtained from the moderator temperature coefficient.

\section{Fuel Pin Backfill Pressure and Plenum Requirements}

Contrary to ceramic fuel, such as $\mathrm{UO}_{2}$, the total fission product gases may be released into the plenum rather than locked in the fuel structure. Clearly some gases will be locked in pockets in the fuel alloy. However, the initial backfill pressure in the plenum and the total plenum size should be determined based on a $100 \%$ plutonium burnup. The time-dependent fission product gas source term can be determined from appropriate isotopic generation and depletion calculations. The pressure and clad requirements can be calculated from the corresponding fuel performance models. 


\section{D-5. BURNUP CALCULATIONS}

The range of the acceptable lattice specifications (fuel material composition, clad, and moderator, as well as the respective dimensions) will be affected by the burnup behavior of the isotopes involved. These will include the plutonium as well as the burnable absorbers. As seen from the pin-pitch data presented earlier, the range of the undermoderated region changes with the presence of absorbers, especially resonance absorbers. The contribution of the resonance absorbers to the Doppler coefficient, after they are depleted with fuel exposure, is expected to be partially compensated for by the production of actinides higher than ${ }^{239} \mathrm{Pu}$. These actinides tend to increase the Doppler effect with burnup in LWR fuels. Absorption from both actinides and fission products contribute to maintaining a negative moderator temperature coefficient with increasing burnup. Specific depletion calculations will yield the magnitude of the contribution and the corresponding isotopic composition of the fuel as a function of exposure.

The reactivity holddown supplied initially by borosilicate rods will be evaluated versus fuel depletion. These analyses will lead to determining the pin-pitch range as well as the fuel cycle length and the desired fuel shuffling patterns for optimal power distributions. 


\section{D-6. REACTOR OPERATIONS AND FUEL MANAGEMENT}

This reactor will be much like an ordinary LWR in its operation. The basic reactivity control may be achieved with control rods. The operating cycle will be designed to be as long as practical, and the fuel may be shuffled in several reactor cycles. Reactivity holddown will be achieved with burnable poisons such as borosilicate rods. 


\section{D-7. REFERENCES}

1. J. F. Briesmeister (ed.), MCNP-A General Monte Carlo Code for Neutron and Photon Transport, Version 3A, LA-7396-M (Rev 2), Los Alamos National Laboratory, September 1986.

2. H. Kauts and R. Sher, Experimental Studies of Slightly Enriched Uranium Water Moderator Lattices, BNL0486, Brookhaven National Laboratory, September 1957.

3. R. A. Grimesey, D. W. Nigg, R. L. Curtis, COMBINE/PC-A Portable ENDF/B Version 5 Neutron Spectrum and Cross-Section Generation Program, EGG-2589, EG\&G Idaho, Inc., Idaho National Engineering Laboratory, February 1991.

4. A. G. Croff, ORIGEN2-A Revised and Updated Version of the Oak Ridge Isotope Generation and Depletion Code, ORNL-5621, Oak Ridge National Laboratory, July 1980. 


\section{Appendix E \\ Thermal-Hyraulic Considerations}




\section{Appendix E}

\section{Thermal-Hydraulic Considerations}

This appendix summarizes thermal-hydraulic considerations for a plutonium-burning reactor and recommends for this purpose a low-powerdensity reactor that is cooled with lowtemperature, low-pressure light water flowing at low velocity. A reactor with this cooling system design is shown to be very safe. This discussion assumes a plutonium-burning reactor that is rated at $1,000 \mathrm{MW}(\mathrm{t})$, with a power density in the range of $10-30 \mathrm{MW} / \mathrm{m}^{3}$ and rod-type fuel. 


\section{E-1. GENERAL FUEL GEOMETRY AND MATERIALS ISSUES}

Reactor thermal-hydraulic considerations start with the fuel materials and geometry. The fuel rod diameter defines the conduction path length through which energy must pass to reach the surface of the fuel rod. A thinner fuel rod has a shorter heat conduction length and, therefore, a smaller internal thermal gradient. Similarly, highconductivity fuel materials produce smaller fuel rod internal thermal gradients. Thus, a thin fuel rod constructed of high thermal conductivity materials has a low operating temperature. This is advantageous because it increases the heat input required to raise the fuel temperatures to failure or melting temperatures. For the same reason, fuel materials possessing high melting point temperatures and high thermal capacitances are advantageous. Low fuel temperatures are also an indication of low fuel stored energy during reactor operation, the removal of which must be accommodated during off-normal events. A thin fuel rod is also advantageous because it possesses a large surface area-to-volume ratio; a large fuel rod surface area is important because it lowers the fuel rod-to-coolant heat flux that is a primary safety parameter. A reactor operating at a low power density generally is advantageous over a high power density reactor from the perspective of all of these considerations.

Table E-1 shows pertinent thermo-physical property data for three potential fuel/cladding materials for a plutonium-burning reactor. Also shown are the fuel material thermal margins available for a representative fuel configuration operating at a low core power density. These data indicate that (a) the margins between the fuel operating temperatures and the fuel damage and melting point temperatures are large and (b) for a loss-of-fuel-cooling event in which core power continues at its full rate, the times required to damage and melt fuel also are large, when compared with high-power-density reactors. Therefore, all three of these potential fuel material types appear to be acceptable from a thermalhydraulic viewpoint for a low-power-density, plutonium-burning reactor. 
Table E-1. Thermo-physical properties and representative operating temperature and accident responses for potential plutonium-burning reactor fuel materials.

\begin{tabular}{lccc}
\hline & \multicolumn{3}{c}{ Fuel materials } \\
\cline { 2 - 4 } Fuel pellet properties & $\begin{array}{c}\mathrm{PuAl} \text { in } \mathrm{Al} \\
\text { with } \mathrm{Al} \text { clad }\end{array}$ & $\begin{array}{c}\mathrm{PuO}_{2} \text { in } \mathrm{ZrO}_{2} \\
\text { with } \mathrm{Zr} \text { clad }\end{array}$ & $\begin{array}{c}\mathrm{PuZrH}_{1.6} \text { with } \\
\mathrm{Zr} \text { clad }\end{array}$ \\
\hline Specific heat $(\mathrm{J} / \mathrm{kg}-\mathrm{K})$ & 962 & 628 & 335 \\
Density $\left(\mathrm{kg} / \mathrm{m}^{3}\right)$ & 2,699 & 5,350 & 6,388 \\
Thermal capacitance $\left(\mathrm{MJ} / \mathrm{m}^{3}-\mathrm{K}\right)$ & 2.60 & 3.36 & 2.14 \\
Thermal conductivity $(\mathrm{W} / \mathrm{m}-\mathrm{K})$ & 180 & 1.8 & 20 \\
Melting temperature $(\mathrm{K})$ & 933 & 2,973 & 2,125 \\
Practical fuel operating & 850 & $?$ & 1,023 \\
temperature limit $(\mathrm{K})$ & & &
\end{tabular}

Assumed configuration and conditions

Fuel rod pitch: $12.5 \mathrm{~mm}$

Pellet diameter: $8.19 \mathrm{~mm}$

Gap thickness: $0.082 \mathrm{~mm}$

Gap conductance: $5676 \mathrm{~W} / \mathrm{m}^{2}-\mathrm{K}$

Cladding thickness: $0.572 \mathrm{~mm}$

Core average power density (structures and fluids): $13.38 \mathrm{MW} / \mathrm{m}^{3}$

Core maximum fuel power density (fuel pellet): $70.83 \mathrm{MW} / \mathrm{m}^{3}$

Fuel maximum/average power ratio: 2.4

Coolant outlet temperature: $344.7 \mathrm{~K}$

Core flow velocity: $0.97 \mathrm{~m} / \mathrm{s}$

Results

Maximum fuel operating temperature

424

596

446

(K)

Heat input required $\left(\mathrm{MJ} / \mathrm{m}^{3}\right)$ to raise fuel

1,320

7,980

3,590

from maximum operating to melting

temperature

Minimum time (s) to fuel melting (loss-

$18.6^{\mathrm{a}}$

$112.6^{\mathrm{a}}$

$50.7^{\mathrm{a}}$ of-fuel cooling at full power)

a. Compare to $1 \mathrm{~s}$ for the Advanced Test Reactor and $8 \mathrm{~s}$ for a commercial pressurized water reactor. 


\section{E-2. STEAM EXPLOSION CONSIDERATIONS}

Because the plutonium-burning reactor proposed in this report is assumed to use a metal or oxide fuel, (such as $\mathrm{Pu}-\mathrm{Al}, \mathrm{Pu}-\mathrm{ZrO}_{2}$, or $\mathrm{Pu}$ $\mathrm{ZrH}_{1.6}$ ) the potential for an energetic steam explosion is of some concern, provided an accident sequence can be identified that leads to large quantities of molten fuel and cladding. The purpose of this section is to discuss some of the steam explosion concerns involving aluminumwater and zirconium-water in relation to the proposed low power density, low flow plutoniumburning reactor.

When contact of a hot liquid (usually a molten material) and a cooler volatile liquid (coolant) occurs, the energy transfer between the molten material and the coolant may suddenly become so rapid and coherent that an explosion results. Such an explosion is referred to as a vapor explosion (called a steam explosion when water is used as the coolant).

At the present time there are basically two approaches used to model vapor explosions. The first approach is a mechanistic one where the various events during a severe accident are modeled in detail. This approach, while appealing, is better left to the evaluation of safety concerns because of a energetic vapor explosion in existing reactors or reactors that are in their final design stages. This method is expensive both in terms of model development and computer requirements. N"any of the phenomenological models used in this type of analysis are at best crude representations of the actual phenomena, however, they are the best mechanistic model that researchers have been able to formulate at this time.

The second approach is to use a thermodynamic model that was first proposed by HicksMenzies. ' The advantage of this model is that a detailed description of the vapor explosion process does not have to be specified. This model does not account for any rate processes that occur during the vapor explosion, such as the heat transfer from the fuel to the coolant or the propagation of the shock wave from the core to the surrounding structure, nor does it provide a detailed vessel wall pressure history that is needed to define failure of the vessel wall. The model does yield an upper bound on the theoretical work that can be generated from a vapor explosion. The value of the calculated work from this model is usually much higher than any value measured from the many experiments that have been run to date. However, this approach does provide a means of measuring the relative importance (in terms of maximum work produced) that the different fuel materials will contribute to the overall severity of a vapor explosion provided one were to occur. This is the vapor explosion model that was used to evaluate two fuel materials, aluminum and zirconium, using the assumption that $\mathrm{Pu}-\mathrm{Al}$ will behave in the same manner as pure aluminum, and that $\mathrm{Pu}-\mathrm{ZrO}_{2}$ and $\mathrm{Pu}-\mathrm{ZrH}_{1.6}$ will behave in the same manner as the pure base materials.

When a metallic fuel interacts with water there is also the possibility that chemical energy will be released to the system. Past vapor explosion studies have neglected the contribution because of a chemical reaction between the metallic fuel and the water because it was thought to be small when compared to the thermal energy release from the fuel. Recently reported experimental studies on aluminum-water steam explosions have indicated that ignition of the molten metallic fuel may have occurred in some of the experiments at some yet unknown critical fuel temperature. For this reason the results presented will address both the case of no fuel ignition and the case corresponding to the ignition of some percentage of the fuel. The analysis was conducted using the following thermal properties.

Results based on the Hicks-Menzies thermodynamic model for both the no fuel ignition case and fuel ignition case are discussed. First the no ignition case will be considered. For this case it was assumed that the aluminum and zirconium fuels were each $200 \mathrm{~K}$ above their respective melting temperatures (s,e Table E-2) when they contacted the coolant. The choice of $200 \mathrm{~K}$ is 
Table E-2. Material considered for plutonium-burning reactor vapor explosior study.

\begin{tabular}{lcccc}
\hline Material & $\begin{array}{c}\text { Melting temperature } \\
(\mathrm{K})\end{array}$ & $\begin{array}{c}\text { Density } \\
\left(\mathrm{kg} / \mathrm{m}^{3}\right)\end{array}$ & $\begin{array}{c}\text { Specific heat } \\
(\mathrm{J} / \mathrm{kg}-\mathrm{K})\end{array}$ & $\begin{array}{c}\text { Chemical energy } \\
(\mathrm{kJ} / \mathrm{kg})\end{array}$ \\
\hline Aluminum & 933 & 2,700 & 1,090 & 17,481 \\
Zirconium & 2,123 & 6,184 & 356 & 6,513 \\
\hline
\end{tabular}

strictly arbitrary because there are presently no severe accident analyses for the plutonium-burning reactor design. However, preliminary molten fuel anaiyses for the Advanced Test Reactor, which uses aluminum clad fuel, indicate that the maximum molten fuel temperature as it leaves the core and first contacts the coolant will be approximately $200 \mathrm{~K}$ above its melting temperature. This does not mean that at some time later in the accident sequence the fuel will not exceed this $200 \mathrm{~K}$ superheat. Because of the interest in differences between the vapor cxplosion work term for the two fuel materials and not absolute values, a choice of $200 \mathrm{~K}$ fuel superheat (above melting temperature) is acceptable from the standpoint of making comparisons between the two fuel materials. In addition, it is assumed the coolant is $50 \mathrm{~K}$ subcooled $(323 \mathrm{~K})$ based on the saturation temperature for an initial system pressure of $0.101 \mathrm{MPa}$. It is also assumed that the initial coolant void fraction is zero. Varying these parameters will only affect the absolute magnitude of the results and not the comparisons among the results.

The analysis indicates that aluminum fuel clearly has an advantage from a maximum work standpoint (smallest potential for the generation of work per unit fuel volume) over the entire range of coolant-to-fuel-volume ratios considered. For example, results obtained with the Hicks-Menzies model, no ignition, and a fuel-to-coolant volume ratio of 1.0 , show a work term per unit fuel volume of $1200 \mathrm{MJ} / \mathrm{m}^{3}$ with aluminum and 3100 $\mathrm{MJ} / \mathrm{m}^{3}$ with zirconium. Zirconium appears to be the less desirable material from an energetic standpoint for the case of no ignition. These results are based on the assumption that molten fuel will be generated, independent of the type of fuel used, and that the likelihood of a vapor explosion is equally probable once the different materials are molten. The likelihood that each material will have an equal probability of causing a vapor explosion is low however. Both the experimental and analytical databases are not extensive enough to be able to address this issue properly.

Next to be considered is the case where $20 \%$ of the cladding material is oxidized. That is, chemical energy from an arbitrary $20 \%$ of the cladding is added to the thermal energy from vapor explosion. The results show that zirconium yields the lowest calculated work term, and aluminum yields the highest work term. The reason for the reversal is that the chemical energy released per unit volume for aluminum $\left(47,200 \mathrm{MJ} / \mathrm{m}^{3}\right)$ is higher than for zirconium $\left(40,280 \mathrm{MJ} / \mathrm{m}^{3}\right)$.

The results from this study, based on vapor explosion energetics, indicate that the best choice of fuel material (assuming that aluminum and zirconium can be used) depends on whether or not the possibility of fuel ignition during the course of a vapor explosion event can be ruled out. If the chance for ignition appears to be high, zirconiumbased fuel is the logical choice based on vapor explosion energetics. If the possibility of ignition can be ruled out, then an aluminum-based fuel is the logical choice from an energetics standpoint.

Because only a low power density reactor is being considered, there is little chance that the molten aluminum will reach a temperature high enough to cause chemical ignition to occur. From an energetic standpoint $\mathrm{Pu}-\mathrm{Al}$ fuel material is a logical first choice as a fuel material. 


\section{E-3. GENERAL CORE COOLING ISSUES}

Fuel operating temperatures are affected directly by the temperature of the fluid employed to cool the fuel. Energy generated primarily within the fuel pellet flows radially outward through the pellet, through a gas-filled gap, through the cladding, and into the coolant. Thus, the coolant temperature represents a sink temperature to which the fuel heat must be passed; if the coolant temperature is raised, then the fuel temperatures are also raised. As discussed in the previous section, for a low-power-density reactor the thermal gradients within the fucl rod and the fuel material temperatures are moderate. If fuel rod and bundle geometries comparable to those of commercial pressurized water reactors (PWRs) are employed in a low-power-density reactor, then the heat flux between the fuel clad wall and the coolant is reduced along with the power density. From a thermal-hydraulic viewpoint, a large fuel rod pitch is desirable because it reduces the core frictional pressure drop and increases the fluid-to-fuel volume ratio. However, because of the modest thermal requirements for a lowpower-density reactor, fuel rod pitch and diameter selections instead may be based primarily on other considerations, such as neutronics, for which employing a small pitch is advantageous for avoiding overmoderation.

Energy is driven from the fuel rod into the coolant by the difference between the fuel rod surface and the bulk coolant temperatures. The heat transfer coefficient associated with this process is determined by the temperatures of the fuel rod and coolant, and the coolant pressure and velocity. Typically, high-power-density reactors require that fluid be forced through the core at high velocity using centrifugal pumps in order for the heat transfer coefficient to be sufficiently large. A forced-convection cooling system generates a considerable frictional pressure drop and, therefore, the pressure can vary significantly from one location to another within the coolant system. For high-power-density reactors, it is also necessary to pressurize the coolant to prevent it from boiling and to raise the margin to fuel rod departure from nucleate boiling. High-power-density reactors with a design goal of electric power production also require employing a hightemperature coolant in order to maximize the steam turbine cycle efficiency. 


\section{E-4. THERMAL-HYDRAULIC RECOMMENDATIONS FOR A PLUTONIUM-BURNING REACTOR}

To take advantage of the opportunities for improving safety afforded by a reactor operating at low power density, a plutonium-burning reactor that is cooled by low-temperature, lowpressure light water flowing at low velocity is recommended.

The recommended reactor consists of a vertical core, assembled from cylindrical fuel pins fabricated from aluminum (the other fuel materials described in Table E-1 would also be acceptable). The fuel pins would be sized and arranged in a manner similar to that employed in commercial PWRs. There would be no channelization of the flow within the core and coolant would flow upward through the core. A sketch of the coolant loop arrangement of such a reactor appears in Figure E-1. Table E-3 compares its core thermalhydraulic parameters with those of two representative high-power-density reactors. Data in the first column are based on a simple one-dimensional RELAP5/MOD3 computer model of the plutonium-burning reactor core.
Multiple pumped primary coolant loops would transport warm coolant from the core outlet upward to elevated heat exchangers. Pumped heat exchanger secondary systems would employ a light water coolant to transport reactor heat to cooling towers and ultimately to the environment. The core flow velocity of $0.75 \mathrm{~m} / \mathrm{s}$ corresponds approximately to that for a commercial PWR under conditions where decay heat is removed to the steam generators by loop natural circulation.

The recommended core exit pressure of $0.2 \mathrm{MPa}$ is attainable by assuming the uppermost elevation of the coolant loops is at atmospheric pressure, with the static head of the coolant loops, elevated about $10 \mathrm{~m}$ above the core, providing the difference. The core inlet temperature, $325 \mathrm{~K}$, is achievable based on Advanced Test Reactor experience, and the core outlet temperature, $347 \mathrm{~K}$, is based on the core geometry of a commercial PWR. The average core fuel rod heat flux

Table E-3. Comparison of thermal-hydraulic parameters for a low-pressure and temperature plutoniumburning reactor, a commercial pressurized water reactor, and the Advanced Test Reactor.

\begin{tabular}{|c|c|c|c|}
\hline & $\begin{array}{l}\text { Plutonium } \\
\text { burner }\end{array}$ & $\begin{array}{l}\text { Pressurized } \\
\text { water } \\
\text { reactor }\end{array}$ & $\begin{array}{l}\text { Advanced } \\
\text { Test Reactor }\end{array}$ \\
\hline Core power (MW) & 1,000 & 3,000 & 250 \\
\hline Core height $(\mathrm{m})$ & 3.66 & 3.66 & 1.22 \\
\hline Core diameter $(\mathrm{m})$ & 5.90 & 3.63 & 0.511 \\
\hline Average power density $\left(\mathrm{MW} / \mathrm{m}^{3}\right)$ & 10.0 & 100 & 1,000 \\
\hline Coolant velocity $(\mathrm{m} / \mathrm{s})$ & 0.75 & 4.57 & 14.6 \\
\hline Coolant inlet temperature $(\mathrm{K})$ & 325.0 & 555 & 325 \\
\hline Coolant outlet temperature $(\mathrm{K})$ & 346.6 & 589 & 348 \\
\hline Core outlet pressure (MPa) & 0.20 & 15.51 & 1.86 \\
\hline Core frictional pressure drop $(\mathrm{MPa})$ & 0.0027 & 0.14 & 0.69 \\
\hline Average fuel/coolant heat flux $\left(\mathrm{MW} / \mathrm{m}^{2}\right)$ & 0.0523 & 0.65 & 1.99 \\
\hline Maximum fuel temperature $(\mathrm{K})$ & 409.2 & 2155 & 533 \\
\hline
\end{tabular}




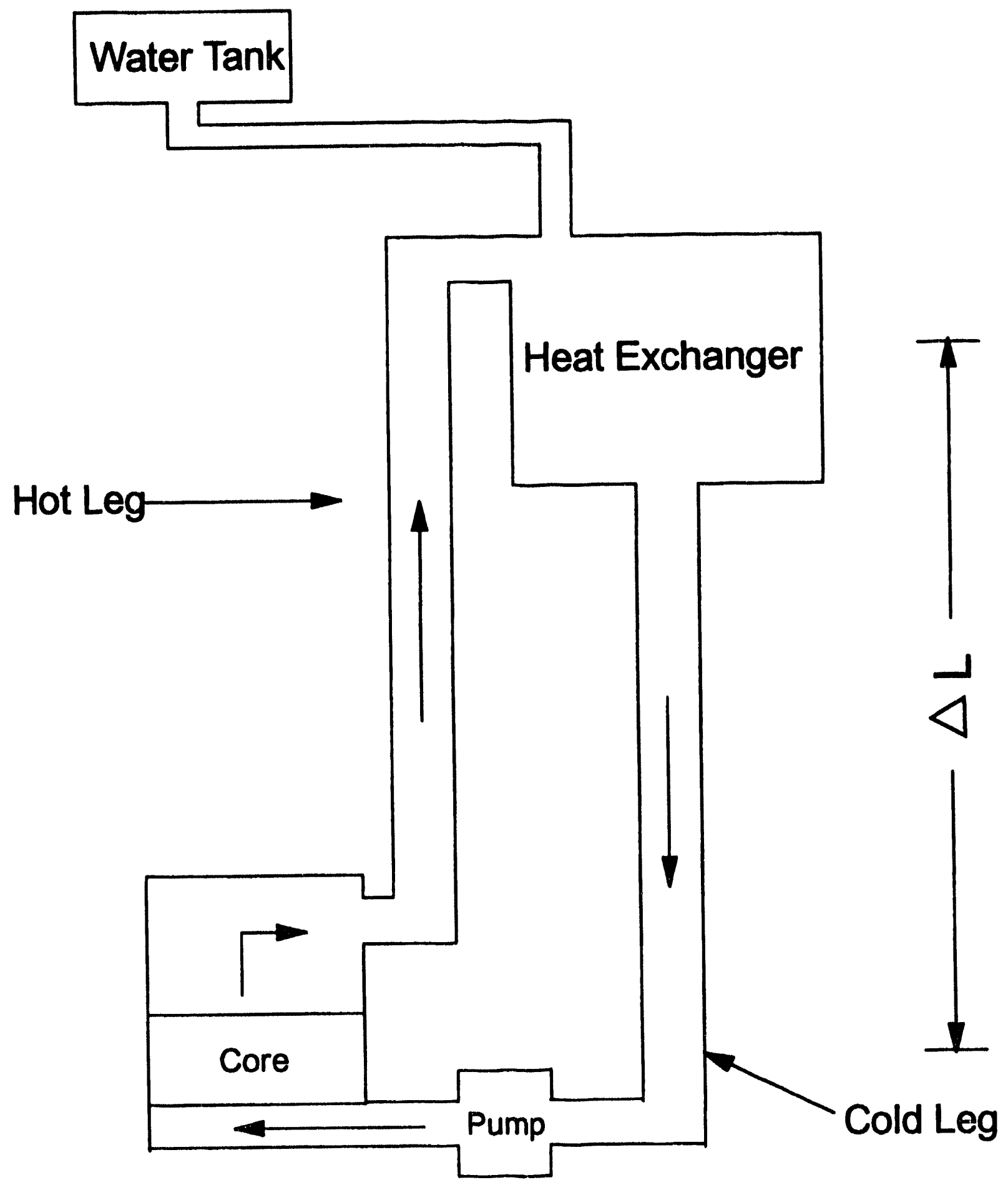

Figure E-1. Schematic diagram of low-flow low-pressure reactor concept. 
is similarly based. The maximum fuel temperature assumes using the plutonium-aluminum fuel material described in Table E- 1 and a very conservative peak-to-average power ratio of 3.33 .

The core of the recommended reactor concept would necessarily be physically large because of its low power density. For example, a $1,000-\mathrm{MW}(\mathrm{t})$ plutonium-burning reactor with a power density of $10 \mathrm{MW} / \mathrm{m}^{3}$ would have a volume, core cross-sectional area, and number of fuel pins 3.33 times greater that of a 3,000-MW(t) commercial PWR. Assuming both have the same 3.66- $\mathrm{m}$ core height, then the diameter of the plutonium burner would be $6.62 \mathrm{~m}$, as compared with $3.63 \mathrm{~m}$ for the commercial reactor. Higher costs would be associated with the greater sizes and numbers of components required for a large reactor. However, compensating cost savings would accrue from the reduced construction requirements for a reactor operating at low pressure and temperature. Clearly, cost issues would be a major factor in the reactor design and, therefore, increasing the power density above $10 \mathrm{MW} / \mathrm{m}^{3} \mathrm{might}$ be more appropriate.

Because of its low core flow velocity and operating pressure, the coolant-loop requirements for supplying flow through the recommended reactor core will be different than for a commercial plant. In particular, the low core flow velocity will result in a low core pressure drop. However, because the core flow area is large, the total core volumetric and mass flow rates are large. As a result, the velocities and pressure drops through the noncore portions of the primary coolant system would also be large, and this situation is not compatible with the proposed low-pressure coolant system. Therefore, primary coolant loops appropriate for the recommended reactor would need to be designed for lower velocities and pressure drops than the loops of a commercial power reactor. This would be accomplished by increasing the number of coolant loops, using largerdiameter piping, and designing heat exchangers appropriate for this application.

Consideration was given to the design of a heat exchanger for the recommended reactor concept.
The major constraint on the design of the primary side of the heat exchanger is whether (for a given power and flow rate) a reasonably-sized heat exchanger is capable of rejecting energy at the required rate with a pressure drop within acceptable limits. Initial studies indicate that this is possible. The constraints used in the study are described as follows. It is desired to have the heat exchanger design be as close as possible to conventional nuclear power plant technology so as to reduce any component development cost. Therefore, the heat exchanger should contain about the same number of tubes of about the same diameter and length as commercial power plant steam generators. Energy rejection from the secondary system to the ultimate heat sink should use conventional cooling tower technology, because the secondary system requirements are very close to those of the Advanced Test Reactor.

A heat exchanger design program ${ }^{2}$ was employed to develop a rough design for the recommended reactor. Geometric data for a Babcock and Wilcox PWR once-through steam generator was used as a rough upper limit on heat exchanger size, and the Advanced Test Reactor primary heat exchanger data was used as a basis for a single phase-to-single phase water heat exchanger. The recommended counterflow heat exchanger design features a shell arrangement with a once-through primary flow on the tube side. Nine of these heat exchangers, operating in parallel, would be required, and their total dry weight would be less than that of two Babcock and Wilcox steam genurators. Each heat exchanger would employ 11,4702-cm OD tubes of $7.1-\mathrm{m}$ length; the shell diameter is $3.7 \mathrm{~m}$. Primary and secondary-side inlet/outlet temperatures are $347 / 325 \mathrm{~K}$ and $302 / 333 \mathrm{~K}$, respectively. Primary and secondary-side total mass flow rates are $10,859 \mathrm{~kg} / \mathrm{s}$ and $7,707 \mathrm{~kg} / \mathrm{s}$, respectively. Primary and secondary-side frictional pressure losses are $2.36 \mathrm{kPa}(0.35 \mathrm{psi})$ and $56.7 \mathrm{kPa}$ $(8.2 \mathrm{psi})$, respectively. The model assumed a fouling thermal resistance magnitude of the order of the shell side heat transfer resistance.

Because the primary-system total frictional pressure drops are so small, the recommended reactor concept primary pump requirements 
could be accommodated with multiple low-head centrifugal pumps. Core decay heat removal to the secondary system in the event of a primary pumping power failure would be accomplished by loop natural circulation. Additional failure of the secondary-side pumps would require decay heat removal from the secondary system to be accomplished by (1) secondary-loop natural circulation to the cooling towers, (2) evaporation of the secondary coolant to the atmosphere, or (3) a combination of these two. Option 1 would require the cooling towers to be elevated significantly above the heat exchangers while Option 2 would require an adequate volume of secondary water and a capability for opening the secondary system to the atmosphere. Option 2 appears to be more feasible. For a 1,000-MW reactor, the water volumes required to remove (by evaporation at atmospheric pressure) the decay heat generated over the first hour, day, and week following shutdown are 29,274 , and $1,133 \mathrm{~m}^{3}$, respectively. Assuming this water is stored in a 20-m-diameter cylindrical tank, evaporation of these water volumes would result in tank level declines of 0.093 , 0.873 , and $3.607 \mathrm{~m}$, respectively. These required water volumes are reasonable and, therefore, in the absence of secondary system pumps and assuming an adequate evaporator can be designed, it appears feasible to remove decay heat to the environment through evaporation of the secondary system coolant.

The thermal-hydraulic advantages and disadvantages of the recommended plutonium-burning reactor concept are described as follows:

\section{Hydraulic Stability}

A reactor with vertically-upward flowing core coolant, unconstrained by internal flow channels within the core, has relatively stable hydraulics. Employing a vertical core ensures a potential to initiate and continue buoyancy-driven natural circulation. An upward normal core coolant flow direction avoids any concern of momentary core flow stagnation during transition from forcedconvection to natural-circulation core cooling. A safety margin penalty is incurred with upward core flow because coolant temperatures are highest at the core outlet, and the core outlet pressure is lower (by the static head of water created by the core height) than it is with downward core flow. However, the advantage of avoiding flow stagnation with upward flow outweighs this disadvantage. Employing elevated coolant loop heat exchangers is advantageous because it provides the potential for buoyancy forces to deliver flow through the core in the absence of coolant pump power. An open core flow arrangement (such as employed in commercial PWRs) is advantageous, compared to one where core flow is channelized, because issues associated with flow instability in parallel heated channels are avoided. With channelized flow, thermal hydraulic design must avoid hot-channel boiling. If the coolant boils, the hot-channel hydraulic resistance increases and its flow decreases, an unstable condition that leads to fuel bumout. An open core flow arrangement is preferred because the hydraulic effects of boiling are averaged across the entire core. As a result, the hydraulic stability safety limits for an open rure are much less restrictive than for a channeli, $\mathrm{u}$ core.

\section{Heat Flux}

A low-power-density design directly leads to a low fuel rod-to-coolant heat flux in normal operation. A low heat flux is important because the margin between it and the critical heat flux (exceeding the critical heat flux would result in fuel rod heat-up) is increased. The critical heat flux itself is adversely affected by the use of low core coolant pressure and velocity. However, employing a low temperature core coolant results in a compensating beneficial effect. A cursory evaluation of the critical heat flux using the Bernath correlation ${ }^{4}$ for the conditions of the recommended reactor indicates a ratio of critical to average fuel rod heat fluxes of 68.7. Assuming a maximum-to-average heat flux ratio of 3.33 , this provides a minimum departure from nucleate boiling ratio (DNBR) of 20.6. For a commercial PWR, the minimum DNBR is about 2 . This demonstrates one safety advantage of the recommended reactor concept. 


\section{Low Temperature}

A reactor operating with low temperature coolant features low coolant and structure stored energy. This feature is advantageous from the perspective of containment requirements. The containment must be designed to absorb any energy release from the reactor system. In normal operation, the energy release rate is low, due mainly to piping heat losses, but nevertheless it must be accommodated with containment coolers. During a loss-of-coolant accident event, the energy release rate is high because of expulsion of primary coolant, and the containment must be designed to absorb this energy without leaking to the environment. The recommended design is advantageous in both of these respects: lower containment cooling costs during normal operation and significantly lower costs associated with constructing a containment capable of withstanding the loss-of-coolant accident loading.

The main disadvantage of a low-ternperature reactor is that the temperature of the coolant is not sufficiently high to efficiently produce electricity with the core power, and heat rejection is more difficult. Therefore, the recommended concept is not suitable if electric power generation is a reactor design goal; the adverse cost implications of this limitation are obvious. The recommended reactor would, however, still produce a high thermal power that must be removed. It may be possible to find otherwise useful applications for this low temperature process heat. In any event, the total core power must either be used or expelled to the environment.

\section{Low Pressure}

A low-pressure core coolant system yields two significant safety advantages over a high pressure system (a) reduced risk because of coolant system depressurization events and (b) compatibility with passive safety injection systems.

For most existing reactors, the risks associated with depressurization events (primarily loss-ofcoolant accidents, but also other accidents and operational transients) are significant contributors to the overall safety risk. The low-pressure design of the recommended concept is advantageous because coolant system pressure is supplied solely by gravity force. Additionally, because the recommended concept employs lowvelocity coolant, pressure does not vary significantly around the coolant loop. Therefore, when compared with high pressure designs, the core pressure for the recommended concept can be expected to remain much more stable during transients and accidents. Pressure stability is important because safety margins generally decline along with the coolant system pressure. To the extent that normal core operating pressure can be maintained, then safety can be enhanced. Therefore, the recommended design has safety advantages because the core pressure is relatively insensitive to external events (such as rupture of piping or loss of pumping power).

A low-pressure coolant system also is advantageous because replenishment of core coolant invent ory can be accomplished with passive safety injection systems. With a high pressure system, safety injection must be accomplished with active components such as centrifugal pumps. Thus, failure of these active components must be accounted for when evaluating risk. With a low-pressure system, a tank of water that is elevated above the primary coolant system is capable of injecting coolant into the system. The probability of failure in such an injection system is significantly less than that of the typical active system.

As previously discussed, one disadvantage of a low-pressure system is that critical heat fluxes are lower than for a pressurized system. However, the low temperature feature of the recommended concept has proven to compensate for this effect. Another disadvantage of a low-pressure system is that the saturation temperature is also low. However, the saturation temperature rises rapidly with pressure. For example, saturation temperature at atmospheric pressure is $372.8 \mathrm{~K}$, but rises to $393.4 \mathrm{~K}$ at twice that pressure. Significant increases in the saturation temperature and the safety margins based upon it may be realized with relatively minor increases in system pressure. In 

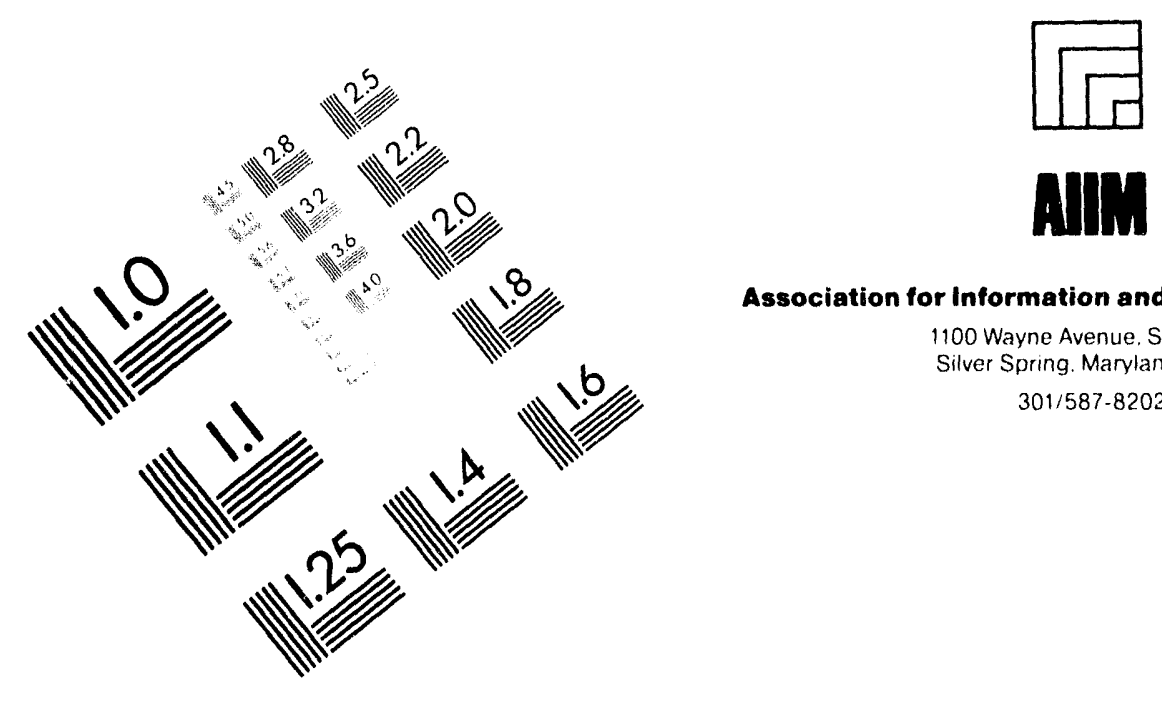

Association for Information and Image Management

1100 Wayne Avenue. Sulte 1100
Silver Spring. Maryland 20910

301/587-8202

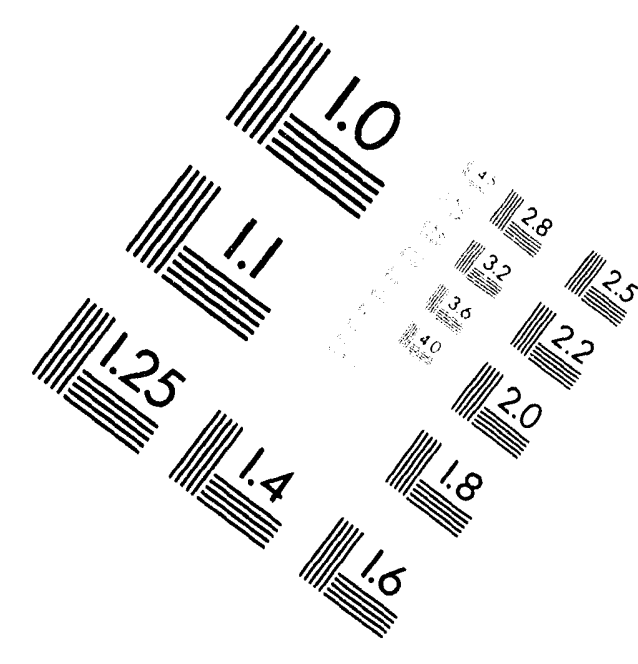

\section{Centimeter}

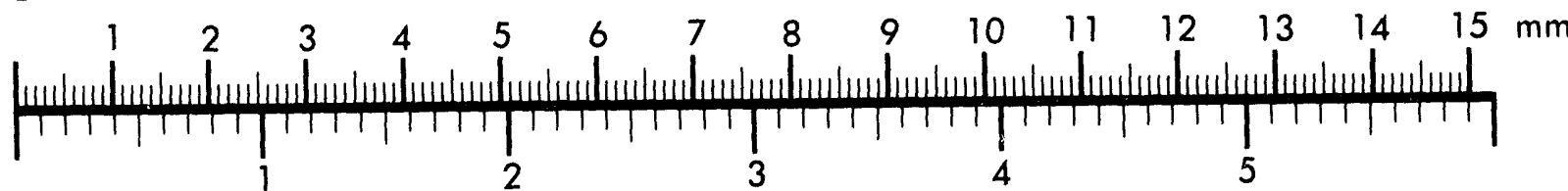

Inches
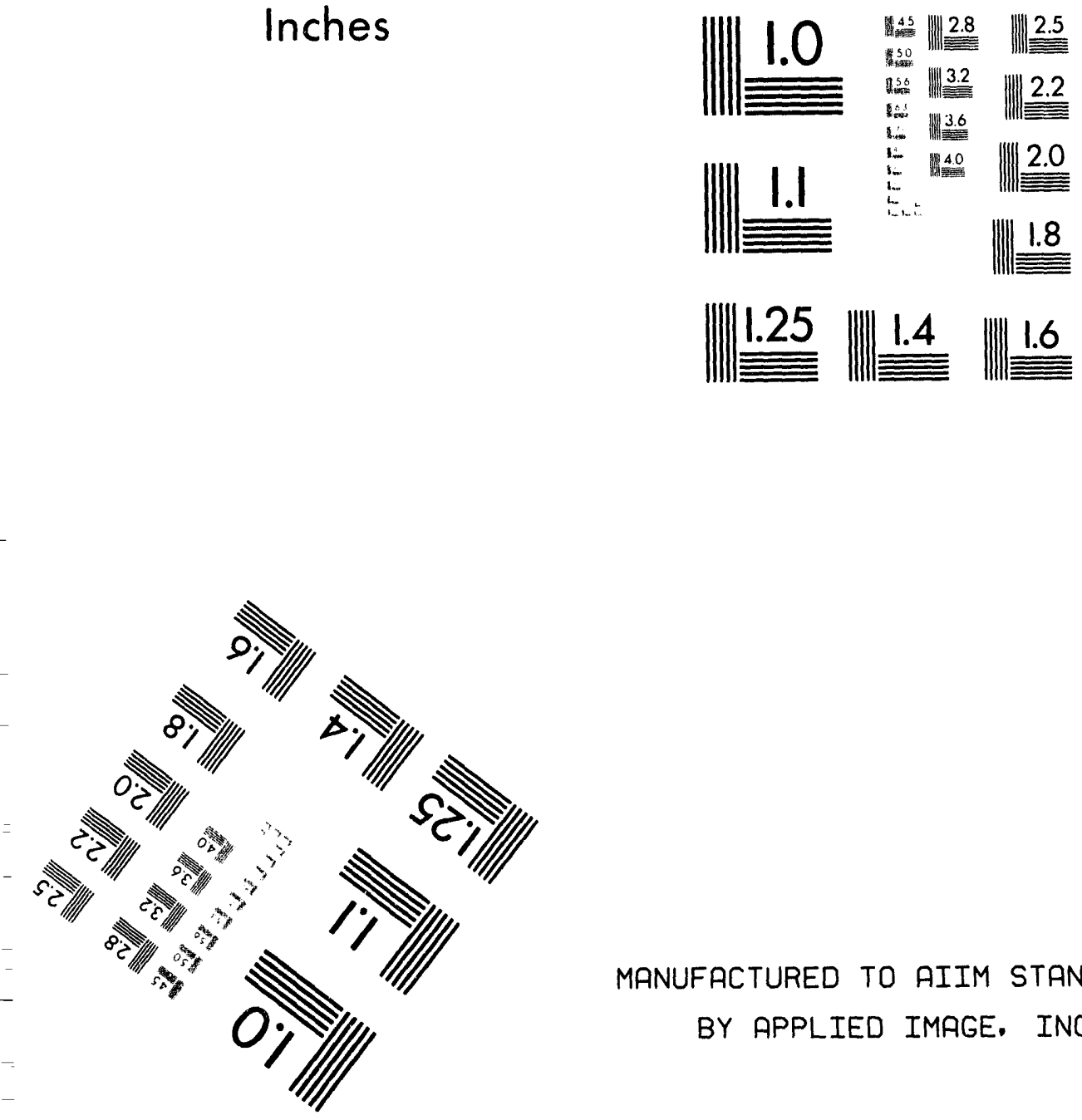

MANUFACTURED TO AIIM STANDARDS

BY APPLIED IMAGE. INC.

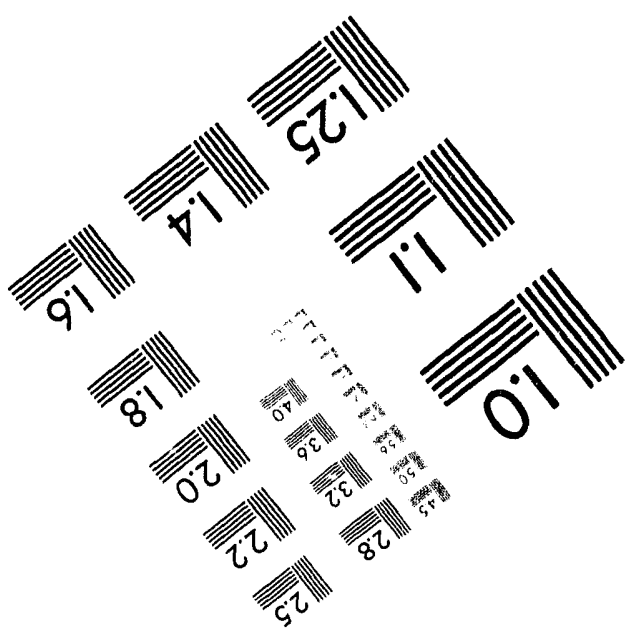



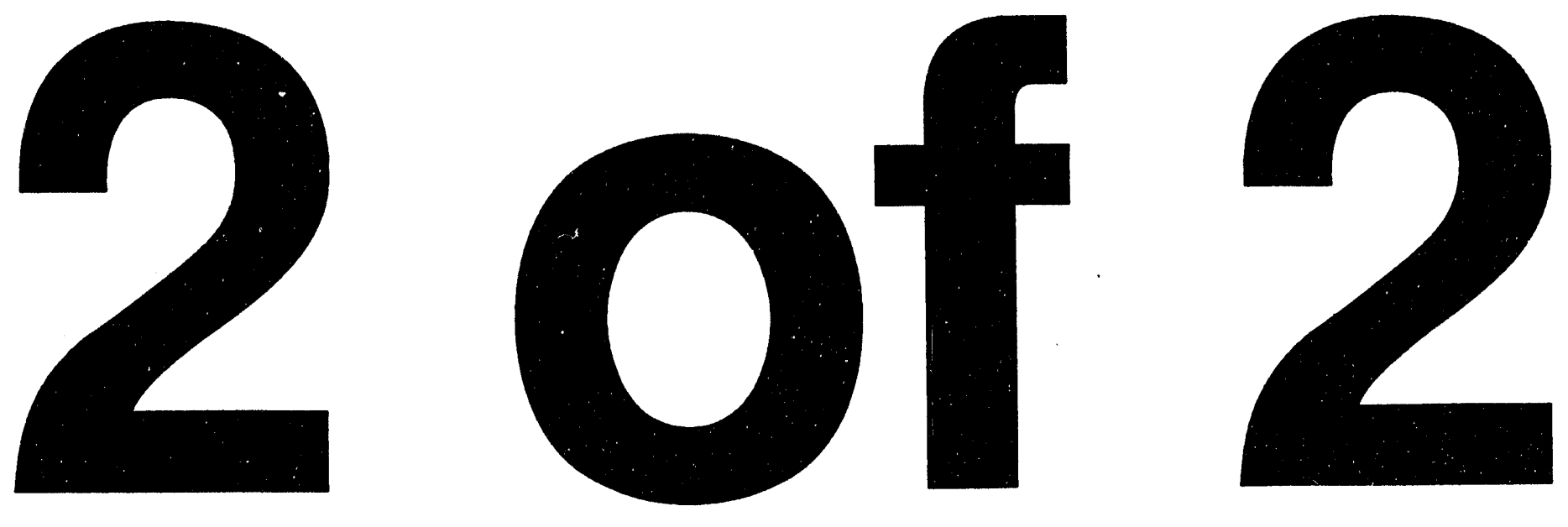
this example, the pressure increase can be accomplished with the gravity head of a water column with a height of only about $10 \mathrm{~m}$. Therefore, passively pressurizing the recommended reactor in such a manner appears to have significant advantages.

\section{Low Core Flow Velocity}

With the recommended core and coolant loop configurations, the frictional pressure losses around the primary coolant loop are minimized. This effect reduces the core pressure variation caused by events affecting the core flow rate (for example a loss of pump power), which enhances safety. However, for any coolant system that employs forced-convection core cooling, it is expected that the loss-of-flow event will be a significant contributor to overall risk. As with existing reactors, this risk can be minimized by ensuring the core flow remains near normal until reactor scram can decrease the core power to the decay heat generation rate. The elevated heat exchangers of the recommended design should be effective for removing decay heat under loop natural circulation conditions.

One disadvantage of a low-velocity coolant system is that critical heat fluxes are lower than for a high velocity system. However, the low temperature feature of the recommended concept has proven to compensate for this effect. 


\section{E-5. EXPLORING THE POTENTIAL FOR PROVIDING CORE FLOW WITH A NATURAL CIRCULATION COOLANT SYSTEM}

The recommended plutonium-burning reactor features a low velocity core flow that appears to be easily attainable with the conventional cooling system technology of commercial power reactors. Specifically, at the suggested coolant velocity, the primary loop frictional pressure drop is quite low and, thus, forced core flow requirements may be met with relatively low-head centrifugal coolant pumps. For example, for a commercial PWR in normal operation, the reactor coolant pumps are required to produce a pressure increase of 0.65 $\mathrm{MPa}$ to overcome the frictional pressure drop of the entire coolant loop (core, reactor vessel, steam generator primary, piping, and fittings). As previously discussed, for the recommended reactor the core frictional pressure drop is about $2.7 \mathrm{kPa}$ and the heat exchanger frictional pressure drop is about $2.4 \mathrm{kPa}$. The frictional pressure drop through the remaining loop piping is estimated at $2.3 \mathrm{kPa}$. This estimate is based on nine coolant loops with hot and cold legs that are each $20 \mathrm{~m}$ long and constructed from $0.762-\mathrm{m}$ diameter pipes. Therefore, for the recommended reactor concept the total loop frictional pressure drop, required to be compensated for with the pumps, is only $7.4 \mathrm{kPa}$, or $0.0074 \mathrm{MPa}$, about $1 \%$ of a PWR value.

Because of the modest pressure increase needed to force the primary coolant flow, a possible alternative to coolant pumps for providing the core flow for a plutonium-burning reactor might be a natural circulation coolant loop arrangement. A natural circulation cooling system would be advantageous because core cooling would be provided passively, by gravity. The safety advantage of such a system is that the probability of loss-of-core-flow events is greatly diminished over that for coolant systems that are driven with pumps.

A natural circulation loop takes advantage of the density difference between fluids in the core outlet and inlet piping to provide a buoyancydriven flow around the loop. Only the vertical sections of the coolant loop are important for determining the driving pressure. In particular, the driving pressure is directly proportional to the elevation rise and the fluid density differences from the heating center (in the core) to the cooling center (in the heat exchanger). Note, however, that the driving pressure must vivercome the frictional pressure drop of both the horizontal and vertical sections of the cooling loop plus any lumped flow resistances (such as due to piping bends and fittings). To a first approximation, the driving pressure available in a natural circulation loop may be calculated simply by multiplying together (1) the difference in densities between the fluids in the core outlet and inlet piping, (2) the acceleration because of gravity, and (3) the elevation rise from the heating center to the cooling center. Factor 1 is inversely proportional to the flow rate (that is, a higher flow rate results in a lower density difference), while the driving pressure required to force flow around the loop is roughly proportional to the square of the flow rate. Therefore, the loop natural circulation flow rate is determined solely by the geometry of the coolant loop and the rate at which it is transporting heat.

The viability of removing core thermal powers on the order of $300 \mathrm{MW}$ with natural circulation cooling systems is demonstrated by decay heat removal without benefit of primary coolant pump power in commercial PWRs. However, employing a natural circulation cooling system as a primary means of heat removal for a reactor with a rated thermal power of $1,000 \mathrm{MW}$ is believed to be unprecedented.

For the recommended reactor concept, the density difference is $11.82 \mathrm{~kg} / \mathrm{m}^{3}$. The required driving pressure has been estimated at $0.0074 \mathrm{MPa}$. For these assumptions, a natural circulation system would require an elevation rise from heating to cooling center of $63.9 \mathrm{~m}$ and it might be unreasonable for a system this tall to be located within a containment. Therefore, employing a natural circulation cooling system might not be feasible. However, the parameters listed in Table E-3 represent only first suggestions, and this design 
appears to have rather large safety margins as compared with existing plants. Furthermore, the required natural circulation system height is particularly sensitive to the system flow rate. For example, assume that lowering the flow rate by $50 \%$ from that shown in Taulc E-2 still results in acceptable safety margins. With the $50 \%$ flow reduction, the density difference is doubled, the required driving pressure is reduced by a factor of about four, and the required elevation rise is reduced to only about $8 \mathrm{~m}$. Under this flow assumption, therefore, a natural circulation system for primary core cooling appears feasible.

Designing a system for natural circulation cooling weuld require constructing as tall of a system as practical and with as low a flow resistance as possible. Seismic risk may limit attempts to increase the elevation difference. Attempts to lower the flow resistance generally will involve employing larger diameter piping, and this approach would have cost disadvantages (although these might be offset to some extent because of the low-pressure design). If the feasibility of a natural circulation cooling system can be demonstrated, then the tradeoff appears to be whether its net safety advantages over a pumped system would be worth its net added cost.

The following incomplete study is offered as an initial investigation into the viability of a natural circulation cooling system for a plutoniumburning reactor. If there is interest in the advantages such a system would offer, this study will be extended.

An initial study regarding feasibility of normal-operation natural circulation cooling for a plutonium-burning reactor was performed using a simple but informative model of a natural circulation loop consisting of a reactor core and heat exchanger as depicted in Figure E-1, except with the pump removed. As there are many core and coolant loop parameters that remain to be selected, it was decided to base this study on the configuration of a commercial PWR (same fuel pin diameter and pitch, same number of fuel pins, same number and geometry for the coolant loops and heat exchanger tubes. However, this configuration was elongated, such that the heating/cooling center elevation gain is $30.48 \mathrm{~m}(100 \mathrm{ft})$. These decisions were made because (a) it was anticipated that a greater elevation gain would be needed in order to approach 1,000 MW heat removal capacity, (b) the base configuration has proven itself for removing decay heat rates of hundreds of megawatts in commercial power plants, and (c) the total coolant loop resistance for the base configuration was conveniently available.

The mass flow rate in a natural-circulation loop can be determined from the following equation ${ }^{3}$ :

$\dot{m}=\left[\frac{2 \beta \Delta T g \Delta L}{R} \mathrm{Q}_{\mathrm{o}}^{2}\right]^{\frac{1}{2-n}}$

where

$\beta=-\frac{1}{\varrho}\left(\frac{d \varrho}{d T}\right) \approx \frac{\left|\varrho_{\text {inlet }}-\varrho_{\text {inlet }}\right|}{\varrho_{\text {ave }} \Delta T}$

and $\Delta T$ is the temperature difference across the core of the reactor, $g$ is the acceleration because of gravity, $\varrho o$ is the fluid density at the core inlet, $R$ is the loop hydraulic-resistance constant, $\mathrm{n}$ is $\mathbf{0 . 2}$ for turbulent flow, and $\Delta L$ is the elevation difference between the thermal center of the core and the thermal center of the heat exchanger. The subscripts, "inlet" and "outlet," refer to the inlet and outlet of the core.

Using typical full power operating conditions for a commercial PWR, such as reported in Table 3-1 of Reference 4, the loop hydraulic resistance may be determined from

$R=\frac{\Delta p_{f} \varrho_{l}}{\frac{1}{2} \dot{m}^{2-n}}$

where $\Delta \mathrm{P}_{f}$ is the total friction-related pressure drop in the loop, and $\rho_{1}$ is the liquid density, taken for this case to be the density of the coolant at the inlet to the core. Using information from Reference 4, the total loop hydraulic resistance $R$ was assumed to be $24.2 \mathrm{~kg} 0.2 / \mathrm{s}^{0.2} \mathrm{~m}^{4}$. Note that $R$ 
was not increased to account for increasing the elevation gain; however, this effect is minor. Equation (1) can be used in conjunction with algebraic equations relating the temperature rise across the core to the average power density of the fuel and the core flow to evaluate the feasibility of designing a reactor that operates on loop natural circulation.

The reactor design is assumed to have a power of 1,000 MW(t), and a peak-to-average core power density ratio of 2.4 . The maximum fuel cladding temperature has been constrained to be less than the minimum saturation temperature of the coolant within the core. The core outlet temperature also has been constrained to be at least $10 \mathrm{~K}$ below the minimum coolant saturation temperature. These constraints are not necessarily optimum, and for safety reasons may need to be reduced. However, they represent reasonable estimates that allow investigation of the overall performance of a natural circulation reactor coolant system. A core inlet temperature of $325 \mathrm{~K}$ was assumed.

The system of equations used to evaluate the natural circulation option is described as follows. The heat transferred from the surface of the fuel cladding to the bulk coolant is

$$
q^{\prime}=2 \pi r_{c o} h\left(T_{c o}-T_{a v e}\right)
$$

where $q^{\prime}$ is the maximum linear power in the core, $r_{c o}$ is the outside radius of the cladding, $h$ is the cladding-to-coolant heat transfer coefficient, $T_{c o}$ is the surface temperature of the cladding, and $T_{\text {ave }}$ is the bulk temperature of coolant. The average internal heat generation rate of the core is

$$
q^{\prime \prime \prime}=\frac{q^{\prime}}{A_{f} F}
$$

where $A_{f}$ is the cross-sectional area of the fuel and $F$ is the maximum peaking factor in the core. The heat transfer coefficient in Equation (4) is calculated using the Dittus-Boelter equation:

$$
N u_{D_{h}}=\frac{h D_{h}}{k}=0.023 \operatorname{Re}_{D_{h}}^{0.8} \operatorname{Pr}^{0.4}
$$

where $R e$ is the Reynolds number, $P r$ is tive Prandtl number, $D_{h}$ is the hydraulic diameter of a single core flow channel, and $k$ is the thermal conductivity of the coolant evaluated at the average fluid temperature (assumed to be the average of the core inlet and outlet temperatures).

The coolant outlet temperature can be calculated using the following equation:

$$
T_{o}=\frac{q^{\prime \prime \prime} A_{f} H_{\text {core }}}{\dot{m} C_{p}}+T_{i}
$$

where $T_{o}$ is the coolant outlet temperature, $H_{\text {core }}$ is the height of the core $(3.66 \mathrm{~m}), C_{p}$ is the specific heat of the coolant, evaluated at its average temperature, and $T_{i}$ is the coolant inlet temperature. The surface temperature of the cladding adjacent to the flowing coolant is

$$
T_{c o}=\frac{q_{\max }^{\prime}}{2 \pi r_{c v} h}+T_{a v e} .
$$

The cladding temperature at the inner diameter of the cladding is

$$
T_{c i}=\frac{q^{\prime} \ln \left[\frac{r_{c o}}{r_{c i}}\right]}{2 \pi k_{c}}+T_{c o}
$$

where $r_{c i}$ is the inner radius of the cladding and $k_{c}$ is the thermal conductivity of the cladding.

The fuel pin used for this evaluation is assumed to have a $0.082-\mathrm{mm}$ gas-filled gap, which is typical of a standard commercial pressurized PWR fuel pin. A gap conductance of $5676 \mathrm{~W} / \mathrm{m}^{2}-\mathrm{K}$ was assumed. Therefore, the temperature of the outer fuel surface is

$$
T_{f o}=\frac{q^{\prime}}{h_{g a p} 2 \pi r_{f}}+T_{c i} .
$$

With the fuel surface temperature and internal heat generation rate known, the fuel centerline temperature is calculated from: 


$$
T_{f c l}=\frac{F q^{\prime \prime \prime} r_{f}^{2}}{4 k_{f}}+T_{f o}
$$

where $\mathrm{F}$ is the peaking factor and $k_{f}$ is the thermal conductivity of the fuel.
Equations (1), (2), and (4) through (11) were solved simultaneously, subject to the two constraints listed above, using the simultaneous equation solver in Mathcad. ${ }^{5}$ The results obtained with this model are summarized in Table E-4 for eight different cases. 
Table E-4. Thermal-hydraulic results for a natural-circulation-cooled, plutonium-burning reactor concept.

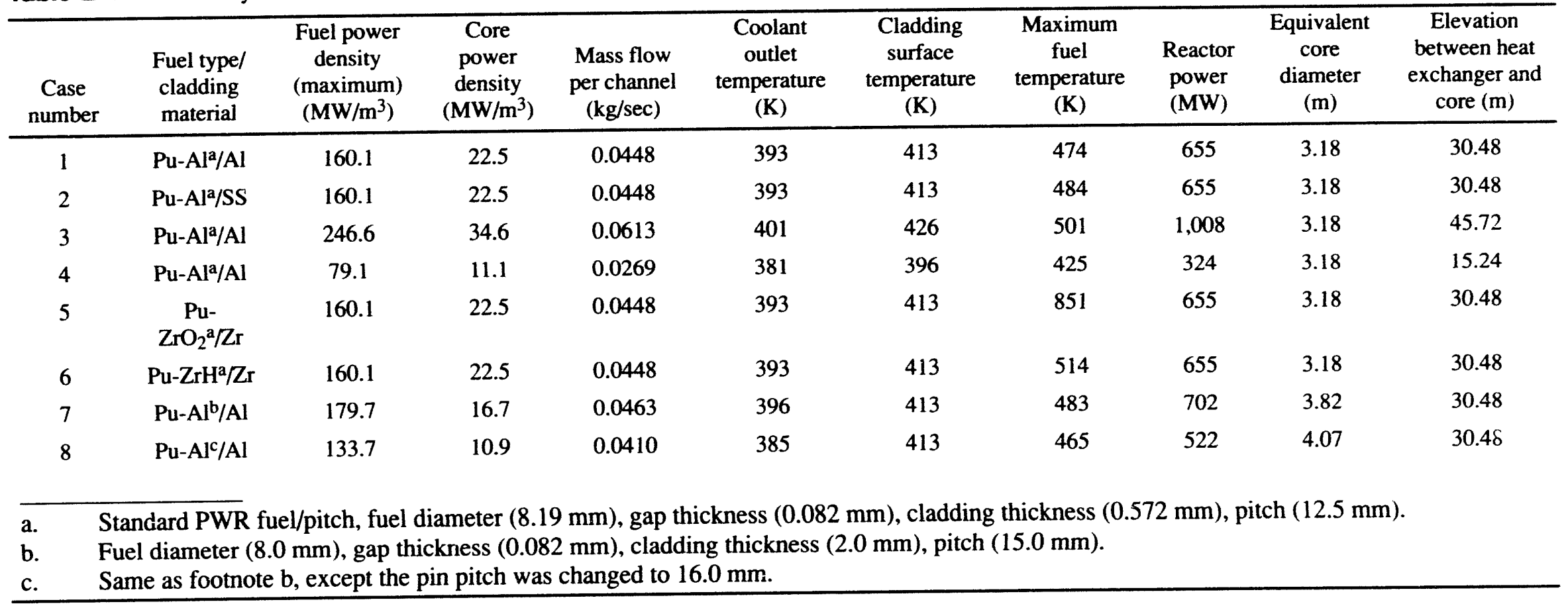


Case 1 uses the same fuel rod diameter and pitch as for a commercial PWR but the rod was assumed to be composed of plutonium-aluminum fuel clad with aluminum. A core inlet pressure of $0.398 \mathrm{MPa}$ (57.7 psia) was assumed, based on an atmospheric pressure condition at the top of the heat exchanger and the gravity-generated static pressure head at the core inlet. Case 1 shows the standard, but elongated, reactor configuration is capable of removing $655 \mathrm{MW}$ under the assumed constraints.

The core power density would be 22.5 $\mathrm{MW} / \mathrm{m}^{2}$, the coolant outlet temperature would be $393 \mathrm{~K}$, and the maximum fuel temperature would be $474 \mathrm{~K}$ (assuming a 2.4 peak-to-average fuel power density ratio). The core flow velocity associated with the $0.0448 \mathrm{~kg} / \mathrm{s}$-per-fuel rod mass flow rate is $0.539 \mathrm{~m} / \mathrm{s}$.

Case 2 evaluated the increased fuel centerline temperature that would result if aluminum cladding is replaced with stainless steel. The results indicate that using stainless steel cladding will only cause the fuel centerline temperature to increase by $10 \mathrm{~K}$ above that obtained with aluminum cladding. Thus, at these low fuel power densities it makes little difference from a thermal-hydraulic viewpoint what cladding material is used for the fuel pin.

Cases 3 and 4 evaluated the influence of varying the elevation difference between the core and heat exchanger. In Case 3, the elevation difference was increased to $45.72 \mathrm{~m}(150 \mathrm{ft})$. This change increased the core inlet pressure to $0.546 \mathrm{MPa}$ (79.2 psia) and allowed the maximum cladding surface temperature to rise from $413 \mathrm{~K}$ to $426 \mathrm{~K}$, the minimum core saturation temperature at this higher pressure. The Case 3 results show the natural circulation system is capable of removing 1,008 MW and that is more than the $1,000-\mathrm{MW}$ goal. The resulting core power density would be $34.6 \mathrm{MW} / \mathrm{m}^{3}$. Case 4 performed a similar evaluation for reducing the elevation difference to $15.24 \mathrm{~m}(50 \mathrm{ft})$. This reduction lowered the maximum allowable cladding temperature to $396 \mathrm{~K}$ and the heat removal capability to only $324 \mathrm{MW}$.

Cases 5 and 6 evaluated the effects of changing the fuel material from plutonium in aluminum to plutonium in $\mathrm{ZrO}_{2}$ and $\mathrm{ZrH}_{1.6}$, respectively. The cladding material for both of these cases was assumed to be zircaloy. Results for Cases 5 and 6 were identical to those for Case 1, except the fuel centerline temperature increased to $851 \mathrm{~K}$ with the plutonium $-\mathrm{ZrO}_{2}$ fuel and to $514 \mathrm{~K}$ with the plutonium- $\mathrm{Zr}_{1.6}$ fuel. These centerline temperatures are very much below the respective fuel melting temperatures and, therefore, it appears from a thermal-hydraulic viewpoint that plutonium fuels based in zirconium could be used in a natural-circulation reactor concept.

Cases 7 and 8 evaluated the effects of changing the fuel rod diameter and pitch as compared with Case 1 (which employed typical commercial PWR geometry). For Cases 7 and 8 it was assumed that the fuel pellet diameter was $8 \mathrm{~mm}$, with a $0.082-\mathrm{mm}$ gap width and a $2-\mathrm{mm}$ cladding thickness (the corresponding typical-reactor values are $8.19 \mathrm{~mm}, 0.082 \mathrm{~mm}$, and $0.572 \mathrm{~mm}$, respectively). Fuel rod pitches of $15 \mathrm{~mm}$ and $16 \mathrm{~mm}$ were evaluated. The larger pin diameters and pitches in Cases 7 and 8 resulted in lower core power densities than did the standard geometry in Case 1, and the core power removal capabilities indicated for Cases 7 and 8 bracket that in Case 1 . Thus, for a given pin diameter, there appears to be a pitch-to-diameter ratio that would optimize core power density and limit the physical size of the reactor.

The studies presented in this section indicate that a natural-circulation cooling system might be a viable option for providing the core flow for the recommended plutonium-burning reactor. Although these studies used simple models and hand calculations, it is believed that the findings are indicative of what would be seen if more detailed calculations were made. It should be noted that the results presented are based on a total loop hydraulic resistance corresponding to a that of a typical PWR coolant loop. If a reactor coolant system (both the core and loops) were designed primarily for natural-circulation operation, then the total loop hydraulic resistance likely could be made significantly smaller. Equation (1) shows that lowering the hydraulic resistance will increase the core mass flow rate, thus allowing a more compact reactor to be constructed. 


\section{E-6. SUMMARY}

A very safe low-power-density, plutoniumburning reactor that is cooled with low-temperature, low-pressure light water flowing at low velocity is recommended. The current recommendation for providing primary coolant system flow is to employ low-head pumps. However, additional safety advantages appear to be attainable if a natural circulation cooling system could be employed. Initial investigations into this possibility have not yet excluded it from consideration.

The recommended reactor concept is shown to have multiple thermal-hydraulic and safety advantages over most existing test and commercial reactor designs: (a) the margin to critical heat flux is very large, (b) the times required to raise fuel temperatures to damage and melting points are long, (c) vertically upward flowing coolant in the core ensures initiation and continuation of natural circulation core cooling should the primary coolant pumps fail, (d) the open, nonchannelized, core flow arrangement diminishes safety issues associated with flow instability, (e) the low coolant and structure stored energy minimize the requirements placed on the containment, and (f) the low-pressure coolant system significantly reduces the safety risk because of loss-of-coolant accidents and is compatible with passive safety injection systems. 


\section{E-7. REFERENCES}

1. E. P. Hicks and D. C. Menzies, "Theoretical Study on the Fast Reactor Maximum Accidents," Proceedings of Conference on Safety, Fuels, and Core Design in Large Fast Power Reactors, ANL-7120, Argonne National Laboratory, October 1965.

2. Heat Transfer Research, Inc., ST-2 Program Manual, 1987.

3. J. R. Lamarsh, Introduction to Nuclear Engineering, 2nd ed., Addison-Wesley Publishing Company, Reading, Massachusetts, 1983, p. 381.

4. N. E. Todreas and M. S. Kazimi, Nuclear Systems II-Elements of Thermal Hydraulic Design, New York: Hemisphere Publishing Corp., 1990.

5. Mathcad, Version 3.1, Cambridge, Massachusetts: MathSoft, 1992. 


\section{Appendix F}

Evaluation of Offsite Releases 


\section{Appendix F}

\section{Evaluation of Offsite Releases}

An evaluation was performed to assess the effects of a plutonium-based reactor on offsite doses in the vicinity of the reactor. This evaluation was performed using the PCDOSE ${ }^{1}$ and RSAC $^{2}$ cornputer codes. The PCDOSE code was developed for the Nuclear Regulatory Commission (NRC) to calculate offsite doses around commercial reactor facilities. The RSAC code can be used to calculate doses to the public as a result of commercial reactor accidents.

To compare the differences in the relative dose impacts of ${ }^{235} \mathrm{U}$ and ${ }^{239} \mathrm{Pu}$ fueled reactors without developing reactor specific accident scenarios, equivalent quantities of ${ }^{235} \mathrm{U}$ and ${ }^{239} \mathrm{Pu}$ were assumed to be released from a plant vent as aerosols as the result of an explosive release. Standard atmospheric dispersion factors, site boundaries, and dose factors were used for the calculations.

Table F-1 lists the calculated doses at a standard facility boundary using the PCDOSE code. As indicated, the dose impact of $1 \mathrm{~kg}$ of ${ }^{239} \mathrm{Pu}$ is significantly greater (6 to 7 orders of magnitude) than the release of a similar quantity of ${ }^{235} \mathrm{U}$. ${ }^{235} \mathrm{U}$ is a worst case estimate for uranium-fueled reactors as the ${ }^{238} \mathrm{U}$ component $(97 \mathrm{wt} \%)$ has a lower dose impact (approximately $10 \%$ of ${ }^{235} \mathrm{U}$ ).
The principal organ dose because of ${ }^{239} \mathrm{Pu}$ is to the bone. When the bone is the principal organ, ingestion and transfer to the bone is assumed.

Dose impacts were calculated using the RSAC code to assess the differences in the worker $(100 \mathrm{~m})$ and public $(500 \mathrm{~m})$ doses. This assessment indicates that the differences in the dose impact were similar to those calculated using the PCDOSE code and that there is a substantial difference in the dose impact of the two radionuclides. However, as discussed below, the dose from the fissile material is not the controlling dose at the site boundary.

In addition to the dose because of the release of fissile material, the dose impact of the fission products present in $1 \mathrm{~kg}$ of ${ }^{235} \mathrm{U}$ or ${ }^{239} \mathrm{Pu}$ was also calculated to assess the relative impact of a plutonium-fueled reactor on the total dose to the environment. The fission yields were assumed to be the same for this analysis. Nominally, doses to the various organs and the whole body because of ${ }^{239} \mathrm{Pu}$ are $<1 \%$ of the total dose. The principal organ for the total dose is again the bone. Therefore, compared with the fission products in spent fuel, the plutonium dose and source term are small. 
Table F-1. Offsite dose impacts of ${ }^{239} \mathrm{Pu},{ }^{235} \mathrm{U}$ and mixed fission products.

\begin{tabular}{|c|c|c|c|c|c|c|c|}
\hline \multirow[b]{2}{*}{ Radionuclide } & \multicolumn{7}{|c|}{ Dose at site boundary } \\
\hline & Bone & Liver & Total body & Thyroid & Kidney & Lung & $\mathrm{Gi} / \mathrm{Li}$ \\
\hline \multicolumn{8}{|l|}{ mrem/kg } \\
\hline${ }^{239} \mathrm{Pu}^{\mathrm{a}}$ & $5.2 \times 10^{3}$ & $6.8 \times 10^{2}$ & $1.3 \times 10^{3}$ & ${ }^{b}$ & $5.3 \times 10^{2}$ & $2.6 \times 10^{2}$ & $1.0 \times 10^{2}$ \\
\hline${ }^{235} \mathrm{U}^{\mathrm{a}}$ & $7.7 \times 10^{4}$ & $-^{b}$ & $1.4 \times 10^{4}$ & $-^{b}$ & $1.7 \times 10^{4}$ & $4.2 \times 10^{4}$ & $6.6 \times 10^{-5}$ \\
\hline F.P. release ${ }^{c}$ & $1.1 \times 10^{6}$ & $3.3 \times 10^{4}$ & $3.1 \times 10^{5}$ & $1.5 \times 10^{4}$ & $1.2 \times 10^{4}$ & $7.5 \times 10^{3}$ & $9.7 \times 10^{5}$ \\
\hline \multicolumn{8}{|l|}{ mrem/curie } \\
\hline${ }^{235} \mathrm{U}$ & 5.1 & $\sim^{b}$ & $9.2 \times 10^{-1}$ & - $^{\mathbf{b}}$ & 1.2 & 2.6 & $4.4 \times 10^{-1}$ \\
\hline${ }^{239} \mathrm{Pu}$ & $1.8 \times 10^{2}$ & $2.4 \times 10^{1}$ & 4.6 & $-^{b}$ & $1.9 \times 10^{2}$ & 9.7 & $3.5 \times 10^{-1}$ \\
\hline
\end{tabular}

a. Dose impact of $1 \mathrm{~kg}$ of ${ }^{239} \mathrm{Pu}$ or ${ }^{235} \mathrm{U}$ at the site boundary when released from a ground level release location. Calculations were not made for ${ }^{238} \mathrm{U}$ because the dose impact of this radionuclide would be significantly less than the dose impact of the ${ }^{235} U$ because of the lesser specific activity. The listed dose is the dose to the adult, doses to children and infants may be higher.

b. No measurable dose to this organ.

c. Dose because of principal fission products present in $1 \mathrm{~kg}{ }^{235} \mathrm{U}$ or ${ }^{239} \mathrm{Pu}$ with a fuel burnup near midcore life. Dose after a 10-hour cooldown to minimize parent daughter corrections. Radionuclides included are ${ }^{137} \mathrm{Cs},{ }^{90} \mathrm{Sr} / \mathrm{Y},{ }^{144} \mathrm{Cd} / \mathrm{Pr},{ }^{95} \mathrm{Nb},{ }^{95} \mathrm{Zr},{ }^{91} \mathrm{Y},{ }^{141} \mathrm{Cd},{ }^{89} \mathrm{Sr},{ }^{140} \mathrm{La} / \mathrm{Ba},{ }^{143} \mathrm{Pr},{ }^{103} \mathrm{Ru},{ }^{131} \mathrm{I},{ }^{106} \mathrm{Ru} / \mathrm{Rh}$, and ${ }^{129} \mathrm{Te}$.

d. For comparison purposes the dose resulting from a curie of each radionuclide is presented. The much higher specific activity of the ${ }^{239} \mathrm{Pu}$ reduces the dose per curie. 


\section{REFERENCES}

1. Calculation of Annual Doses to Man from Routine Releases of Reactor Effluents for the Purpose of Evaluation Compliance with 10 CFR Part 50, Appendix 1, Regulatory Guide 1.109 Rev. 1, October 1977.

2. D. R. Wenzel, "Radiological Safety Analysis Center Computer Program (RSAC-4) Rev. 4," Westinghouse Idaho Nuclear Company, April 1990. 
Appendix G Economics 


\section{Appendix G}

\section{Economics}

Costs associated with construction, operation, decontamination and decommissioning, as well as waste processing and disposal, must be considered for all facilities. These nuclear facility costs demand that methods, processes, and requirements be critically reviewed and improved if these facilities are to be affordable in the future. Cost-reduction ideas for these concepts must be developed and implemented.

Because concept development has just begun, there is no baseline configuration. Without this configuration, costs cannot be estimated. Insights are presented regarding potential cost savings that are useful to guide the design.

As discussed in the "Introduction," at the request of NAS, the INEL is focusing only on the main goal: destruction of total plutonium as rapidly as possible. Because the reactor concept will not generate electricity, a major source of revenue is lost. Although revenue is not generated from the sale of electricity, capital costs are reduced by eliminating turbines, generators, some support facilities, some backup safety systems, and a thick pressure vessel. Reactor containment costs are reduced. The reactor design becomes simpler and more flexible, which reduces capital and operations costs.

Other sources of revenue could be generated. For example, this concept could produce tritium, medical isotopes, or other beneficial isotopes. Excess core reactivity exists to support these missions. However, the reactor cycle length could be a few years, and most isotope production requires shorter residence times. Rabbit tubes and the capability for online target insertion and removal could be developed. However, that development would require extra design time. For now, a concept is being designed to achieve the main mission in the best way possible.

One cost concern was mentioned specifically by the NAS: the cost of fuel fabrication. As mentioned in Appendix D, burnable poisons will be added to the reactor to hold down core reactivity (to allow a higher plutonium density and a longer cycle length) and to improve the temperature coefficients of reactivity. Thus, cycle lengths longer than one year and possibly much longer are expected. This reduces fuel fabrication costs. The INEL is not familiar with the proposed processes to extract plutonium from the weapon pits. Overall, fuel fabrication costs are not expected to be a large part of the total costs. In particular, no clear cost advantage is seen with any of the fuel types being examined. Because of the brief nature of this study, these fabrication costs have not been explored in detail.

At this stage in the preconceptual design effort, it is important to look at the overall process. A broad set of cost concerns and develop costreduction ideas that address those concerns must be examined. As a first step, lists of concerns and ideas from the ongoing Broad Application Test Reactor design at the INEL $^{1}$ have been used. These lists were modified as appropriate for the plutonium-burning reactor, and are presented below. 


\section{G-1. COST CONCERNS}

The costs of design, construction, and operation of nuclear facilities continue to increase at a rate that casts doubt on the affordability of the nation's future capability for plutonium dispositioning. Following is a list of cost drivers and concerns associated with design, construction, and operation of nuclear facilities.

\section{Cost of Materials and Equipment}

Materials and equipment for a nuclear facility include the reactor system, which is comprised of the reactor vessel, vessel internals, and reactor controls; primary coolant system; heat removal system consisting of the secondary coolant system and cooling tower; reflector cooling system; reactor instrumentatini and control system; fuel pool cleanup system; fire protection system; utilities; diagnostics, data acquisition system; and much more. The increasing cost of materials may be attributed to:

- The cost of quality assurance in procurement of nuclear grade materials

- Limitation of approved code materials for construction

- Nonstandard products used in construction and fabrication of nuclear systems

- Overspecification of requirements

- $\quad$ Size and uniqueness of the equipment

- Decrease in available suppliers because of limited demand resulting from the present environment toward acceptance of the nuclear industry.

\section{Cost of Research, Development, and Design}

Nuclear reactor development is very expensive, in part, because of the necessary support facilities, equipment, and required software systems. The high consequence of an abnormal nuclear event has resulted in the demand for fully developed, proven systems and methods. Hence, the usual design approach generally involves unique development, testing, and evaluation of all reactor systems and supporting systems prior to their actual use or implementation. This has also resulted in demand for redundant systems, overly conservative compliance with regulatory requirements, and overspecification of criteria/ requirements.

Design costs also tend to increase as a result of changing requirements because of new regulations. Delays resulting from these perturbations have a cascading effect on subsequent activities, leading to further cost escalation.

\section{Fuel Costs}

Fuel costs for special plutonium-based reactors are inherently high because of the amount of development necessary to support the uniqueness of the fuel. Fuel costs will probably be a major reactor design driver. The limited demand for this unique fuel tends also to limit suppliers (those with capability and interest), resulting in high fabrication costs. Methods for the processing and disposal of spent fuel also contribute significantly to the ultimate cost of fuel.

\section{Cost of Licensing/Regulation}

The long lead time associated with the funding process, approval cycles, and the long duration from concept to startup of nuclear facilities contributes significantly to the cost of DOE facilities, as does also the increasing number of rules and regulations associated with nuclear facilities (see Appendix B). Interpretation and communication of these regulations often results in overspecification of the requirements (added/compounded rigidity) to ensure strict compliance.

\section{Construction}

Construction costs are the most significant part of the capital cost of a nuclear facility. The costs 
for these unique and specialized facilities also include costs for architectural engineering services as well as construction management and construction subcontractors. Effective construction management is key to efficient contractor interfacing and change control. The impact of ineffective subcontractor schedule performance has a cascading effect on interfacing operations, which results in increased costs because of changes.

\section{Infrastructure Costs}

Infrastructure costs include those basic necessities such as access to utilities, roads, and local services. Drilling of wells, laying pipelines, hook-up to an electrical power gridwork, and construction of power stations are very dependent on siting of the facility and contribute significantly to capital costs. Location of the facility is also important to operation of the facility because of services such as transportation, cafeteria services, road maintenance, and warehousing that must be provided. A major operating cost will be associated with fuel storage facility security. Weapons-grade plutonium storage requires the highest levels of security.

\section{Cost of Operations/Maintenance}

Operation of a nuclear facility includes significant administrative functions that include safety, radiation control, configuration management, low-level waste disposal, training, plant services, and plant engineering, as well as the normal plant operating and maintenance functions such as reactor operations, preventative maintenance, and craft support. Normal operational activities include refueling and experiment handling for which operating costs might be significantly reduced through automation and robotics. Automation of many of the administrative processes could also provide substantial benefits during operation. The initial cost of automated features would most likely be significant, however, benefits would also be substantial.

\section{Cost of Program Management/Oversight}

A major cost driver is the long duration of many projects. Contributors to these schedule extensions are increasing amounts of regulation, changing requirements, excessive oversight, and insufficient capitalization. One thought that could be applied to this situation is to reduce decision/ approval delays by critical review of the oversight function and empowerment of cognizant engineers and managers. Projects must be completed as quickly as possible to reduce the cost of financing. 


\section{G-2. COST-REDUCTION IDEAS}

When several of the cost-reduction ideas are implemented, the overall cost of designing, constructing, and operating a reactor can be reduced significantly. The following ideas were identified as having the potential for high reductions in net costs of a plutonium-burning concept.

\section{Research, Development, and Design}

Use of Proven Techrology/Demonstrated Fuel Design. A new plutonium-burning reactor should be based on conventional reactor technology. This is also helieved to be the approach most likely to satisfy safety requirements that will be imposed on the reactor. By basing the design on technology and design concepts that have evolved and been proven (by the successful design and operation of other reactors), significant research and development costs normally associated with the design of a new reactor could be saved. Typically, fuel research and development costs are very high. This is especially true when the fuel design being developed is new or unique. These costs could be significantly reduced by basing the fuel element design on one that has previously been developed and proven.

\section{Use of Existing Hardware and Software.} Acquire and use existing off-the-shelf hardware and software wherever reasonable as a means of reducing development cost. This could also contribute to schedule savings, which translate to additional cost savings. This should contribute to direct cost reduction as well as indirect cost reduction by shortening the development time required. The shorter the development time, the less the program would be plagued with changing ground rules or regulations.

\section{Simplicity/Minimize Limiting Conditions of Operation. The design and operation of the reactor should be kept as simple as possible with- out compromising the ability of the reactor to per- form its mission. Geometric simplicity enables}

accurate analysis at the lowest cost. Parts interchangeability permits spare parts inventories to be minimized. A simple reactor minimizes capital costs and is easier to reconfigure during between-cycle shutdowns; thus, operating costs will be lower.

Designing a safe facility with a relatively small number of limiting conditions of operation (LCOs), could also lead to a simpler and more reliable facility. The Reactor Facility Technical Specifications contain limiting operating conditions (LOCs) that are upper and/or lower values of critical physical parameters (e.g., temperatures, pressures, levels, flow rates) within which the facility must always operate. If instrument readings for these parameters are outside of the LOC tolerances, the facility must be shut down. The complexity of the facility systems, including instrumentation and alarm systems, are greatly increased as the number of LOC parameters increases. Conversely, the availability of the facility can be inversely proportional to the number of LOCs because there are more physical parameters that can shut down the facility. However, designing a reactor with simpler core geometry or improving analysis techniques so trending analysis can be used to prevent exceeding an LCO may be more cost effective. A very forgiving reactor system with large operating margins is being proposed.

\section{Reactor Systems}

\section{Passive Safety Systems/Natural Circula-} tion Emergency Cooling. Active safety systems in conventional reactor facilities require extensive active components to protect the reactor from overheating during accidents or power loss. The active safety systems must also be powered by uninterruptable or emergency power that is independent of the normal power systems. The core cooling safety functions are to continue primary system flow, limit the system depressurization rate, replace coolant lost through system rupture, and remove decay heat from the heat exchangers. Passive safety systems, however, 
enhance facility safety because active components (whose failure must be accounted for in overall facility risk) are eliminated or reduced. Passive injection systems that could replenish coolant by using elevated tanks or the reactor pool would cost less than the current active safety systems. Passive systems for removal of decay heat from the primary-coolant heat exchanger would also cost less than the current active safety systems. A passive emergency core cooling system would remove decay heat by establishing a natural upward circulation of coolant through the core immediately after a reactor scram. Therefore, passive safety systems would be more reliable, would significantly reduce cost, and would enhance safety by minimizing or eliminating active safety components and their corresponding uninterruptable and emergency power supplies.

\section{Low Design Pressures and Tempera-} tures. It is desirable to select the lowest possible design pressures and temperatures for the reactor without compromising either mission or safety. By holding design conditions to lowest possible values, very conventional and proven design solutions could be selected, and design can be straightforward and simple, as opposed to the complexity typically involved in the design of high pressure/temperature systems. The benefit of this would be lower construction costs, higher degree of reliability, and improved maintainability. In addition, the stored energy in a lowpressure system is much easier to deal with for accidents involving coolant blowdown, and this should reduce the size and complexity of safety systems required to mitigate blowdown accidents.

Minimum Waste Discharge. Environmental regulation has become a significant factor in the design, construction, and operation of nuclear power plants. Such regulation is undoubtedly permanent and will have to be dealt with throughout the life of the reactor. The best way to deal with environmental regulation may be by design of a safe and environmentally clean facility. Such an approach would include designs to achieve minimum discharge of radioactive waste. By initially designing such features into the plant (e.g., process treatment of liquid, gaseous, solid radioactive waste), costs, such as those for licensing, would be reduced and operation (in terms of dealing with waste disposal) would be made simpler.

Long Life Core. Considerable reactor downtime is involved in refueling, first to allow the activity in the fuel to decay before handling and then to perform the refueling operation. Substantial savings could be realized by maintaining the core design simple enough to minimize refueling and by providing sufficient plutonium in the fuel to permit long cycle length operation. It may also be possible to incorporate online refueling into the design to minimize reactor downtime because of refueling.

No-Repair Maintenance Capablilty. Maintenance is a factor that can have a very significant influence on the cost and reliability of a system. Traditionally, high reliability requirements have been satisfied by preventive maintenasce programs where maintenance is provided by frequent scheduled maintenance and overhaul to protect against equipment deterioration with operation. A different approach to achieving high reliability has been successfully employed throughout the commercial reactor industry for a number of years. This approach is called "no repair maintenance." The term describes a high inherent reliability approach to operation in which the basic equipment design has a sufficient margin of safety built in so that it can successfully function over a longer period of time. This approach has allowed commercial power reactor operating cycle lengths to extend well beyond one year. By reducing the number of maintenance shutdowns, reactor operation can be made more efficient and the size of the maintenance organization can be reduced.

\section{Plant Systems}

Waste Heat Utilization. A certain amount of reactor waste heat could be used for space heating by routing a side stream of secondary coolant through heating coils when the reactor is operating. Most of the buildings near the reactor could 
be heated in this manner, which results in reduced heating costs.

\section{Site and Buildings}

\section{Low Susceptibility to Natural Phenomena}

Site. By selecting a site location that has low susceptibility to natural phenomena events, earthquakes and floods for example, design and construction costs can be greatly reduced when compared to what would be required where higher levels of susceptibility exist. Some site selections have been very poor, requiring significant funding to be spent to mitigate potential natural phenomena consequences.

Site Coupling. There is a potential to reduce plant system costs, particularly utility costs, by locating the reactor at a site where utility services presently exist. By using existing and available utility systems (i.e., commercial power, water, and roads, plant system costs could be reduced).

Use of Existing Facilities/Capabilities. Make effective use of existing facilities, equipment, and software systems wherever feasible in the process of development, test, and operation of the reactor.

\section{Operation}

Automated Survelllance Capability. Both the NRC and International Atomic Energy Agency regulations place a high level of importance on surveillance (monitoring of plant operation) to ensure that existing defenses that protect against the release of fission products are not deteriorating. Much of the surveillance work is typically performed when the reactor is shut down and available for inspection. Costs for surveillance, both in terms of manpower and equipment, are significant. These costs could be reduced by automating the surveillance function, incorporating surveillance requirements into the design of the plant, and using robotic technology to perform surveillance.

Consider Performance Based Training. Use performance-based training (i.e., training based on job and risks involved) for operations and craft personnel.

\section{Regulation/Rules/Compliance}

Graded Approach to Specification of Quality Assurance Requirements. Use a graded approach based on "importance to safety" for establishment of quality assurance (QA) requirements.

Improved Procurement Process. Review procurement processes to eliminate barriers to procurement of off-the-shelf items where acceptable.

Reducing NRC Regulatory Guides Appllcable to the Reactor. Because the reactor will probably be a DOE-owned facility and not an NRC-licensed facility, it may be that only the technical requirements in the Regulatory Guides are applicable to the reactor. In addition, if passive safety features are employed in the design, guidance or recommendations provided in the Regulatory Guides may not be applicable to design, construction, or operation of the reactor. Therefore, the extent of applicability of the NRC Regulatory Guides to the reactor should be determined.

Reducing the Cost of Compliance. As noted in Appendix I, "Federal Standards, Codes, Regulations, and Requirements," the ensuing costs resulting from increased regulatory requirements is far outpacing inflation. Short of noncompliance or a complete streamlining rewrite of the applicable Federal codes, new methods must be developed to expeditiously meet the spirit and intent of the requirements without added administrative burden. With this in mind, the following ideas are put forward:

- Privatization. The private sector, because of lower overhead, may be better able to accomplish a task at lower cost. All areas that can be performed by the private sector should be identified and turned over to them. An extreme example would be to privatize the ownership and operations of reactors and facilities that currently are owned 
and operated by the Federal Government. The Federal Government would then purchase those products and services it requires. However, consideration must be given to possible constraints that may then be imposed on the facility such as, under current law, the facility may not be permitted to produce special nuclear material or strategic defense isotopes. Other limitations or obstacles may also apply such as DOE order or NRC licensing inconsistencies.

- Freezing Designs and Requirements. Design and requirement changes in Federal projects are a major contributor to increased costs. Sometimes these changes cannot be avoided and are truly for the overall benefit of the project. However, other times these changes may be a result of an evolving design that does not have clear requirements or it may be the result of new regulatory requirements. In both cases, cost can be avoided if designs are frozen and no changes other than the most critical are allowed. From the regulatory perspective, this means that once a design is completed, new regulations will not, in general, be implemented. This may cause some shortterm debate, but in the long term it will result in the cheaper and faster successful completion of projects.

- Shorter Schedules. A major cost driver is the long duration of many projects. Contributors to these schedule extensions are rigid administrative processes, changing requirements, and insufficient capitalization. One thought that could be applied to this situation is to reduce the number of projects ongoing at any given moment so that they can be completed as quickly as possible, thus reducing the "cost of financing."

\section{Customer Management/ Oversight}

Avold Excessive Overhead Costs. Inefficiency and loss of effectiveness resulting from duplicate administrative responsibilities that are frequently applied to a task can lead to excessive overhead costs. If the engineering teams and their technical managers are empowered to do the job, then the duplication of administrative responsibilities should be able to be significantly reduced without adverse impact to the project. 


\section{G-2. REFERENCES}

1. J. P. Sekot et al., Broad Application Test Reactor Cost Reduction Study, EGG-NRE-10735, EG\&G Idaho, Inc., Idaho National Engineering Laboratory, 1993. 


\section{Appendix $\mathbf{H}$ \\ Other Reactor Concepts}

H-1 


\section{Appendix $\mathbf{H}$}

\section{Other Reactor Concepts}

Because all reactors without fertile material at the same power level and capacity factor burn plutonium at the same rate, nearly any concept could accomplish this mission. There was no time to investigate several different concepts without fertile materials. Other concepts also have desirable features and may be better overall clioices than the one that has been selected. Some of these concepts are listed below, along with ideas and features that have been discussed. This list is certainly not complete.

- Canadian Deuterium-Uranium Reactor (CANDU). The CANDU reactor is interesting because it can run continuously and be fueled online. With a capacity factor near $100 \%$, the CANDU burns plutonium the quickest. Online fueling would also be very useful for putting the entire inventory through one reactor rapidly to self-protect the fuel. Because plutonium provides excess core reactivity, the core could be cooled and moderated with light water instead of heavy water. The large core also allows low power densities. However, this modified CANDU concept could have positive temperature coefficients of reactivity. Lack of experience with this concept is the main reason that it has not been studied further.

- Modular High Temperature GasCooled Reactor (MK TGR). Two advantages make this concept interesting. First, it is a very safe reactor. Second, the fuel particles can withstand very high burnups. The MHTGR should be investigated further. An LWR over graphite was selected because the MHTGR fuel blocks cannot be shuffled quickly, which is a disadvantage for selfprotecting the entire inventory. In addition, waste management may be more difficult for this concept.
- Advanced Liquid Metal Reactor (ALMR). This reactor concept without uranium is being developed by Argonne National Laboratory (ANL) and General Electric Co., so it was not appropriate to duplicate their work. The core expansion coefficient is the main negative reactivity feedback mechanism, but a negative Doppler coefficient is also needed. The plutonium ALMR presents challenges in maintaining low sodium void worths and burnup reactivity swings. The ANL is busy working to solve these problems. The ALMR has an advantage of being able to burn up more of the higher actinides than thermal reactors. One strategy would be to rapidly burn as much plutonium as possible in an LWR, then perform a second burn in the ALMR. This has the added advantage of allowing more time for the ALMR technology to be developed.

- Pebble Bed Reactor. This reactor has been tested in Europe, and consists of fuel pebbles that are much larger than those in the particle bed reactors proposed by Brookhaven National Laboratory. The major advantage is online refueling. An online fuel assay system could also be developed to determine the exposure of each pebble. The major drawback is that this technology is not well known in the United States.

- $\quad$ Fluid Fueled Reactors. These concepts include the Molten Salt Reactor, the Molten Chloride Reactor, and aqueous solutions. Online refueling allows high capacity factors and low source terms. Online processing reduces fission product inventory. However, the possibility of selective removal of an essentially pure fissile stream during online reprocessing is a concern. These concepts can have strong negative temperature coefficients of reactivity 
because of fluid expansion. However, circulating fluid fuels in the primary system presents serious safety concerns. In addition, it is unclear how uniform the plutonium distribution remains in these concepts. One advantage is the weapon pits could be dissolved or melted directly into the solution. Overall, these concepts generated a lot of interesting discussions, but were rejected as near-term solutions to plutonium disposi- tion because the technology is not mature.

- Accelerator-Based Reactor Concepts. A subcritical reactor concept triggered by an accelerator has been proposed by Los Alamos National Laboratory. The technology associated with this concept is not mature, and its feasibility has not been established. This concept is not viable in the next few decades and, thus, cannot achieve the mission requirements. 


\section{LARGE POOL-TYPE NATURAL CIRCULATION SYSTEM}

A natural circulation system that was not considered in the main text is a pool type system. This would employ the same fuel lattice chosen for the natural or forced circulation systems evaluated in Appendix $E$ and may involve some tradeoff of advantages and disadvantages.

Fuel in a very large open pool of light water made of LWR-like lattice assemblies could be submerged deep below the pool surface. The first fuel load may be a small core of a few assemblies, (e.g., say 16 assemblies in a 4 by 4 grid). These assemblies can achieve criticality as demonstrated in the pin cell calculations in Appendix D, and their infinite multiplication factor of about 1.2 is held down by some leakage and by burnable poisons. As the fuel burns, additional fresh fuel (driver fuel) can be added to the center of the core, while the burned fuel is shuffled radially outward, as shown in Figure H-1. This variable size reactor can grow with the periodic addition of new fuel at the center, and the corresponding shuffle of increasingly burned (driven) fuel to the periphery of the critical assembly. This fuel stays in the pool and burns past 90 at $\%$ of its plutonium content. In its latter stages, it is essentially being stored until it is removed to be put in the final disposal casks for spent fuel burial. Preliminary thermal and hydraulic analyses indicate that this concept is feasible with the pin pitch and fuel characteristics range given in Figures D-1 and D-2 of Appendix D, although there may be limitations on the total power level. The advantages in this very simple design are in sufety and cost reduction.

\section{Advantages}

1. Inherently safe reactor because of the large coolant body surrounding the fuel

2. No pressurization, steam generators, complicated piping, and engineered safety features that have significant probability of failure.

3. Cost advantages include no heavy containment, pumps, expensive piping, or pressurizers.

4. The reactor provides a source of neutrons at low fluxes for various scientific, medical, and industrial purposes.

5. No need exists for a separate spent fuel pool. Once the fuel enters the pool reactor, it stays there until it is to be prepared for burial.

\section{Disadvantages}

1. Because of the very low power levels achievable with pool-type natural circulation of water, the plutonium-burning campaign will take a long time. This can be mitigated in part by the large reactor size achievable and by building many such prototypes.

2. As more fuel is added, the reactor size will become huge. 


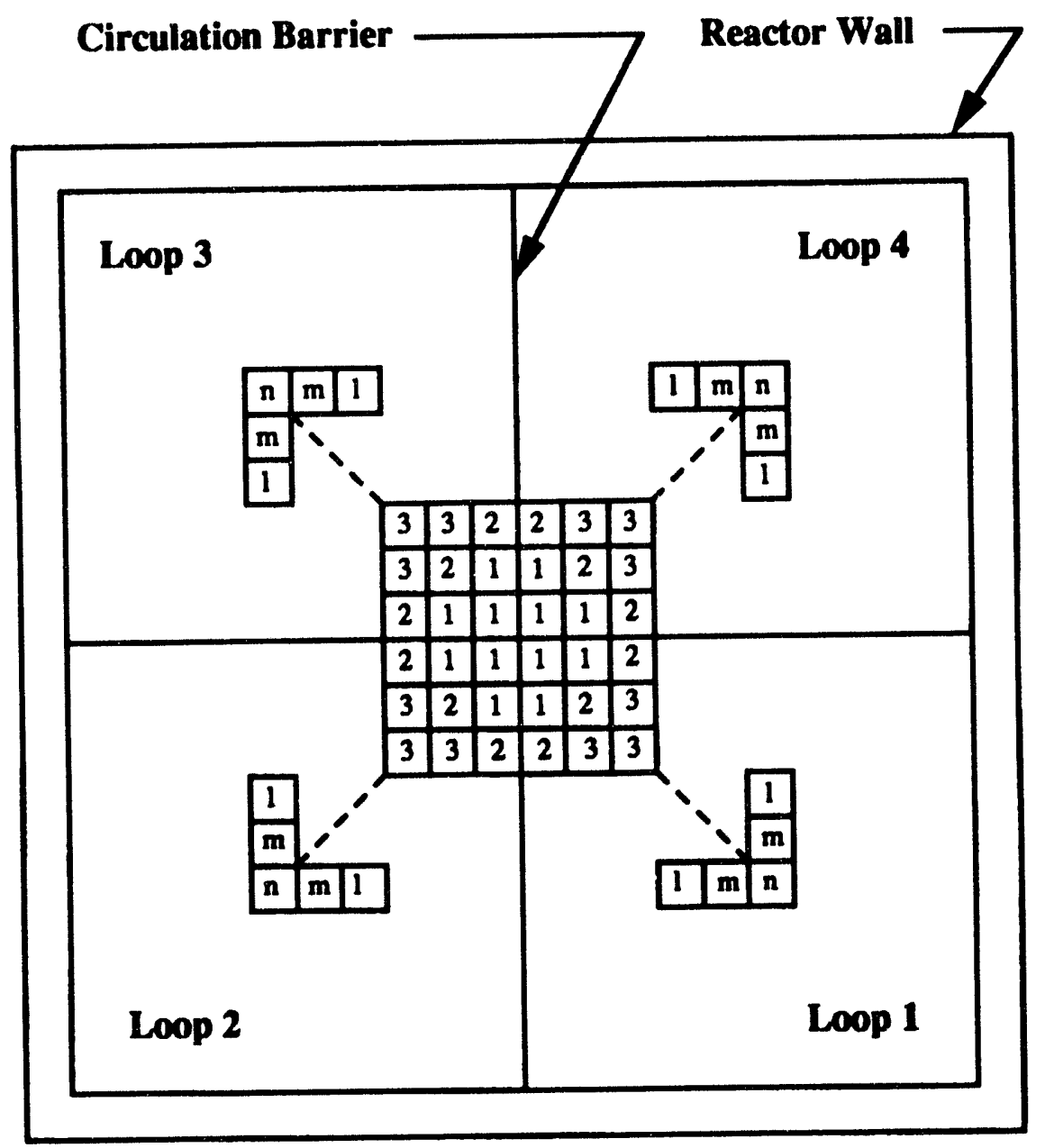

i] Fuel assembly that has been shuffled i times

Figure H-1. Fuel management scheme for a large pool natural circulation reactor. 


\section{Appendix I \\ Federal Standards, Codes, Regulations, and Requirements}




\section{Appendix I \\ Federal Standards, Codes, Regulations, and Requirements}

A new plutonium-burning reactor would probably be designed, built, and operated under DOE ownership, and therefore, under 10 CFR 50.11, would not be subject to the NRC licensing process. However, DOE orders require DOE reactors to meet appropriate standards, codes, and guides that are applied to comparable licensed facilities. In addition to meeting the requirements given in DOE orders, the reactor will also use appropriate NRC General Design Criteria (GDC). Furthermore, because the reactor will undoubtably incorporate some passive safety systems into the design, Supplemental Design Criteria (SDC) are needed to provide a complete list of GDC.

Regulations and compliance requirements can be categorized in various ways. For this study they are categorized as falling under Federal regulations, Federal guidelines, and technical standards. In addition to these Federal and national standards, state and local agencies also have mandatory compliance regulations. All of these get implemented through extensive project documents such as procedures, plans, and engineering and system descriptions.

Most of the following specific instances are taken from the Conceptual Safety Analysis Report (CSAR), Volumes 1 through 4, (ORNL/ ANS/INT-33) for the Advanced Neutron Source (ANS). These four volumes constitute a major project document and total about 2,000 pages. 


\section{l-1. FEDERAL REGULATIONS}

The ANS CSAR references several types of Federal regulations. These include the Code of Federal Regulations, DOE orders, and environmental statutes.

\section{DOE Orders}

The ANS will be a DOE facility. Therefore, it will be designed and operated in compliance with DOE requirements, including DOE and DOE Operations Office orders. DOE orders specify applicable Code of Federal Regulations, NRC Regulatcry Guides, and national codes and standards.

The ANS CSAR references 38 DOE orders. The listing with a brief description of each order takes seven pages. Each of these orders in turn further reference other requirements.

\section{Code of Federal Regulations}

DOE orders incorporate applicable requirements of the Code of Federal Regulations. Two major parts were explicitly cited in the ANS CSAR (i.e., 10 CFR Part 50 and 10 CFR Part 100 ). However, the project as stated will comply with all requirements. The most frequently used nuclear-related parts of CFR Title 10 are:

- Part 1 Statement of Organization and General Information

- Part 2 Rules of Practice

- Part 20 Standards for Protection Against Radiation

- Part 50 Licensing of Production and Utilization of Facilities

- Part 51 Licensing and Regulatory Policy and Procedures for Environmental Protection

- Part 55 Operator's Licenses
- Part $70 \quad$ Domestic Licensing of Special Nuclear Material

- Part 100 Reactor Site Criteria.

- Environmental Law Statutes

- The project will also comply with all environmental requirements that are largely found in Title 40 of the Code of Federal Regulations. The National Environmental Policy Act of 1970 was the first major piece of environmental legislation. It is the basis for required Environmental Assessments and Environmental Impact Statements. Since its promulgation, environmental statues have proliferated. A partial listing of some of the most relevant ones includes:

- Toxic Substance Control Act

- Federal Insecticide, Fungicide, and Rodenticide Act

- $\quad$ Endangered Species Act

- Clean Water Act

- $\quad$ Safe Drinking Water Act

- Solid Waste Disposal Act

- Clean Air Act

- Resource Conservation and Recovery Act

- Comprehensive Environmental Response, Compensation, and Liability Act

- Emergency Planning and Community Right-To-Know Act

- Pollution Prevention Act

- Marine Protection, Research and Sanctuaries Act 
- Oil Pollution Act

- Administrative Procedure Act.

The complete text of these Federal statutes totals over 1,200 pages. Generally speaking, there are eight areas of environmental compliance requirements:

1. Notification

2. Point of discharge waste-end control and emission limits
3. Process-oriented controls and pollution prevention

4. Product-oriented controls

5. Regulation of activities

6. Safe transportation requirements

7. Response and remediation requirements

8. Compensation requirements. 


\section{1-2. QUALITY PROGRAM REQUIREMENTS}

The quality assurance (QA) program requirement for the ANS project come from DOE, NRC, Martin Marietta Energy Systems, and nationally recognized standards organizations. The principle DOE source of QA requirements is DOE Order 5700.6, "Quality Assurance," which is invoked by other applicable DOE orders, such as:

- DOE Order 4700.1, "Project Management System"

- DOE Order 5480.6, "Safety of DOE-Owned Reactors"

- DOE Order 6410.1, "Management of Consiruction Projects"
- DOE Order 6430.1, “General Design Criteria."

Furthermore, the principle NRC rules for the content of a QA program are detailed in 10 CFR 50 Appendix B. These criteria are the bases for, and essentially equivalent to, the basic requirements of ASME/NQA-1, Quality Assurance Requirements. The provisions of ASME/NQA-2, Quality Assurance Requirements for Nuclear Facility Application, and ASME/NQA-3, Quality Assurance Requirements for Site Characterization, also apply to certain project activities. 


\section{1-3. FEDERAL GUIDELINES}

Federal guidelines do not carry the weight of law, but generally are strongly recommended to be followed unless a substantial reason or acceptable alternative is presented.

\section{NRC Regulatory Guides}

The purposes of the NRC Regulatory Guides are (a) to describe methods acceptable to the NRC regulatory staff for implementing parts of the commission's regulations and (b) to provide guidelines to applicants for permits and licenses. The ANS CSAR cites 214 separate Regulatory Guides. A listing of these with a brief description of each requires 43 pages in the ANS CSAR.

\section{NRC General Design Criteria}

In accordance with DOE 5480.6, all of the NRC General Design Criteria (GDC) per 10 CFR 50, Appendix $A$, and their definitions were reviewed by the ANS project for applicability. The 55 GDCs are divided into six groups and establish the minimum requirements for the design of nuclear power plants.

These six groups are:

1. Overall requirements

2. Protection by multiple fission product barriers

3. Protection and reactivity control systems

4. Fluid systems

5. Reactor containment

6. Fuel and reactivity control.

The listing with a brief description of each of the associated 55 GDC requires 19 pages in the ANS CSAR. 


\section{I-4. ANS SUPPLEMENTAL DESIGN CRITERIA}

Appendix A of 10 CFR 50 states that there will be some water-cooled nuclear plants for which the GDC will not be sufficient and for which additional criteria must be identified and satisfied in the interest of public safety. The ANS facility design includes features that do not exist in or are significantly different from NRC licensed light water power reactors. To account for these differences, additional design criteria had to be developed. These additional safety-related design criteria are called Supplemental Design Criteria (SDC). The ANS CSAR identifies 27 SDC. A listing of these with a brief explanation requires nine pages in the CSAR. 


\section{1-5. BRANCH TECHNICAL POSITIONS, NUREGS, AND STANDARD}

REVIEW PLANS

In addition to all the requirements and guidelines identified above, the ANS CSAR references a number of other guiding documents. These include seven separate NRC Branch Technical Positions, eight NRC NUREGs, and several DOE Secretary of Energy Notices. 


\section{1-6. NATIONAL STANDARDS}

The ANS CSAR references many national standards throughout each chapter. These national standards in turn can comprise volumes of detailed rules, guidance, and requirements. The national technical societies that are the promulgators of standards cited most frequently are:

- ACl American Concrete Institute

- AISC American Institute of Steel Construction

- ANSI American Nuclear Standards Institute

- ASCE American Society of Chemical Engineers

- ASHRAE American Society of Heating. Refrigerating, and Air Conditioning Engineers

- ASME American Society of Mechanical Engineers

- ASTM American Society of Testing and Materials
- AWWA American Water Works Association

- EPRI Electric Power Research Institute

- IAEA International Atomic Energy Agency

- IEEE Institute of Electrical and Electronics Engineers

- IES Illumination Engineering Society of North America

- ISA Instrument Society of America

- NFPA National Fire Protection Association

- NUMARC Nuclear Utility Management and Resource Council

- UBC Uniform Building Code

- UL Underwriters' Laboratories, Inc. 


\section{1-7. AGENCIES}

The ANS CSAR references many agencies that are sources of additional standards and guidance. These include:

- NASA National Aeronautics and Space Administration

- NOAA National Oceanic and Atmospheric Administration

- US DOC U.S. Department of Commerce

- US DOE U.S. Department of Energy
- US DOT U.S. Department of Transportation

- US EPA U.S. Environmental Protection Agency

- US FEMA U.S. Federal Emergency Management Agency

- US NRC U.S. Nuclear Regulatory Commission. 

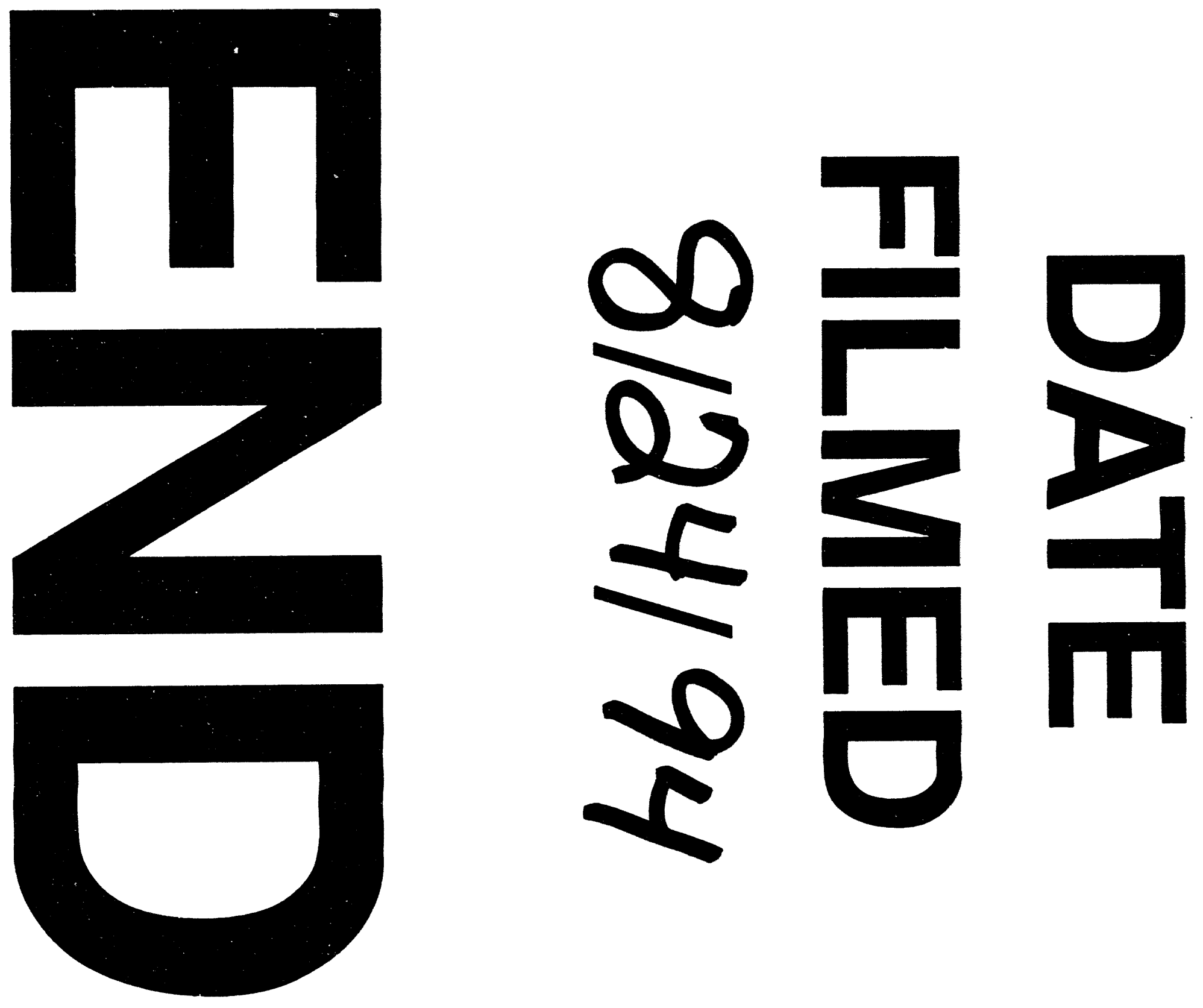

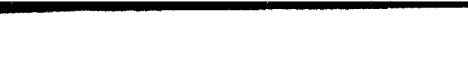

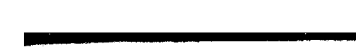

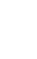

